\title{
Reproductive Allocation and Maternal Investment in Intertidal Whelks
}

\author{
by \\ John van der Sman
}

\begin{abstract}
A thesis
Submitted to Victoria University of Wellington

In partial fulfilment of the

Requirements for the degree of

Master of Science

In Marine Biology
\end{abstract}

Victoria University of Wellington

2007 


\section{Acknowledgements}

I would like to thank my supervisor Nicole Phillips for her guidance, clear thought, timely responses, support, dedication and enthusiasm. You've got to be the best supervisor anyone could hope to have.

Thanks to Aaron Jones and Lynsie Kerr for field and lab assistance. You helped to make tedious parts enjoyable.

Thanks to David Aguirre for making available equipment that saved time in setting up the experiments, for help with measuring of calcein stained juveniles and for statistical advice.

Thanks to Lynsie Kerr for proof reading drafts and providing encouragement. I'm glad that you didn't have to eat your hat.

Thanks especially to my mother and late father for encouraging me to take the first step and then providing support in many ways along the way. It was time to change direction and now the path ahead looks brighter. 


\begin{abstract}
Parental investment per offspring is a key life history trait in which offspring size and number combinations are balanced in order to maximise fitness. When food is scarce and energy for reproduction is reduced, changes in reproductive allocation can be expected. These adjustments may go on to influence the growth and survival of the next generation.
\end{abstract}

Trade-offs in reproductive allocation in response to food availability occurred differently in each of the three whelks species of this study. However, each species traded numbers of offspring rather than size of offspring when fed low food. Offspring size was more variable among and within capsules than among food treatments. Capsule size was a plastic trait that varied in response to food treatments in each of the species and varied among populations of the same species.

Carry-over effects of maternal nutrition influenced juvenile growth in all three species. However, while juvenile growth was greater when adults were fed high food in two of the species, high adult food suppressed the growth of juveniles of the third species. This may be a mechanism to prevent potential negative consequences of rapid growth. There was no evidence of a maternal effect of mortality in any of the three species.

Greater variation in hatchling size occurred in the species in which nurse egg feeding occurred. Nurse egg feeding may be a successful strategy in unpredictable environments where optimal offspring size changes from year to year.

Regional differences in reproductive allocation between whelks separated by small distances suggest that populations may be isolated from one another and may need to be managed separately for conservation purposes. This study highlights the influence of maternal nutritional effects on life history and the potential impacts that these may have on population and community structure. 


\section{Table of Contents}

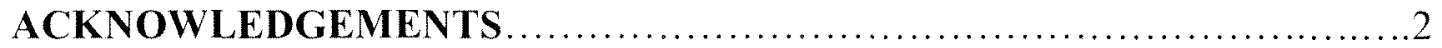

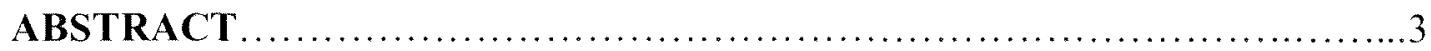

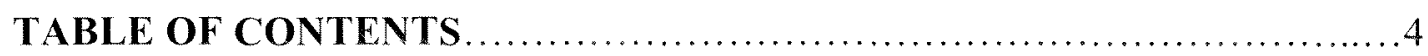

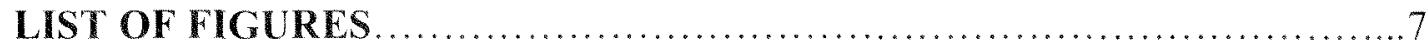

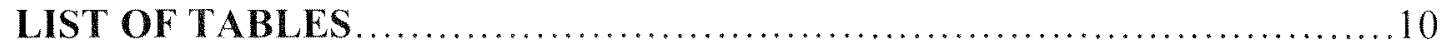

CHAPTER 1: General Introduction........................................... 11

CHAPTER 2: Trade-Offs and Reproductive Allocation in Intertidal Whelks.. 17

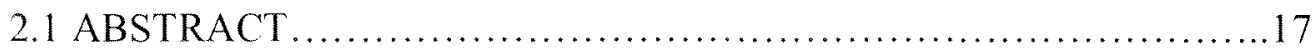

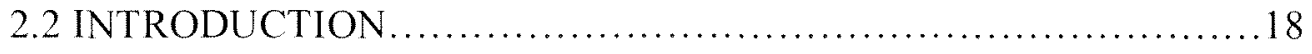

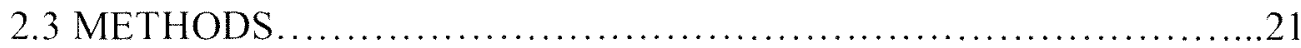

2.3.1 Estimation of capsule volume.............................24

2.3.2 Statistical analysis....................................24

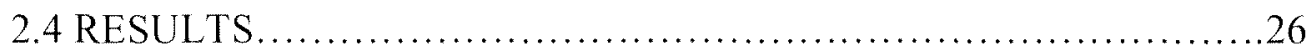

2.4.1 Adult growth...........................................26

2.4.1 a) Shell length..................................26

2.4.1b) Weight....................................28

2.4.1 c) C. maculosa regional growth........................30

2.4 .2 Adult sex ratio............................................ 30

2.4.3 Adult mortality ............................................. 31

2.4 .4 Capsule laying......................................... 31

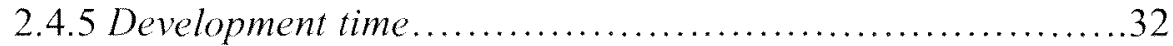

2.4.6 Investment in capsules.....................................34

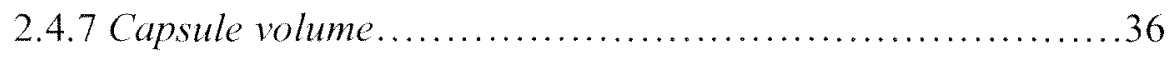

2.4.8 Variation in hatchlings per capsule........................... 37

2.4.8a) H. scobina ........................................37

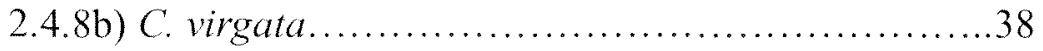

2.4.8c) C. maculosa ......................................40

2.4 .9 Hatchling size ..........................................41

2.5 DISCUSSION ............................................... 44

2.5.1 Capsule variation.....................................46

2.5.2 Hatchling variation .................................48

2.5.3 Overall outcome of capsule and hatchling variation 


\section{CHAPTER 3: Carry Over Effects of Adult Nutrition on Hatchling Growth}

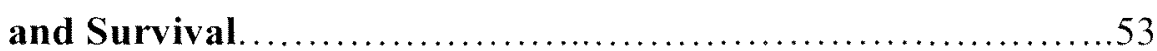

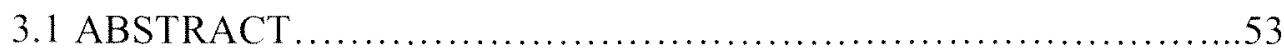

3.2 INTRODUCTION ........................................... 54

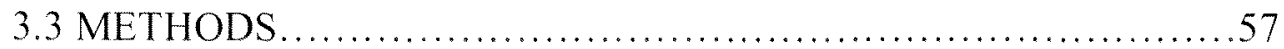

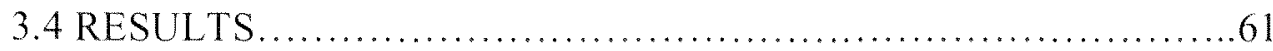

3.4.1 Growth............................................61

3.4.1 a) Growth rates...................................61

3.4.1b) Size increase ...............................64

3.4.1c) Calcein trial results ..........................65

3.4.2 Mortality..............................................66

3.4.3 Predicted juvenile size and number eight weeks after

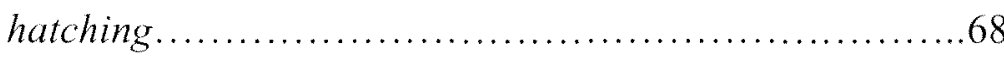

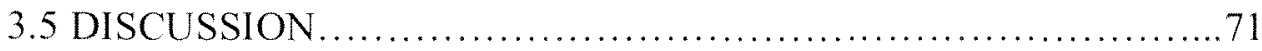

3.5.1 H. scobina................................................71

3.5.2 C. virgata.......................................... 72

3.5.3 C. maculosa................................................73

3.5.4 Future directions...........................................75

3.5 .5 Conclusion..........................................76

CHAPTER 4: The Role of Nurse Eggs in H. scobina and C. maculosa

Embryo Growth and Development.......................79

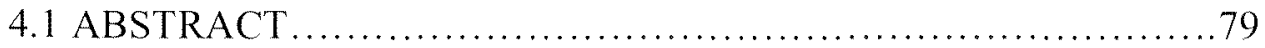

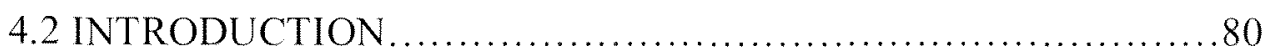

4.3 METHODS ..................................................... 82

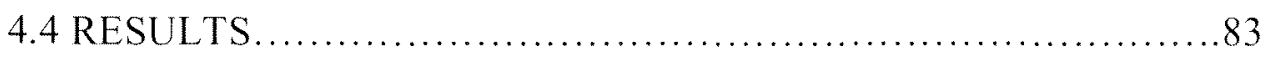

4.4.1 Change in number of propagules during development ......83

4.4.2 Embryo development.................................85

4.4 .3 Embryo growth ................................... 86

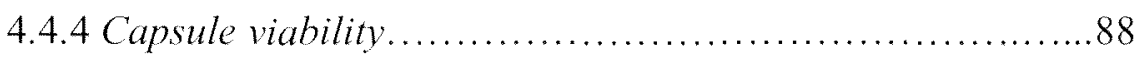

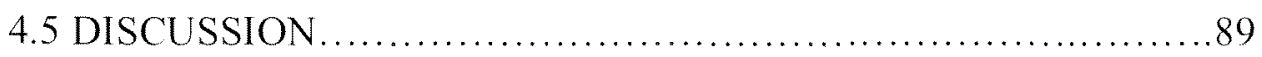

CHAPTER 5: General discussion.................................... 95

APPENDIX 1: Feeding trial............................................. 101

APPENDIX 2: Justification for combining treatments......................103 


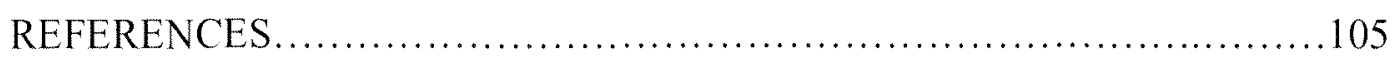




\section{List of Figures}

Figure 2.1. Collection sites of adult whelks. Wellington Harbour (1: Point Howard, 2: York Bay; 3: Point Halswell, 4: Kau Bay) and South Coast (5: Island Bay, 6: Moa Point, 7: Tarakena Bay).

Figure 2.2. Representative capsules of three whelk species. A and B: H. scobina; C and D: C. virgata; E and F: C. maculosa. H. scobina and C. maculosa capsules have multiple hatchlings while $C$. virgata capsules contain a single hatchling. Scale bars: A,C,E $=5 \mathrm{~mm} ; \mathrm{B}, \mathrm{D}, \mathrm{F}=1 \mathrm{~mm}$. Photos A,C and $\mathrm{E}$ by N. Phillips.

Figure 2.3. Shell growth in four groups of intertidal whelks subjected to low and high food treatments. Error bars indicate $95 \%$ confidence intervals.

Figure 2.4. Percentage increase in shell length for four groups of intertidal whelks raised in the laboratory in the spring of 2006. Error bars indicate 95\% confidence intervals.

Figure 2.5. Change in mean wet weight of four groups of intertidal whelks subjected to low and high food treatments. Error bars indicate $95 \%$ confidence intervals.

Figure 2.6. Mean percentage change in wet weight for four groups of intertidal whelks raised in the laboratory in the spring of 2006. Error bars indicate $95 \%$ confidence intervals.

Figure 2.7. Growth of C. maculosa from the Harbour and South Coast after 25 weeks. Mean change in length (left), mean change in weight (right). Error bars indicate $95 \%$ confidence intervals.

Figure 2.8. Numbers of new egg capsules laid weekly by four groups of whelks in the period $3 / 7 / 06$ to $22 / 12 / 06$. H. scobina: dark colour and diamonds; C. virgata: light colour and squares; $C$. maculosa (Harbour): dashed line and triangles; $C$. maculosa (South Coast): light colour and crosses. Note that recording of $H$. scobina and C. virgata capsules ceased at an earlier date (13/11/06).

Figure 2.9. Mean minimum developmental times of the egg capsule of three whelk species raised in the laboratory in the summer of 2006/7. Error bars indicate $95 \%$ confidence intervals.

Figure 2.10. Regression comparing capsule laid date with development time for each group. The capsule development times of all three species were shorter for capsules that were laid later in the experiment, when water temperatures were higher.

Figure 2.11. Mean numbers of capsules per female laid by four groups of intertidal whelks. The number of replicate baskets containing egg capsules (of twelve) is shown above the boxes. Error bars indicate $95 \%$ confidence intervals.

Figure 2.12. Mean capsule volume between treatments for four groups of intertidal whelks. Error bars indicate $95 \%$ confidence intervals. 
Figure 2.13. Correlation between capsule volume and number of hatchlings per capsule in H. scobina. Dark coloured diamonds and line represent low food treatment data and regression line; light coloured squares and line represent high food treatment data and regression line.

Figure 2.14. A: Frequency distribution of $C$. virgata clutch sizes in low and high food treatments. B: Relationship between mean size at hatching and clutch size between low and high food treatments. C: Relationship between the proportion of females in a replicate basket and the number of clutches produced. Dark coloured diamonds represent low food treatments data; light coloured squares represent high food treatments data.

Figure 2.15. Variation in number of hatchlings per capsule in whelks from the Harbour and South Coasts. A: frequency distribution, B and C: Correlation between capsule volume and number of hatchlings per capsule in Harbour and South Coast sourced whelks. Dark coloured diamonds represent data from low food treatments; light coloured squares represent data from high food treatments.

Figure 2.16. Mean hatchling size at emergence from capsule in four groups of intertidal whelks. Error bars indicate $95 \%$ confidence intervals.

Figure 2.17. Estimated numbers of hatchlings from ten adult whelks subjected to low (L) and high $(\mathrm{H})$ food treatments (corrected to values for five adult females per basket). Oval shapes represent relative hatchling sizes.

Figure 3.1. Growth measurement of a calcein stained hatchling. Line illustrates 19 days of growth by a C. maculosa hatchling in a high food treatment.

Figure 3.2. Growth of $H$. scobina hatchlings in two four week periods after capsule emergence. Error bars indicate $95 \%$ confidence intervals.

Figure 3.3. Growth of $C$. virgata hatchlings in two four-week periods after capsule emergence. Error bars indicate $95 \%$ confidence intervals.

Figure 3.4. Growth of C. maculosa hatchlings in two four-week periods after capsule emergence. Error bars indicate $95 \%$ confidence intervals.

Figure 3.5. Mean shell length of three intertidal whelk species at hatching and after eight weeks of growth. Open bars = initial shell length; closed bars = final shell length; NS = non significant difference. Error bars indicate $95 \%$ confidence intervals.

Figure 3.6. Shell growth after 19 days for early juveniles of two intertidal whelk species in response to adult and hatchling food treatments. Error bars indicate $95 \%$ confidence intervals.

Figure 3.7. Cumulative mortality of the hatchlings of three intertidal whelks showing effects of hatchling and adult food treatments. Dark colours: high hatchling food 
treatments; light colours: low hatchling food treatments; diamond shapes: high adult food treatments; crosses: low adult food treatments.

Figure 3.8. Estimated numbers of hatchlings remaining eight weeks after capsule emergence. Initial numbers of hatchlings (before arrows) are based on the mean number of capsules laid by 10 adult whelks in each of the food treatments from Chapter 1. Oval shapes represent relative hatchling sizes. L: low adult food treatment; $\mathrm{H}$ : high adult food treatment; 1 : low hatchling food treatment; $\mathrm{h}$ : high hatchling food treatment.

Figure 4.1. Numbers of propagules encapsulated within capsules of $H$. scobina and $C$. maculosa at the time of laying (open bars) and at time of hatching (filled bars). Error bars indicate $95 \%$ confidence intervals.

Figure 4.2. Mean numbers of propagules encapsulated within $H$. scobina capsules during eleven weeks of development. Error bars indicate $95 \%$ confidence intervals.

Figure 4.3. H. scobina development. Photographs taken at weekly intervals. Letters A-K indicate weeks one to eleven. Nurse eggs are visible in B and F.

Figure 4.4. C. maculosa development. Photographs taken at weekly intervals. Letters $\mathrm{A}-\mathrm{H}$ indicate weeks one to eight.

Figure 4.5. H. scobina embryo growth. A: mean embryo size within capsules, B: mean weekly growth. A large increase in embryo size occurred during week two. Hatchlings emerged after eleven weeks. Error bars indicate $95 \%$ confidence intervals.

Figure 4.6. C. maculosa embryo growth. A: mean embryo size within capsules, B: mean weekly growth. A large increase in embryo size occurred during week four. Hatchlings emerged after eight weeks. Error bars indicate $95 \%$ confidence intervals.

Figure 4.7. Proportion of capsules containing viable embryos in the weeks before hatching. A $\log$ curve provided a good estimate of the proportion of viable $H$. scobina capsules in any week $\left(\mathrm{R}^{2}=0.82, \mathrm{p}<0.01\right)$ while a log curve fitted to $C$. maculosa data was non-significant $\left(\mathrm{R}^{2}=0.41, \mathrm{p}=0.08\right)$.

APPENDIX 1, Figure 1. Total daily consumption of three whelk species during a seven day trial using two types of food. Consumption was high on the first day of the trial then slowed. More mussel food was eaten over the period.

APPENDIX 2, Figure 1. Changes in shell length (left) and wet weight (right) in four food treatments for four groups of intertidal whelks. The $10 \%$ and $20 \%$ treatments, and the 50\% and 100\% treatments, were combined for the analysis. Differences within groups that were combined $(10 \%$ and $20 \% ; 50 \%$ and $100 \%)$ were small when compared with differences between combined groups. Error bars indicate $95 \%$ confidence intervals. 


\section{List of Tables}

Table 2.1. Sex ratios in four groups of intertidal whelks. P-values are from binomial tests comparing female sex ratios with a $50 \%$ value. P-values $>0.05$ indicate female sex ratio is not significantly different from $50 \%$.

Table 2.2. Adult mortality among species, among treatments and among baskets. Each treatment contained 120 whelks initially.

Table 2.3. Comparison of observed and expected numbers of egg capsules.

Table 2.4. Comparison of growth of whelks in replicates with and without egg capsules.

Table 2.5. Results of nested ANOVAs comparison of hatchling sizes between food treatments.

Table 2.6. Summary of egg capsule and hatchling responses to low and high food treatments.

Table 3.1. Summary of numbers of egg capsules laid per basket and treatment from Chapter 2.

APPENDIX 1, Table 1. The results of independent $\mathrm{t}$-tests between treatments of adult whelk groups that were combined for the analysis. 


\section{CHAPTER 1 \\ General Introduction}

Maximising fitness is an optimisation process balancing the proportional expenditure on reproduction (reproductive effort) and parental commitment per offspring (parental investment) in combinations that produce the highest average numbers of reproductive recruits. This can be achieved both by increasing the number of young produced in the parent's life and by increasing the survivorship of the young. The number and size of offspring a parent produces reflects the optimising action of natural selection by balancing the advantages of high fecundity with the benefits of producing higher quality larger offspring (Smith \& Fretwell 1974). Such trade-offs are fundamental aspects of life history theory (Roff 2001).

Balance and compromise are complicated because increased expenditure on reproduction leaves less energy for growth that may enhance parental survival and the chances of future reproduction. Total lifetime production of offspring could be maximised by maturing early and allocating all resources to the production of one very large clutch of offspring (Cole 1954), but many organisms don't do this because of the costs associated with reproduction (Williams 1966). By keeping reproduction expenditure relatively low at any reproductive event, an organism may reproduce many times in its lifetime and increase lifetime reproductive success (Schwarzkopf 1994). Further complications arise because of developmental constraints. There may be physical limitations for example, on the size of offspring a parent is able to produce, or limitations on access to resources necessary for development (Chaffee \& Strathmann 1984; Sinervo 1991; Fox \& Mousseau 1998).

Optimisation models predict that there is an offspring size / offspring number combination that maximises fitness for each species (Smith \& Fretwell 1974; Brockelman 1975). However, there is increasing acceptance that variation in offspring size can also be the target of selection (McGinley et al. 1987). For example, it is thought that variation in offspring size may be an adaptation for unpredictable environments (Stearns 1992), Different environmental circumstances will tend to invoke different optimal solutions. Large offspring size may increase the likelihood of 
survival when conditions are adverse by reducing susceptibility to desiccation and predation (Semlitsch \& Gibbons 1990; Gallardo et al. 2004). These benefits are reduced however, when conditions are benign. Under these circumstances higher fitness can be achieved with a larger number of smaller offspring (McGinley 1989; Moran \& Emlet 2001).

Energy for reproduction can be derived from food acquired during the reproductive period ("income breeding") or from stored reserves ("capital breeding") (Stearns 1992; Reznick \& Yang 1993). The amount of reproductive investment is not necessarily predetermined. Changes in resource levels during the reproductive period can alter energy allocation (McGinley et al. 1987). A mother's experience of the environment can lead to variation in her condition and physiological state that can be transmitted to her offspring. The degree to which offspring are affected is likely to be strongly influenced by the mother's stored reserves when food for offspring is scarce.

The classical view of life history evolution was that a suite of characters co-adapted by natural selection to maximise reproductive success in a particular environment. Recent work indicates that much of the intraspecific variation in life histories represents a plastic response to environmental heterogeneity (Stearns 1992). These findings suggest that many maternal effects have evolved as mechanisms for transgenerational phenotypic plasticity that increases offspring fitness in heterogenous environments (Fox \& Mousseau 1998). A mother that is able to adjust reproductive allocation to suit the conditions her offspring are likely to experience, would have an advantage in changing conditions. Such plasticity can result in lags in evolutionary response of a trait to selection and can cause evolution in a direction opposite to that favoured by selection (Kirkpatrick \& Lande 1989; Bernardo 1996a). Maternal effects that contribute substantially to offspring phenotype are common across a diverse range taxa including plants (Roach \& Wulff 1987), insects (Mousseau \& Dingle 1991a), bryozoans (Marshall 2005), molluscs (Moran \& Emlet 2001; Lloyd \& Gosselin 2006), echinoderms (McEdward 1996), fish (Reznick 1991), amphibians (Kaplan 1998), lizards (Sinervo 1990), birds (Lindstrom 1999) and mammals (Cowley 1991), and are important aspects of life history evolution. 
Maternal effects are often strongest in the earliest stages of the next generation and diminish over time (Roach \& Wulff 1987; Cowley 1991; Mousseau \& Dingle 1991a). This may occur because of constraints imposed by biochemical machinery and developmental pathways. For example, diminishing levels of adult hormone in developing embryos could result in fading maternal influence of a particular trait (Mousseau \& Dingle 1991b). In addition, differences in levels of maternal influence are likely to have evolved among species because of differences in their offspring's ability to feed after hatching. The survival of offspring unable to find food immediately after hatching may be buffered by the presence of extra maternal reserves of energy (Gallardo et al. 2004).

What a mother eats is likely to have a strong effect on the degree to which resources are channelled into reproduction, impacting on the fate of subsequent generations. However, most studies of maternal effects focus on propagule size without considering the longer term consequences of juvenile growth and mortality (Bernardo 1996a). The potential influence that maternal carry-over effects, such as adult nutrition, may have in influencing outcomes for juveniles and in structuring communities is unknown.

Effects of early growth can impact on characteristics later in life (Bernardo 1996a). Faster attainment of reproductive size by offspring could result in increased fitness for example. However, there may also be negative aspects to rapid growth. A body of evidence has identified a number of costs that are associated with rapid growth such as incomplete development, shortened life span and altered mortality patterns (Metcalfe \& Monaghan 2001). These factors affect not only for an organism's lifetime fitness, but also have wider implications. Patterns of distribution may be caused by bottom up processes (Menge 1992). Maternal influence on factors such as early juvenile growth and survival are likely to have a strong influence in structuring populations and communities (Gosselin \& Qian 1997; Lindstrom 1999; Metcalfe \& Monaghan 2001; Lummaa \& Clutton-Brock 2002). 
Whelks

Reproductive investment is a major focus of life history theory, but most attention has been given to terrestrial examples. Most phyla however, occur exclusively in aquatic environments where differences in oxygen solubility, diffusion and viscosity can be predicted to create different dynamics (Lee \& Strathmann 1998). Marine organisms exhibit a wide range of life history modes both within and among taxa and are therefore well suited to studies of life history (Thorson 1950; Strathmann 1985).

Intertidal environments are particularly useful study systems. The unpredictable nature of daily fluctuations in wind, sunlight, salinity and wave action have given rise to organisms with a range of adaptations. Neogastropod molluscs (whelks) are common in intertidal environments and are characterised by direct development, with complete larval development occurring within capsules that are attached to hard surfaces. Capsules are thought to have arisen to ameliorate the effects of physical stress (Pechenik 1979; Chaffee \& Strathmann 1984; Strathmann \& Strathmann 1989) and to provide protection from predators and micro organisms (Rawlings 1999).

Maternal inheritance was recognised early in the study of gastropods (Boycott et al. 1930). With no energy transferred to the embryo once the eggs are deposited in capsules, all food reserves used during development must be available to embryos at the time of oviposition. Egg capsules therefore represent total maternal investment. In addition, a consequence of direct development is that juveniles emerge into the same environment as their parents. The absence of a planktonic larval stage enables juveniles of individual mothers to be readily identified. These factors mean that whelks are model organisms for the study of maternal effects that are carried over to the next generation.

Offspring size is a critical factor in intertidal environments. Abiotic factors such as desiccation and wave action may be size selective (Spight 1976a; Etter 1989; Gosselin \& Qian 1997). For example larger size decreases surface area to volume ratio reducing the risk of desiccation, while small size reduces exposure to wave action. However, some studies have found that intertidal environments are not strongly size selective and that variation in offspring size may be more advantageous in these areas 
(Rivest 1983; Moran 1999a). Others point out that a number of stressors that exist in intertidal environments are temporarily and spatially variable. These may interact in both size-dependent and size-independent manners to influence early juvenile mortality or performance (Moran \& Emlet 2001).

Among species, whelk egg capsules vary widely in shape and in the number of eggs that are encapsulated (Pechenik 1986). Some species encapsulate non-developing eggs that have a nutritive role for developing embryos called nurse eggs. Nurse egg feeding is thought to be a favoured means of development in intertidal environments because it generates offspring that are variable in size (Rivest 1983). Most studies of whelk reproduction however, are confined to a small number of Northern Hemisphere genera and knowledge of Southern Hemisphere species is lacking.

\section{Study Species}

The predatory whelk Haustrum scobina (Neogastropoda: Muricidae) and the scavenging whelks Cominella virgata and Cominella maculosa (Neogastropoda: Buccinidae) are common on the rocky intertidal shores throughout New Zealand (Morton \& Miller 1968).

H. scobina is present on open rock surfaces of moderate shelter including reefs of harbours and estuaries (Morton \& Miller 1968). H. scobina is a borer of barnacles and has been shown to play a major role in determining their lower limit of distribution (Luckens 1974; Davis \& Kibblewhite 1986).

H. scobina encapsulates over 100 eggs, however it is thought that most are consumed by a small number of developing embryos and have a nutritional role as nurse eggs. C. virgata and C. maculosa are found in pools, under stones or in moist depressions down to the sublittoral fringe and can also be found subtidally (Morton \& Miller 1968). Both species are scavengers. C. virgata has also been reported to feed occasionally on living top shells and cats-eyes by drilling, however C. maculosa never drills (Stewart \& Creese 2004). C. virgata encapsulates a single egg per capsule while C. maculosa deposits several eggs inside each capsule but all usually develop and nurse eggs are thought to be absent. 
A predatory snail searching for barnacles and mussels on a rocky shore must tolerate exposure to air once or twice a day during low tide cycles. Another snail that scavenges lower on the shore will have substantially different requirements and will face a very different suite of threats to its existence (Spight 1976a). Large differences in reproductive allocation and in maternal carry-over effects could therefore be predicted among species. Whelks have limited dispersal ability which is a consequence of direct development. Within a species, populations of whelks separated by small distances could be predicted to show differences in reproductive allocation that result from local conditions.

In Chapter 2, the reproductive allocation of three species of whelks is tested after a period of conditioning to low and high food treatments. The aim is to compare differences in trade-offs in reproductive allocation among species and within populations of the same species. It was predicted that trade-offs in capsule and hatchling size would occur and that these would vary in different ways among species. Differences in reproductive allocation were predicted to occur within populations of the same species because whelks have limited ability to disperse, and this is likely to have resulted in some degree of regional isolation.

The growth and survival of hatchlings from the capsules of Chapter 2 are measured in Chapter 3. The aim is to measure the influence of maternal nutrition on the growth and survival of the next generation and its interaction with juvenile feeding. Hatchlings born from adults in high food treatments were predicted to have faster growth and greater survival than hatchlings born from low food adults. The influence of maternal nutrition was predicted to be short lived.

In Chapter 4, within capsule growth and development are compared between two species (H. scobina and C. maculosa) that have multiple embryos in their capsules. The aim is to examine the influence of nurse egg nutrition on these factors. It was predicted that hatchling size would be more variable and that development time would be shorter as a result of nurse egg nutrition. 


\section{CHAPTER 2}

\section{Trade-Offs and Reproductive Allocation in Intertidal Whelks}

\subsection{ABSTRACT}

When organisms face adverse environmental conditions, life history trade-offs occur as adjustments in the use of energy for growth and reproduction are made to maximise fitness. In this study adults of three species of intertidal whelks were collected from Wellington Harbour and subjected to a range of food treatments (high to low) to examine the effects of nutrition on reproductive allocation. In addition, adults of one species (Cominella maculosa) were collected from Wellington South Coast locations to examine possible regional specific responses. Whelks were fed for several months until egg laying commenced. Sizes and numbers of egg capsule and hatchlings were used as measures of maternal investment and compared among food treatments.

H. scobina and C. virgata commenced capsule laying around the same time in mid September while C. maculosa did not commence until late November. Development time was shorter within C. maculosa capsules, averaging 61 days, compared with 91 days for both $H$. scobina and $C$. virgata. Greatest relative growth occurred in $C$. maculosa suggesting that this species saves more energy for future reproduction than H. scobina or C. virgata.

H. scobina responded to low food by laying bigger capsules with fewer hatchlings and the overall outcome of reproduction was fewer hatchlings of marginally larger size in low food treatments. C. virgata laid fewer, smaller capsules in low food treatments, but hatchling size was the same as in high food treatments.

Regional differences occurred in the reproductive allocation of C. maculosa. Harbour sourced whelks laid fewer capsules in low food treatments that were the same size as capsules in high food treatments. The outcome of reproduction was half as many hatchlings in low food treatments as in high food treatments. In contrast South Coast sourced whelks laid more capsules in low food treatments that were the same size as 
those in high food treatments. The outcome of reproduction in South Coast $C$. maculosa was twice as many hatchlings in low food treatments.

Overall, trade-offs in offspring number were greater than trade-offs in offspring size, and variability was greater among and within capsules than among food treatments. Capsule volume varied more in response to the food treatments than hatchling size. Taken together these results highlight species specific trade-offs in response to changing food supply. Regional differences in populations of C. maculosa separated by small distances suggest that they may be isolated from one another and may need to be managed separately for conservation purposes.

\subsection{INTRODUCTION}

A foundation of life history theory is the premise that trait combinations are constrained by trade-offs (Roff 2001). The trade-off between the number and size of offspring a female can produce is one of the most fundamental. Traditional models assume that there is an optimal offspring size for each species that should be favoured by selection (Smith \& Fretwell 1974; Brockelman 1975) and more recent models provide support for these predictions (Strathmann 1995; Peck \& Waxman 1997). Empirical evidence for this is not convincing however, and wide variation in offspring size occurs commonly within species across a wide selection of diverse taxa (McGinley et al. 1987).

Alternative models have suggested that variation in offspring size can also be the target of selection, and predict size difference advantages in unpredictable environments (Capinera 1979; Bernardo 1996b). While smaller offspring may have high survival in benign conditions, larger offspring are more likely to survive when conditions are adverse. By producing offspring of variable size, an organism is able to increase the likelihood of the survival under a wide range of conditions (Stearns 1992; Reznick \& Yang 1993).

An additional consideration is that offspring size and number trade-offs are not necessarily predetermined for a particular species and may instead be under maternal 
control. A mother's experience of the prevailing conditions may influence the way in which reproductive allocation is traded-off between offspring size and number. This is most likely to be the case in species with limited dispersal where offspring are likely to experience the same conditions as their parents (Rossiter 1996).

Whelks fit into this category and are model organisms for the study of maternal influence on trade-offs in reproductive allocation. Direct development occurs within egg capsules which are attached to benthic surfaces and hatchlings often emerge into the same environment as their parents (Pechenik 1986). Some species encapsulate multiple embryos and size-number trade-offs may occur at several levels. As well as trade-offs between the size and number of capsules, trade-off may also occur between the size and number of hatchlings within individual capsules. Further, species with multiple embryos sometimes encapsulate non-developing nurse eggs which provide nutrition for development (Hughes 1986). Offspring size and number trade-offs may result from variation in the ratio of nurse eggs to embryos in these species.

Size at hatching has been found to have a strong influence on the survival of juvenile whelks (Moran \& Emlet 2001; Gosselin \& Rehak 2007). It has been suggested that for each species there is a critical size at which the rate of mortality becomes greatly reduced and that adverse environmental conditions may prevent juveniles from reaching this size (Gallardo et al. 2004). It follows that adult whelks that are able to produce larger offspring when subjected to reduced food availability, would benefit by achieving increased fitness for their offspring.

In this study, I compared the reproductive responses to food availability among three species of common intertidal whelks with different reproductive strategies. (Cominella virgata with a single embryo per capsule, Cominella maculosa with multiple embryos per capsule, and Haustrum scobina with multiple embryos per capsule and nurse eggs). The experiment was designed to isolate the effects of maternal nutrition by using similarly sized adults and randomly assigning them to different food treatments while keeping all other factors constant.

I predicted that: 1) capsule size would vary more than hatchling size because capsules are less costly to construct; 2) hatchling size would be smaller in high food treatments 
and that adults would respond to higher food levels by producing a larger number of smaller offspring to maximise fitness; 3) hatchling size in low food treatments would show greater variability due to a maternal bet hedging strategy; 4) the species with multiple embryos per capsule (i.e. H. scobina and C. maculosa) would decrease the number of encapsulated embryos when subjected to low food in order to increase hatchling size and the likelihood of offspring survival.

The partitioning of energy for growth and reproduction may be predetermined genetically or under maternal control (Bernardo 1996a). Semelparous species for example are pre-programmed to channel all available energy into reproduction once critical growth is achieved. There are also many examples of maternal control over the allocation of energy for reproduction (see reviews in Roach \& Wulff 1987; Cowley 1991; Mousseau \& Dingle 1991; Reznick 1991). If the genetic component determining reproductive allocation has more influence than the maternal component, it could be predicted that organisms sourced from areas having consistently high levels of food would allocate more energy to reproduction than organisms sourced from areas with consistently low food levels. If however maternal control has more influence over reproductive allocation, then organisms sourced from areas with high and low food levels would show no difference in the way that energy was allocated when subjected to identical conditions.

A further component to the study was therefore to compare reproductive responses of C. maculosa collected from two different regions. This was motivated by the large differences in intertidal community structure in the Wellington region with communities of benthic invertebrates much denser and species rich in Wellington Harbour compared to the Wellington South Coast (Gardner 2000; Helson \& Gardner 2004; Helson et al. 2007). Therefore it is likely that food availability for these whelks is much lower at sites on the South Coast. I predicted that whelks sourced from Harbour and South Coast sites would channel similar amounts of energy into reproduction when subjected to identical conditions and that variation in reproductive allocation between the two regions would be maternally controlled and not genetically predetermined. 


\subsection{METHODS}

In June 2006, 240 adult whelks of each of the three whelk species were collected from the intertidal zone at sites within Wellington Harbour (Point Howard, York Bay, Point Halswell, Kau Bay). In addition, a further 240 adult $C$. maculosa whelks were collected from Wellington South Coast sites (Moa Point, Tarakena Bay, Island Bay) (fig. 1). Whelk shell lengths were measured to the nearest $0.1 \mathrm{~mm}$ using dial callipers. Shell lengths ranged from 15.2 to $25.3 \mathrm{~mm}$ (H. scobina), 27.3 to $40.1 \mathrm{~mm}(C$. virgata), 32.0 to $47.5 \mathrm{~mm}$ (C. maculosa Harbour), and 32.5 to $46.3 \mathrm{~mm}$ (C. maculosa South Coast).

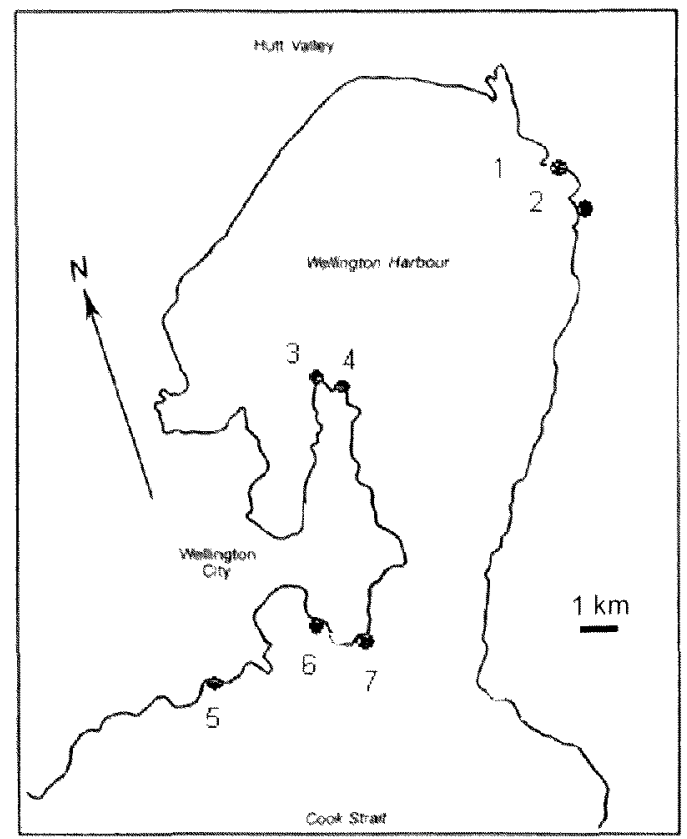

Fig. 1. Collection sites of adult whelks. Wellington Harbour (1: Point Howard, 2: York Bay; 3: Point Halswell, 4: Kau Bay) and South Coast (5: Island Bay, 6: Moa Point, 7: Tarakena Bay).

Whelks were brought to the Victoria University Coastal Ecology Laboratory facility where they were subjected to different feeding regimes under controlled conditions. C. maculosa whelks from the Harbour and South Coast were subjected to treatments separately in order to test for potential regional differences in maternal investment.

Whelks were confined within mesh-lined baskets $(250 \mathrm{~mm} \times 160 \mathrm{~mm} \times 90 \mathrm{~mm})$ positioned randomly in a large shallow tank supplied with constantly flowing fresh 
seawater at ambient temperature. Water was able to flow freely through all baskets and was maintained at a level of approximately $50 \mathrm{~mm}$. Ten whelks of each species were assigned to six replicates of each of four feeding treatments (detailed below). Individual whelks were tagged with bee tags attached with superglue, all of which remained in place throughout the experiment. Shell lengths were measured (nearest $0.1 \mathrm{~mm}$ ) and individuals were weighed (nearest $0.01 \mathrm{~g}$ ) following standard blotting (Morton 1986). This was done both before and after the experiment so that growth in response to the feeding treatments could be determined.

In the period June to December 2006, whelks of each species were subjected to four feeding treatments designed to cover a range of food availability from low to high (but not so low as to prevent egg laying). In a feeding trial (appendix 1), an amount of food was determined for each species that corresponded to the daily mean consumption rate. The four feeding treatments in the experiment corresponded to $10 \%, 20 \%, 50 \%$ and $100 \%$ of the amount for each species (see appendix 1 for more details).

Food consisted of chopped up portions of the mussel Perna canaliculus. The amount of food determined by the feeding trial was used in the first week of the experiment but was found to be too high as food remained in some of the $10 \%$ treatment baskets. Food was then reduced to a weekly amount of one quarter of that determined by the feeding trial and remained at this level throughout the experiment. At this level food was sometimes left over in the 50 and $100 \%$ treatments after one week, but never left over in the $10 \%$ and $20 \%$ treatments.

Feeding took place weekly and baskets were cleared of any left over food from the previous week immediately before this took place. Whelks responded well to this regime and mortality over the period was low (H. scobina $0.8 \%, C$. virgata $2.1 \%, C$. maculosa (Harbour) 1.2\%, C. maculosa (South Coast) 1.7\%).

Baskets were checked for egg capsules at weekly intervals. Egg capsules were unique for each species (fig. 2). Communal laying of H. scobina and C. maculosa capsules meant that clutches laid by individual females could not be identified. C. virgata clutches however, were usually laid in isolated groups which enabled the analysis of 
clutch size variation. The feeding regime was ceased after 19 weeks for $H$. scobina and $C$. virgata, when egg laying had markedly declined. C. maculosa had a later period of egg laying than the other two species and feeding continued for 25 weeks. Adults were sexed, measured and weighed after feeding was ceased.
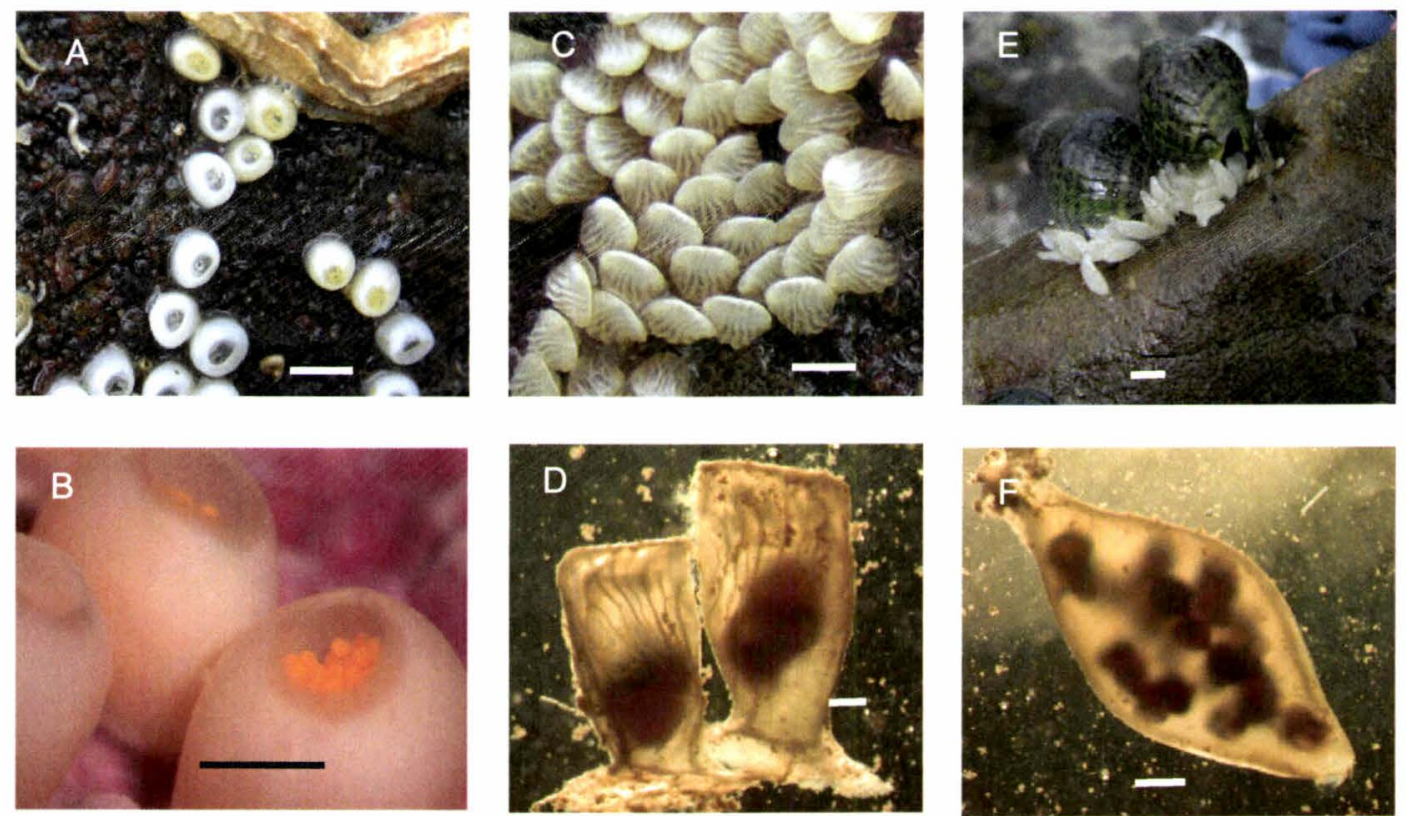

Fig. 2. Representative capsules of three whelk species. A and B: H. scobina; C and D: C. virgata; E and F: C. maculosa. H. scobina and C. maculosa capsules have multiple hatchlings while $C$. virgata capsules contain a single hatchling. Scale bars: $\mathrm{A}, \mathrm{C}, \mathrm{E}=5 \mathrm{~mm} ; \mathrm{B}, \mathrm{D}, \mathrm{F}=1 \mathrm{~mm}$. Photos $\mathrm{A}, \mathrm{C}$ and $\mathrm{E}$ by N. Phillips.

In order to test for a potential relationship between capsule size and the number of encapsulated hatchlings, individual H. scobina and C. maculosa capsules were isolated. Samples of egg capsules were carefully prised from the baskets in which they were laid using a scalpel, placed into $30 \mathrm{~mm}^{2}$ nylex mesh bags (mesh size = $500 \mu \mathrm{m})$ and sealed using hot-melt glue. Egg capsules remained intact throughout this procedure. Mesh bags were kept in a large flat tank supplied with constantly flowing fresh seawater at ambient temperature. Hatchlings were counted and measured a few days after the emergence of the first individual. Hatchlings remaining in the capsule were removed at this time.

A sample of three newly laid H. scobina and C. maculosa egg capsules from each replicate basket was frozen. These were later dissected in order to count the number of 
initially encapsulated eggs. Eggs disintegrated during freezing however and counts were not possible.

\subsubsection{Estimation of Capsule Volumes}

H. scobina capsule volumes were calculated assuming the shape approximates a cylinder with a half sphere top: $V=\pi r^{2}(h-r)+2 / 3 \pi r^{3}$, where $r$ is capsule radius and $h$ case height measured using a dissecting microscope (Zeiss 9901) equipped with a graticulated eyepiece.

C. virgata capsule volumes were calculated assuming the capsule approximates a cuboid with a half cylinder top: $V=h w c-w c^{2 / 2}+\pi w c^{2} / 8$, where $h$ and $w$ are the capsule height and width measured using a microscope as above. Capsule depth $c$ was assumed to be constant and estimated to be $2.03 \pm 0.03 \mathrm{~mm}(95 \%$ confidence interval, $\mathrm{n}=65)$.

C. maculosa capsule volumes were calculated assuming that the capsule shape approximates an ellipsoid: $V=4 / 3 \pi a b c$, where $a$ and $b$ are the major and minor axes (capsule length and width) measured using a microscope as above. The other minor axis $c$ (depth) was estimated using a regression equation $(y=0.163 x+1.345)$ obtained from measurements of 207 whelk egg capsules collected in the field (Phillips unpublished data). Capsule depth was found to be moderately related to capsule length $\left(R^{2}=0.158, \mathrm{p}<0.05\right)$.

\subsubsection{Statistical analysis}

The statistical package SPSS ( $\mathrm{v} 12.0$ ) was used to carry out all of the data analysis.

Data from the $10 \%$ and $20 \%$ treatments were combined into a "low food" treatments class and data from the $50 \%$ and $100 \%$ classes combined into a "high food" class to simplify interpretation and to increase statistical power. Adult shell length and wet weight increases were found to be similar for the $10 \%$ and $20 \%$ as well as for the $50 \%$ and $100 \%$ treatments in each of the whelk groups. Differences between these groups were t-tested (10\% vs. $20 \%$ and $50 \%$ vs. $100 \%$ for each species). A number of these 
comparisons were found to be statistically significant. However differences within treatments that were combined were small when compared with differences between combined treatments (appendix 2).

For each species, differences in adult growth between treatments were tested with two way ANOVA using replicate baskets as a blocking factor. Levene's test was used to test the assumptions of equal variance. Transformation of the length data for $C$. maculosa from both the Harbour and South Coast was necessary to meet the requirement for equality of variance $(y=\log l 0(x+1), y=\operatorname{arcsine}(x)$ for $C$. maculosa Harbour and South Coast respectively). Differences in the percentage shell length and weight changes between treatments were t-tested for each species individually. Ttests were used to compare the adult growth in replicate baskets containing capsules with growth in baskets without capsules, in order to test for a potential growth tradeoff with reproductive allocation.

Non-parametric binomial tests were used to compare the sex ratio of each species with expected $(50 \%)$ values and to compare the total number of capsules laid in combined low and high food treatments for each species with expected $(50 \%)$ values.

Regional differences in the growth of C. maculosa were tested using two way ANOVA using species and treatment as fixed factors. Length data was transformed $(y=\operatorname{sqrt}(x))$ to meet the requirement of equality of variance. No transformation of weight data was necessary.

Development time was calculated as the time between the laying of the first capsule until the emergence of the first hatchling in each of the baskets. Only one measurement was possible from each basket because capsules were not monitored individually. T-tests were carried out for each species to detect differences in development time between food treatments. Regression analysis of capsule laid date and capsule development was carried out for each of the species. C. maculosa data from the Harbour and the South Coast were combined to increase sample size in these analyses. 
Regression analysis was used to estimate the strength of the relationship between capsule volume and the number of hatchlings encapsulated for each of the species. Five C. maculosa (Harbour) and one C. maculosa (South Coast) data points were found to have high Cook's distance or high leverage values and had strong influence on the result. These points were assumed to be outliers and removed from the analysis.

ANCOVA was used to test for differences in the low and high food regression lines that were generated when comparing the relationship between the number of hatchlings per capsule and capsule volume. Log transformation of hatchling number data was required for $H$. scobina to satisfy the requirement of equality of variance. ANCOVA was also used to test for differences in the regression lines generated for low and high food treatments when comparing the relationship of $C$. virgata clutch sizes with (1) the mean hatchling size per clutch and (2) the proportion of females in each replicate basket. Regression analysis was used to estimate the strength of the above relationships.

Nested ANOVAs were used to test for differences in hatchling size in response to food treatments. Individuals were nested within capsules, capsules within baskets and baskets within food treatments for $H$. scobina. Individuals were nested with clutch and clutch within baskets for C. virgata. Individuals were nested within capsules, capsules within baskets and baskets for C. maculosa. For C. maculosa, there was an additional factor of location. Capsule and replicate basket (H. scobina, C. maculosa) and clutch and replicate basket $(C$. virgata) were treated as random effects.

\subsection{RESULTS}

\subsubsection{Adult growth}

a) Shell Length

Shell length growth was greater in the high food treatments of three out of four of the whelks groups $\left(C\right.$. virgata: $F_{1,11}=15.37, \mathrm{p}<0.01 ;$ C. maculosa Harbour: F1,11=103.04, 
$\mathrm{p}<0.01$; C. maculosa South Coast: $\mathrm{F} 1,11=81.50, \mathrm{p}<0.01$ ). There was no significant difference in H. scobina shell length growth between low and high food treatments $\left(\mathrm{F}_{1,1}=1.19, \mathrm{p}=0.30\right.$, fig. 3).

Within species variation among replicate baskets was significant for C. maculosa Harbour $\left(\mathrm{F}_{1,11}=2.92, \mathrm{p}=0.04\right)$. Variation among replicate baskets of other groups was non significant $\left(H\right.$. scobina: $\mathrm{F}_{1,11}=0.70, \mathrm{p}=0.72, C$. virgata: $\mathrm{F}_{1,11}=0.39, \mathrm{p}=0.94, C$. maculosa (South Coast): $F_{1,11}=0.72, p=0.71$ ). Transformation of $C$. maculosa data was necessary to satisfy the requirement for equality of variance.
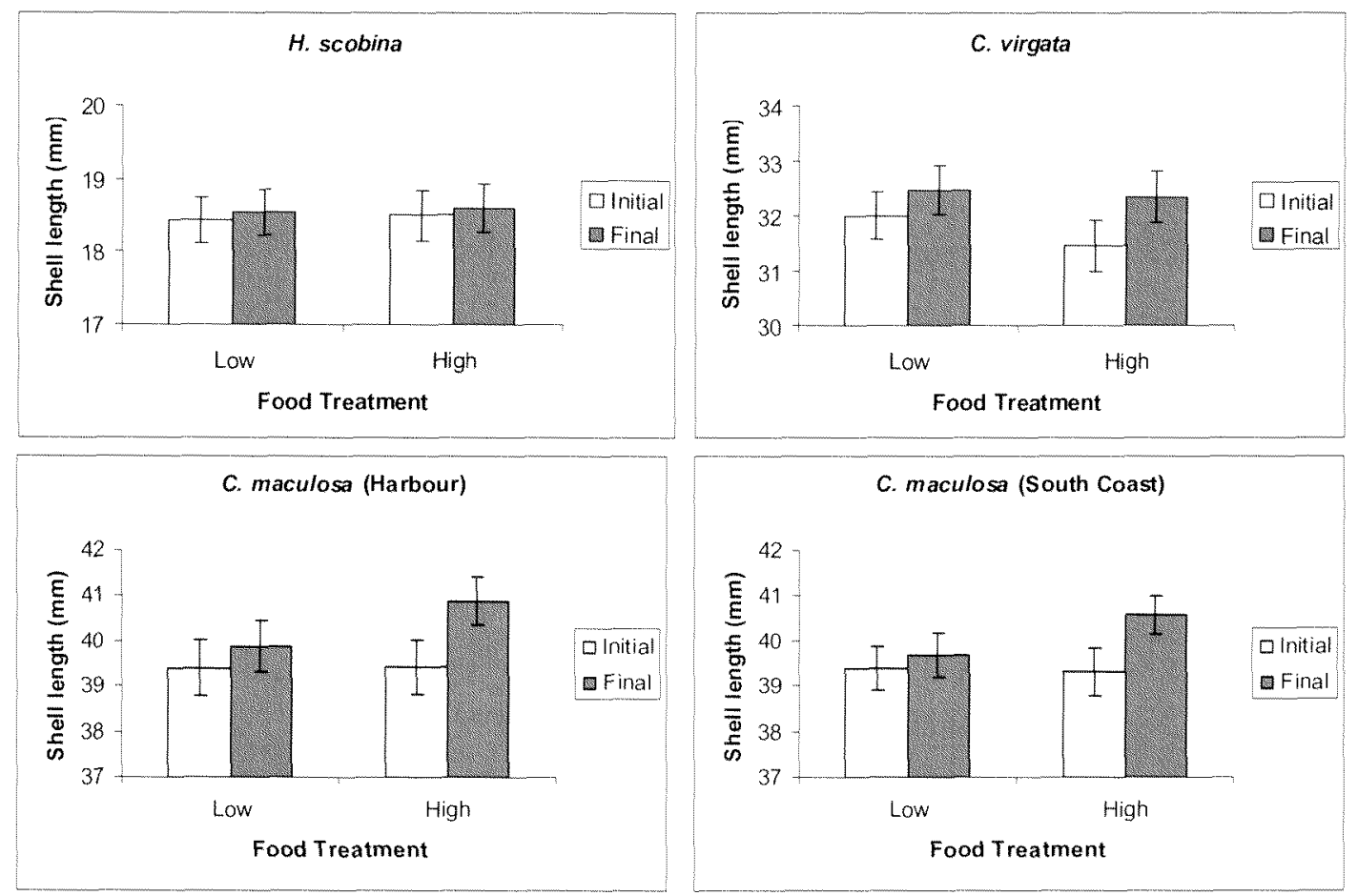

Fig. 3. Shell growth in four groups of intertidal whelks subjected to low and high food treatments. Error bars indicate $95 \%$ confidence intervals.

Shell length increase as a percentage of total length was higher in high food treatments in all groups with the exception of $H$. scobina which showed no difference in percentage increase between high and low food treatments $(t=1.46, p=0.14, n=238)$. C. maculosa from the Harbour exhibited the greatest change in shell length increasing by an average of $3.7 \%$ in 25 weeks (fig. 4). 


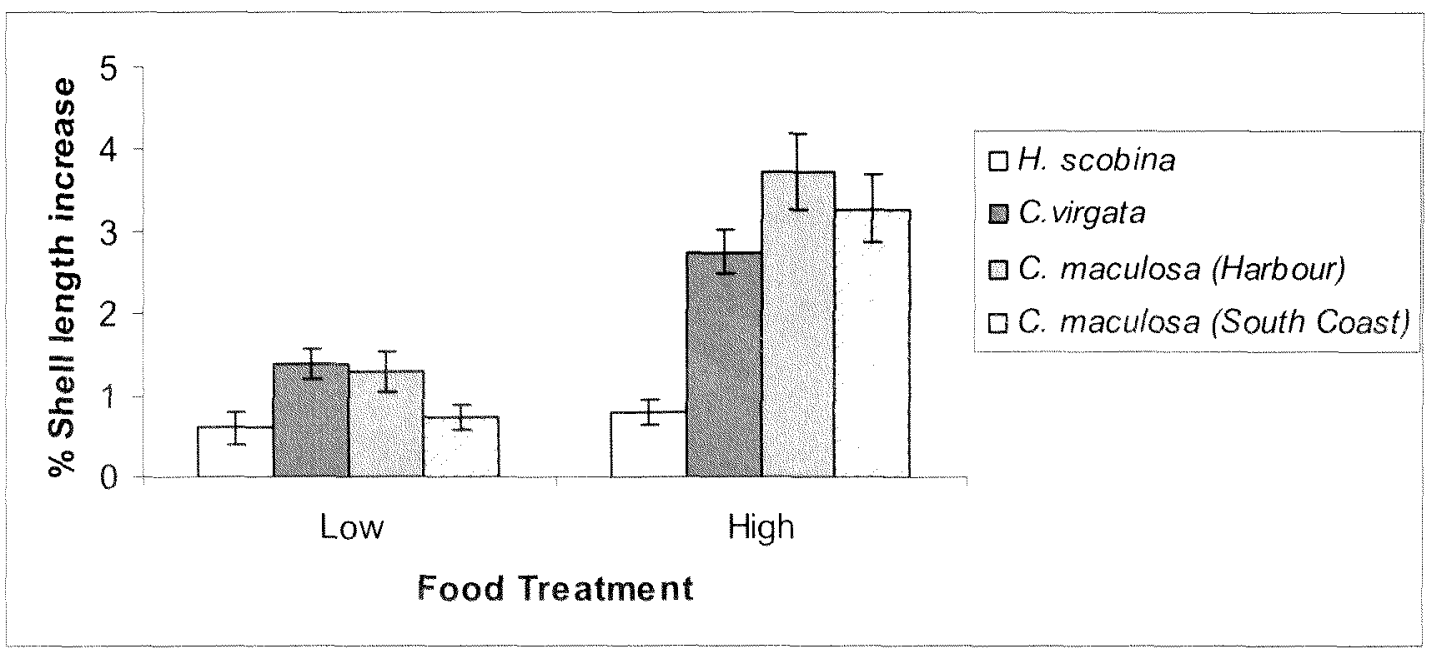

Fig. 4. Percentage increase in shell length for four groups of intertidal whelks raised in the laboratory in the spring of 2006 . Error bars indicate $95 \%$ confidence intervals.

\section{b) Weight}

Mean wet weight increased in the high food treatments and decreased in low food treatments in three of the groups. Weight change was significant for $C$ virgata $\left(\mathrm{F}_{1,1}=112.2, \mathrm{p}<0.01\right)$, C. maculosa Harbour $\left(\mathrm{F}_{1,11}=93.52, \mathrm{p}<0.01\right)$ and $C$. maculosa South Coast $\left(F_{1,11}=159.39, p<0.01\right)$. There was no significant difference in the change of $H$. scobina mean wet weight between food treatments $\left(F_{1.11}=1.80, p=0.21\right.$, fig. 5$)$.

Within species variation among replicate baskets was not significant in any treatment (H. scobina: $\mathrm{F}_{1,11}=0.69, \mathrm{p}=0.73$, C. virgata: $\mathrm{F}_{1,11}=1.82, \mathrm{p}=0.17$, C. maculosa Harbour: $\mathrm{F}_{1,11}=1.56, \mathrm{p}=0.24$, C. maculosa South Coast: $\mathrm{F}_{1,11}=0.70, \mathrm{p}=0.71$ ). 


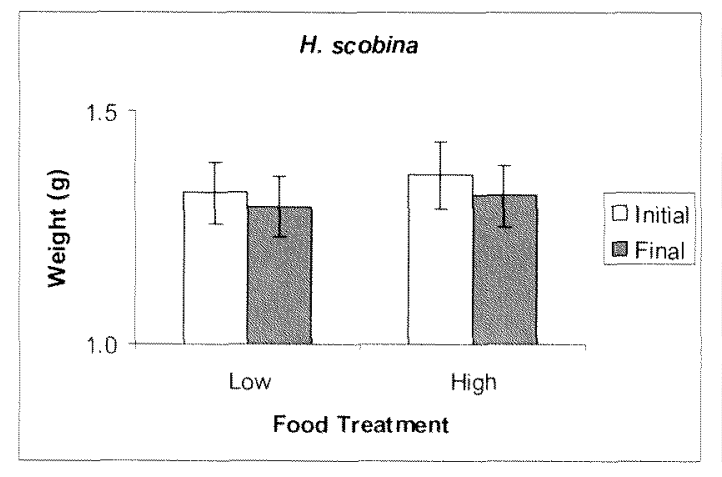

C. maculosa (Harbour)

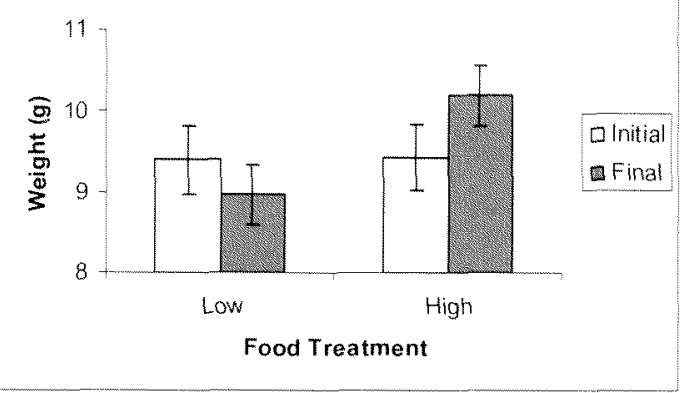

c. virgata

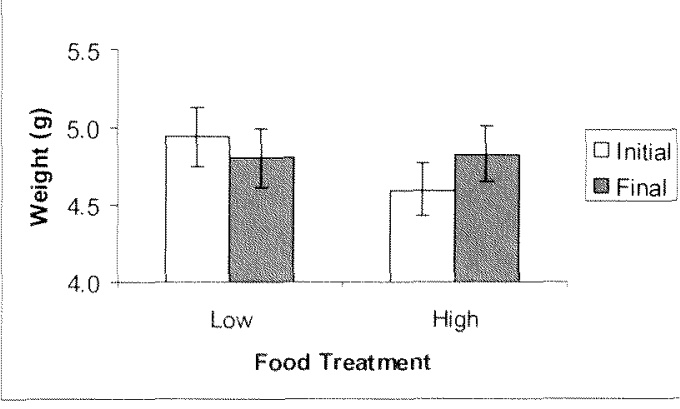

C. maculosa (South Coast)

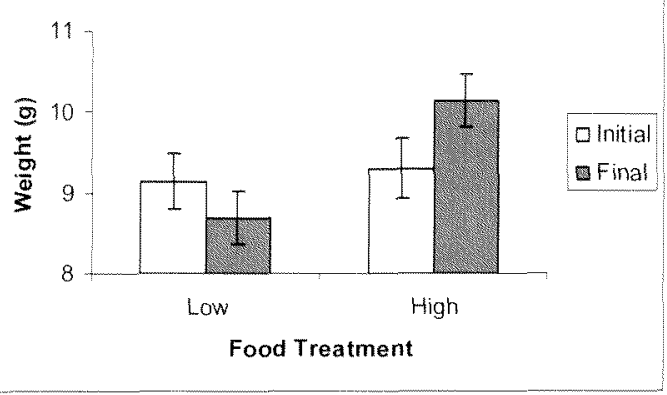

Fig. 5. Change in mean wet weight of four groups of intertidal whelks subjected to low and high food treatments. Error bars indicate $95 \%$ confidence intervals.

The greatest weight gain was achieved by $C$. maculosa from the South Coast which increased by an average of $8.8 \%$ in 25 weeks. C. maculosa from the South Coast also had the greatest weight decrease in the low food treatment, averaging a loss of weight of $5.2 \%$ in 25 weeks (fig. 6). The overall loss of weight in H. scobina was no different between high and low treatments $(t=1.40, p=0.16, n=238)$.

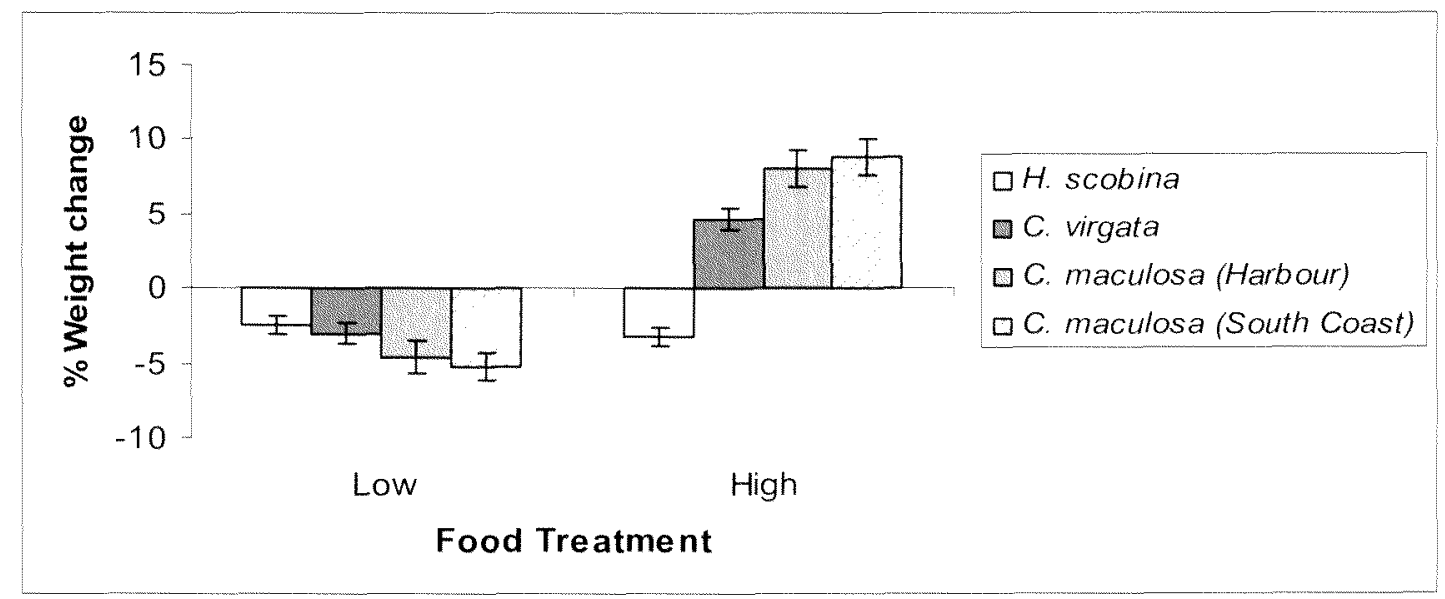

Fig. 6. Mean percentage change in wet weight for four groups of intertidal whelks raised in the laboratory in the spring of 2006 . Error bars indicate $95 \%$ confidence intervals. 
c) C. maculosa regional growth

ANOVA analysis detected a significant effect of food treatment on the increase in length of C. maculosa $\left(\mathrm{F}_{1,1}=307.85, \mathrm{p}<0.01\right)$ as well as a significant effect of source region $\left(F_{1,1}=14.97, p<0.01\right)$. The interaction term was not significant. T-tests revealed that the shell length of Harbour sourced adults in low food treatments increased significantly more than the shell length of South Coast sourced adults $(\mathrm{t}=4.20, \mathrm{p}<0.01)$. A non significant trend of greater shell length increase in Harbour sourced adults occurred in high food treatments (fig. 7).

ANOVA analysis of weight changes over the 25 week period found significant difference between food treatments only, such that high food whelks gained weight while low food whelks lost weight $\left(F_{1,1}=635.91, p<0.01\right)$. No difference was detected in the change of weight of $C$. maculosa from the two different regions within the same treatment.
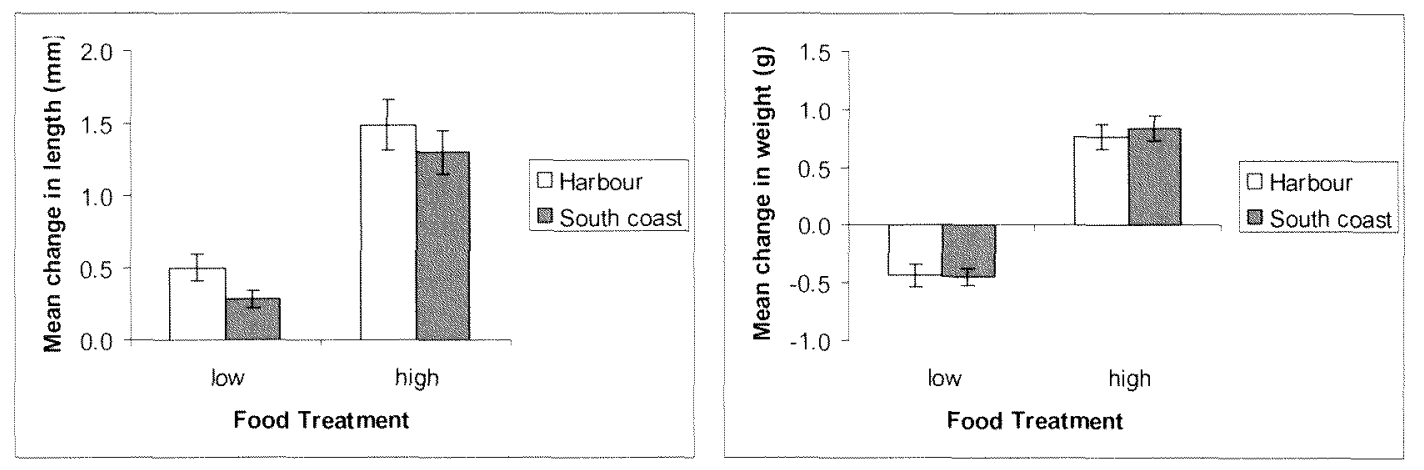

Fig. 7. Growth of $C$. maculosa from the Harbour and South Coast after 25 weeks. Mean change in length (left), mean change in weight (right). Error bars indicate $95 \%$ confidence intervals.

\subsubsection{Adult sex ratio}

Total female sex ratios were slightly less than $50 \%$ in $H$. scobina and C. virgata and slightly greater than $50 \%$ in both C. maculosa groups but did not differ significantly from a value of $50 \%$ in any of the groups (table 1 ). 
Table 1. Sex ratios in four groups of intertidal whelks. P-values are from binomial tests comparing female sex ratios with a $50 \%$ value. P-values $>0.05$ indicate female sex ratio is not significantly different from $50 \%$.

\begin{tabular}{lcccc}
\hline Species & $\mathrm{n}$ & Females & Female sex ratio & $\mathrm{p}$ \\
\hline H. scobina & 238 & 107 & 1.22 & 0.136 \\
C. virgata & 234 & 110 & 1.13 & 0.395 \\
C. maculosa (Harbour) & 237 & 131 & 0.81 & 0.119 \\
C. maculosa (South Coast) & 236 & 124 & 0.90 & 0.474 \\
\hline
\end{tabular}

\subsubsection{Adult mortality}

Fifteen individuals from an initial 960 died during the experiment. Mortality was spread among species, among treatments and among baskets (table 2). The highest mortality within a replicate basket was three individuals (C. maculosa South Coast (high food)).

Table 2. Adult mortality among species, among treatments and among baskets. Each treatment contained 120 whelks initially.

\begin{tabular}{lcccc}
\hline Species & \multicolumn{4}{c}{ Treatment } \\
\hline & \# Deaths & $\begin{array}{c}\text { Low } \\
\text { \# Baskets with } \\
\text { dead adults }\end{array}$ & \# Deaths & $\begin{array}{c}\text { High } \\
\text { \# Baskets with } \\
\text { dead adults }\end{array}$ \\
H. scobina & 2 & 2 & 0 & 0 \\
C. virgata & 3 & 2 & 3 & 3 \\
C. maculosa (Harbour) & 0 & 0 & 3 & 2 \\
C. maculosa (South Coast) & 0 & 0 & 4 & 2 \\
\hline
\end{tabular}

\subsubsection{Capsule laying}

H. scobina capsule laying commenced eight weeks after feeding began and climbed slowly to a maximum of 103 capsules per week in week 13. There was a steady decline after week 13 and by week 19 no new capsules were recorded (fig. 8).

C. virgata capsule laying commenced in week nine and climbed rapidly to a plateau of approximately 400 capsules per week by week 12 . This level persisted until week 15 after which capsule laying steadily declined. In the final week of monitoring (week 19) there was an unexpected peak in laying. The feeding experiment for H. scobina and $C$. virgata ceased on 13 November 2006 and adults were removed from the baskets at this time. 
C. maculosa capsule laying in whelks from the Harbour commenced in week 16 and remained at a level of approximately 60 capsules per week until week 20 after which there was an increase to a maximum of 250 capsules per week in week 22. Capsule laying decreased steadily after this maximum.

C. maculosa capsule laying in whelks from the South Coast commenced in week 17 and remained at a steady level of approximately 40 capsules per week until week 21 . Capsule numbers then increased to a maximum of 216 in week 23 and then rapidly decreased. A single clutch of 6 capsules was laid in week eleven. The feeding of $C$. maculosa ceased on 22 December 2006 and adults were removed from the baskets at this time.

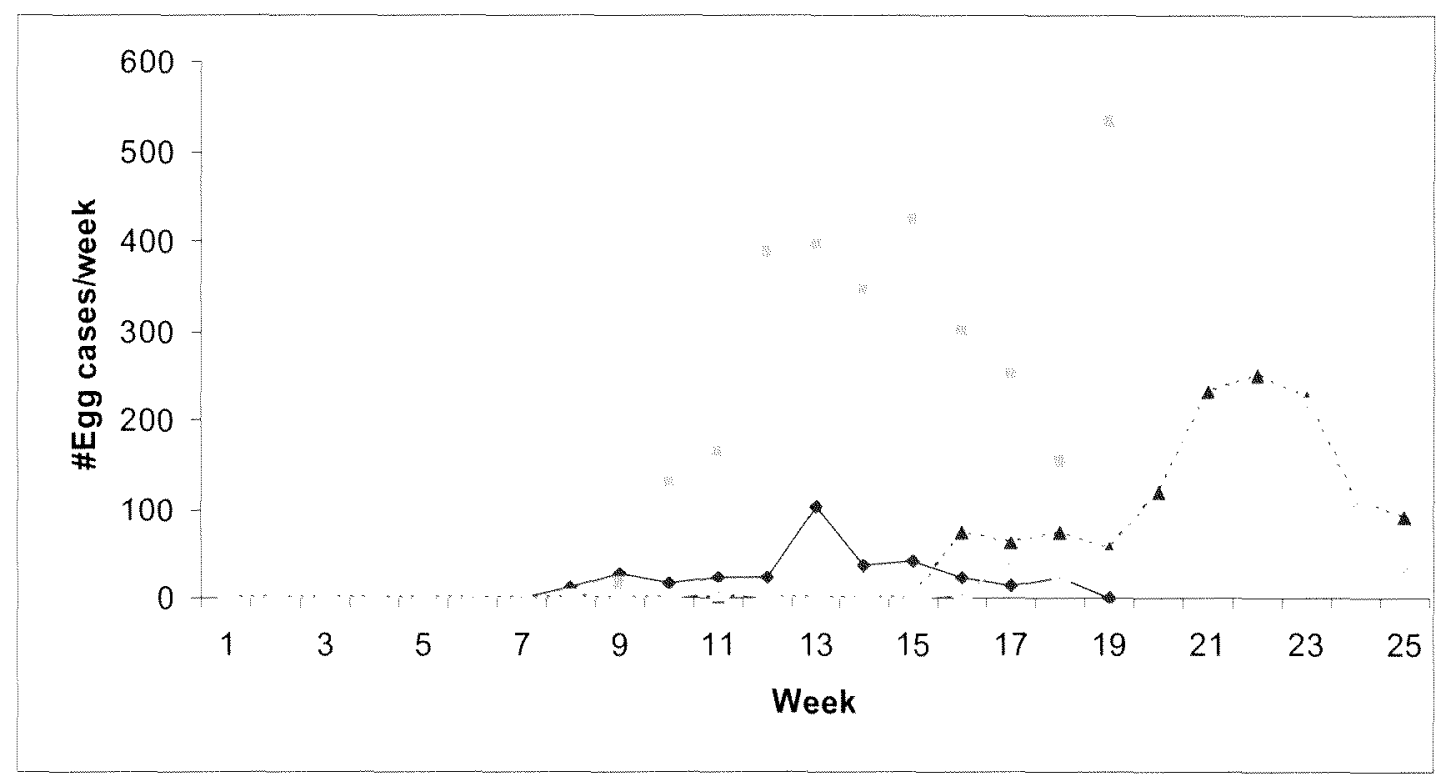

Fig. 8. Numbers of new egg capsules laid weekly by four groups of whelks in the period $3 / 7 / 06$ to $22 / 12 / 06$. H. scobina: dark colour and diamonds; C. virgata: light colour and squares; C. maculosa (Harbour): dashed line and triangles; C. maculosa (South Coast): light colour and crosses. Note that recording of $H$. scobina and $C$. virgata capsules ceased at an earlier date $(13 / 11 / 06)$.

\subsubsection{Development Time}

The average minimum developmental time in $H$. scobina was 90.8 days $(\mathrm{n}=10), 91.4$ days in $C$. virgata $(n=22)$ and 61.3 days for C. maculosa $(n=21)$. Developmental time did not differ significantly between treatments for any of the species (fig. 9). Data for C. maculosa was pooled from Harbour and South Coast whelks. 


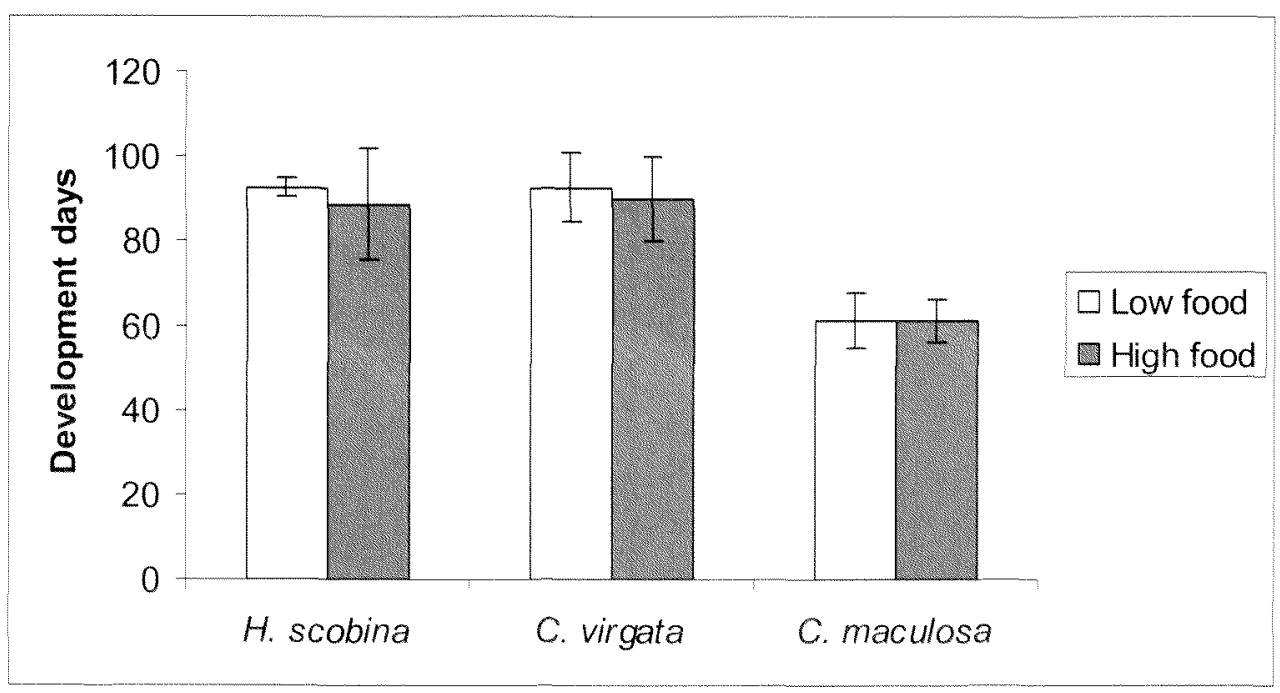

Fig. 9. Mean minimum developmental times of the egg capsule of three whelk species raised in the laboratory in the summer of $2006 / 7$. Error bars indicate $95 \%$ confidence intervals.

There was a significant negative relationship between the date that capsules were laid and the capsule development time in all three species. Capsules that were laid later took less time to develop (H. scobina: $\mathrm{R}^{2}=0.479, \mathrm{~F}=7.354, \mathrm{p}=0.03$, C. virgata: $\mathrm{R}^{2}=0.541, \mathrm{~F}=22.396, \mathrm{p}<0.01$, C. maculosa: $\mathrm{R}^{2}=0.638 . \mathrm{F}=33.341, \mathrm{p}<0.01$, fig. 10 ). Data for C. maculosa was pooled from Harbour and South Coast whelks.

Water temperatures ranged between $11.2^{\circ} \mathrm{C}$ and $15.8^{\circ} \mathrm{C}$ and were higher later in the experiment (fig. 10). 

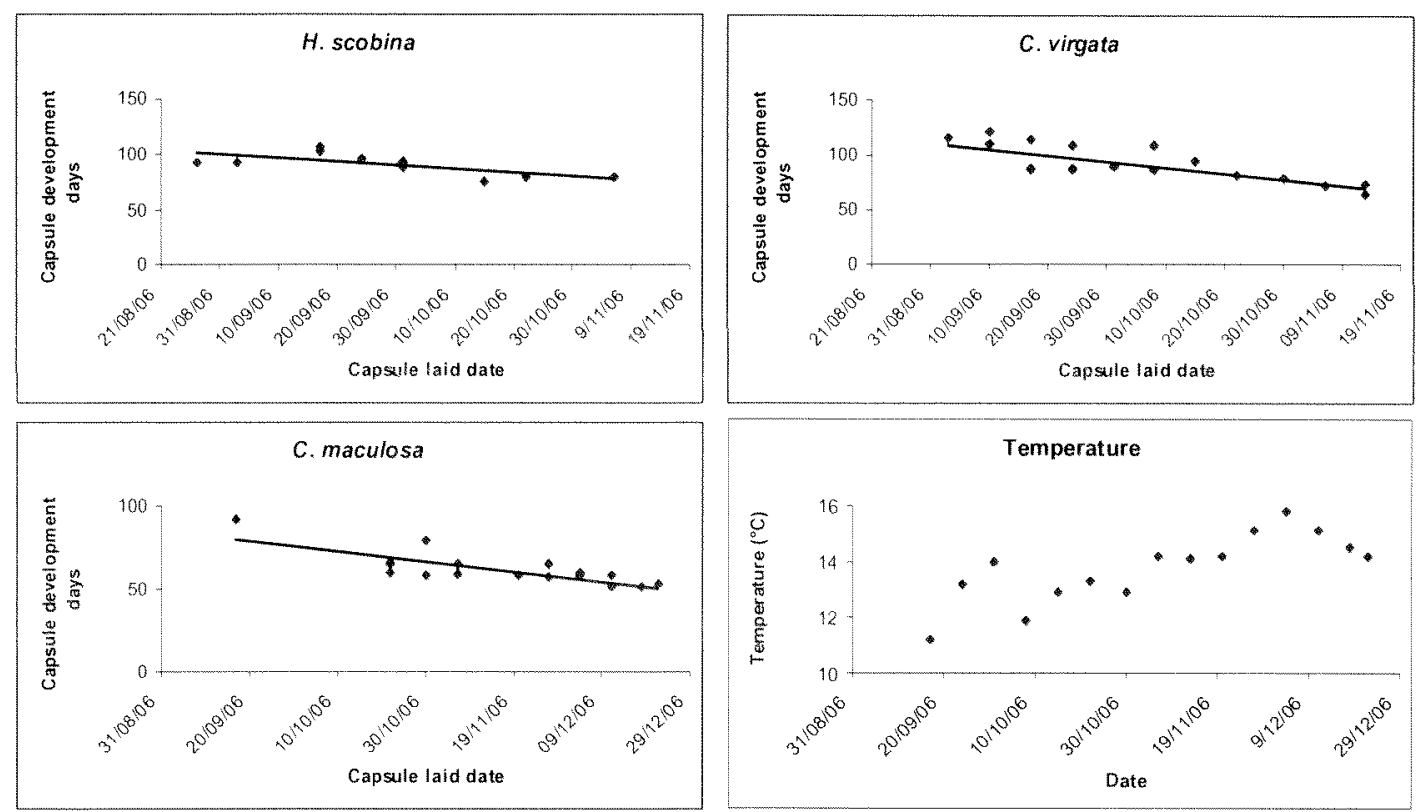

Fig. 10. Regression comparing capsule laid date with development time for each group. The capsule development times of all three species were shorter for capsules that were laid later in the experiment, when water temperatures were higher.

\subsubsection{Investment in capsules}

Across all treatments, more than half of the replicate baskets $(58 \%)$ contained egg capsules. C. virgata egg capsules were laid in almost all replicates $(92 \%)$, while $H$. scobina capsules were laid in $58 \%$ of replicates, C. maculosa (Harbour) in $50 \%$ of replicates and C. maculosa (South Coast) in 46\% of replicates. Replicates containing egg capsules were spread evenly between treatments in all four of the whelk groups (fig. 11). Differences in mean numbers of egg capsules laid in low and high food treatments were not significantly different for any of the whelk groups (MannWhitney: $\mathrm{U}=61.5, \mathrm{p}=0.53($ H. scobina $) ; \mathrm{U}=53.5, \mathrm{p}=0.30($ C. virgata $) ; \mathrm{U}=57.5, \mathrm{p}=0.37$ (C. maculosa Harbour); $\mathrm{U}=55.0, \mathrm{p}=0.28$ (C. maculosa (South Coast)). 

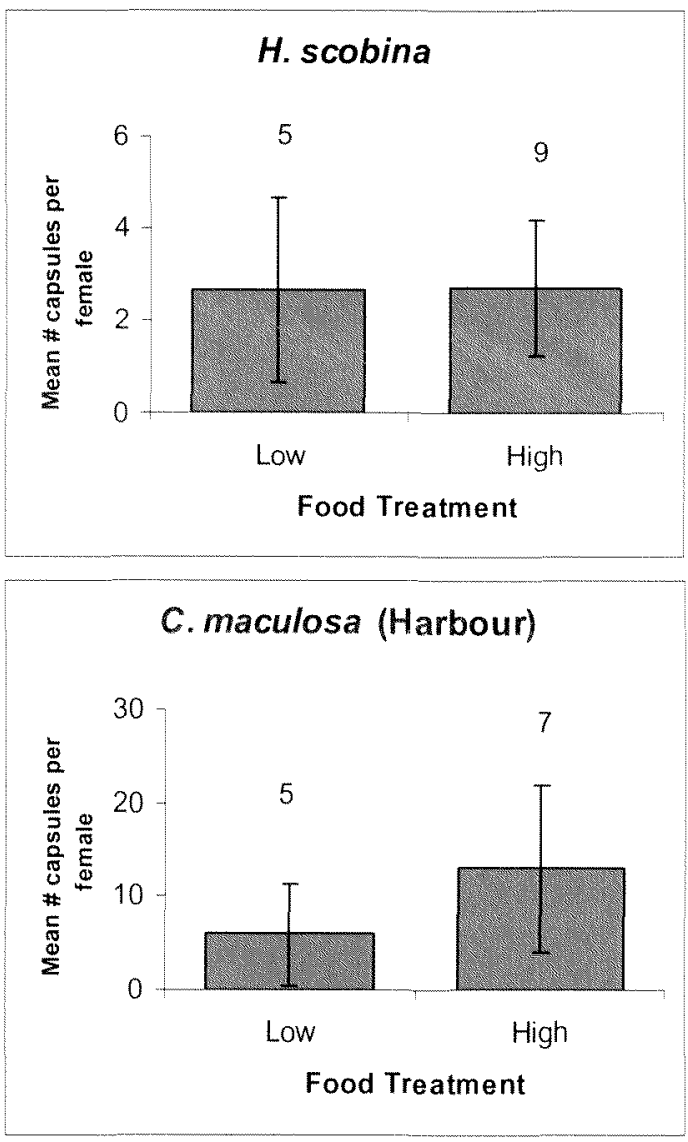

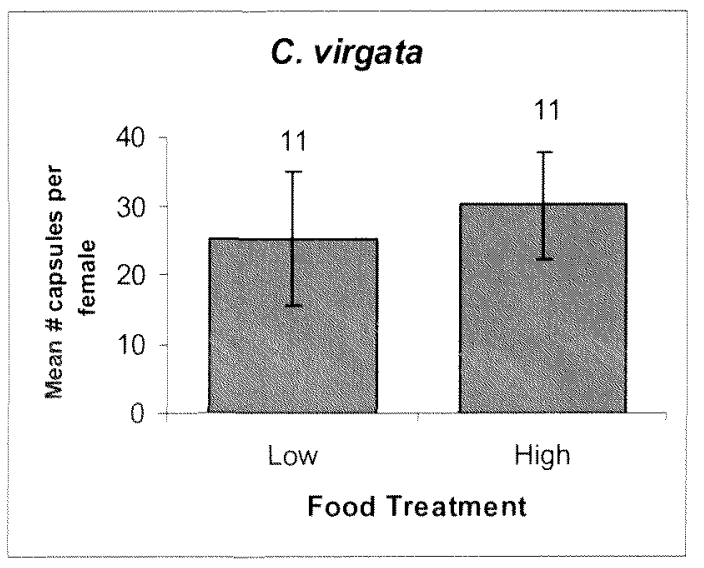

\section{C. maculosa (South Coast)}

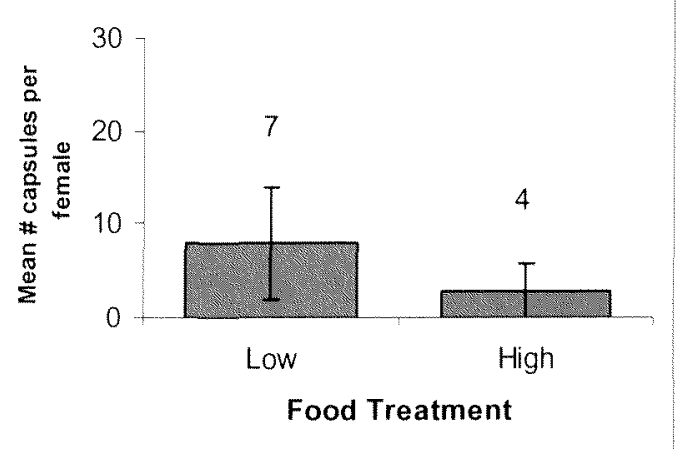

Fig. 11. Mean numbers of capsules per female laid by four groups of intertidal whelks. The number of replicate baskets containing egg capsules (of twelve) is shown above the boxes. Error bars indicate $95 \%$ confidence intervals.

Due to the large variation in the number of egg capsules within each replicate for each whelk group, total numbers of capsules across all baskets were also compared for each species. Binomial tests comparing the observed number of capsules in combined baskets within food treatments with expected numbers of capsules (capsules evenly divided between treatments) revealed significant deviation from expected values. The proportion of capsules laid by C. virgata, C. maculosa Harbour and C. maculosa South Coast whelks in low and high food treatments differed significantly from a value that would expected $(50 \%)$ were the food treatments to have no effect. Significantly more capsules were deposited by C. virgata and C. maculosa Harbour sourced whelks in high food treatments. In contrast significantly more capsules were deposited by $C$. maculosa South Coast sourced whelks in low food treatments. Observed numbers of $H$. scobina capsules were no different from predicted numbers of capsules (table 3 ). 
Table 3. Comparison of observed and expected numbers of egg capsules.

\begin{tabular}{cccccccc}
\hline Species & Treatment & Expected & Observed & $\mathrm{n}$ & $\mathrm{p}$ & $\begin{array}{c}\text { Replicates } \\
\text { with } \\
\text { capsules }\end{array}$ & range \\
\hline H. scobina & Low & 0.5 & 0.5 & 169 & 1 & $5 / 12$ & $23-49$ \\
& High & 0.5 & 0.5 & 169 & & $9 / 12$ & $4-41$ \\
C. virgata & Low & 0.5 & 0.45 & 1407 & $<0.01^{* *}$ & $11 / 12$ & $5-250$ \\
& High & 0.5 & 0.55 & 1699 & & $11 / 12$ & $43-288$ \\
C. maculosa & Low & 0.5 & 0.38 & 492 & $<0.01^{* *}$ & $5 / 12$ & $11-204$ \\
(Harbour) & High & 0.5 & 0.62 & 800 & & $7 / 12$ & $3-219$ \\
C. maculosa & Low & 0.5 & 0.7 & 466 & $<0.01^{* *}$ & $7 / 12$ & $5-204$ \\
(South Coast) & High & 0.5 & 0.3 & 196 & & $4 / 12$ & $8-92$ \\
\hline
\end{tabular}

There was no significant difference in the growth of whelks from replicate baskets containing egg capsules and those without egg capsules, in both low and high food treatments (table 4). C. virgata was not compared because only one replicate basket contained no egg capsules in both high and low food treatments).

Table 4. Comparison of growth of whelks in replicates with and without egg capsules.

\begin{tabular}{ccccc}
\hline Species & Treatment & Measurement & $\mathrm{t}$ & $\mathrm{p}$ \\
\hline H. scobina & Low food & Length & 0.539 & 0.59 \\
& & Weight & 0.071 & 0.94 \\
& High food & Length & 0.481 & 0.63 \\
& & Weight & 0.475 & 0.64 \\
C. maculosa & Low food & Length & 2.004 & 0.05 \\
(Harbour) & & Weight & 1.491 & 0.14 \\
& \multirow{2}{*}{ High food } & Length & 0.651 & 0.52 \\
& & Weight & 1.694 & 0.09 \\
C. maculosa & \multirow{2}{*}{ Low food } & Length & 0.038 & 0.97 \\
(South Coast) & & Weight & 0.215 & 0.83 \\
& \multirow{2}{*}{ High food } & Length & 0.191 & 0.85 \\
& & Weight & 0.636 & 0.53 \\
\hline
\end{tabular}

\subsubsection{Capsule volume}

There were significant differences in egg capsule volumes between low and high food treatments in $H$. scobina $(\mathrm{t}=2.62, \mathrm{p}=0.01, \mathrm{n}=218)$, in $C$. virgata $(\mathrm{t}=8.21, \mathrm{p}<0.01$, $\mathrm{n}=2591$ and in C. maculos $a$ from the South Coast $(\mathrm{t}=3.479, \mathrm{p}<0.01, \mathrm{n}=420)$. No significant difference was found between food treatments in C. maculosa from the Harbour $(\mathrm{t}=0.145, \mathrm{p}=0.88, \mathrm{n}=753)$. H. scobina capsules laid by whelks in low food treatments were on average $11 \%$ larger with a mean volume of $11.5 \mu 1$ compared with a mean volume of $10.2 \mu \mathrm{l}$ in capsules from high food treatments. In contrast, $C$. 
virgata egg capsules and C. maculosa (South Coast) capsules had larger volumes in high food treatments. C. virgata capsules were on average $5 \%$ larger in high food

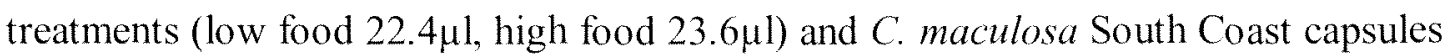
were on average $7 \%$ larger in high food treatments (low food $37.5 \mu$, high food $40.2 \mu \mathrm{l}$, fig. 12 ).

C. maculosa whelks collected from Harbour sites laid capsules that were significantly larger than those collected from South Coast sites in both high and low food treatments (low food: $\mathrm{t}=27.855, \mathrm{p}<0.01$; high food: $\mathrm{t}=4.510, \mathrm{p}<0.01$ )
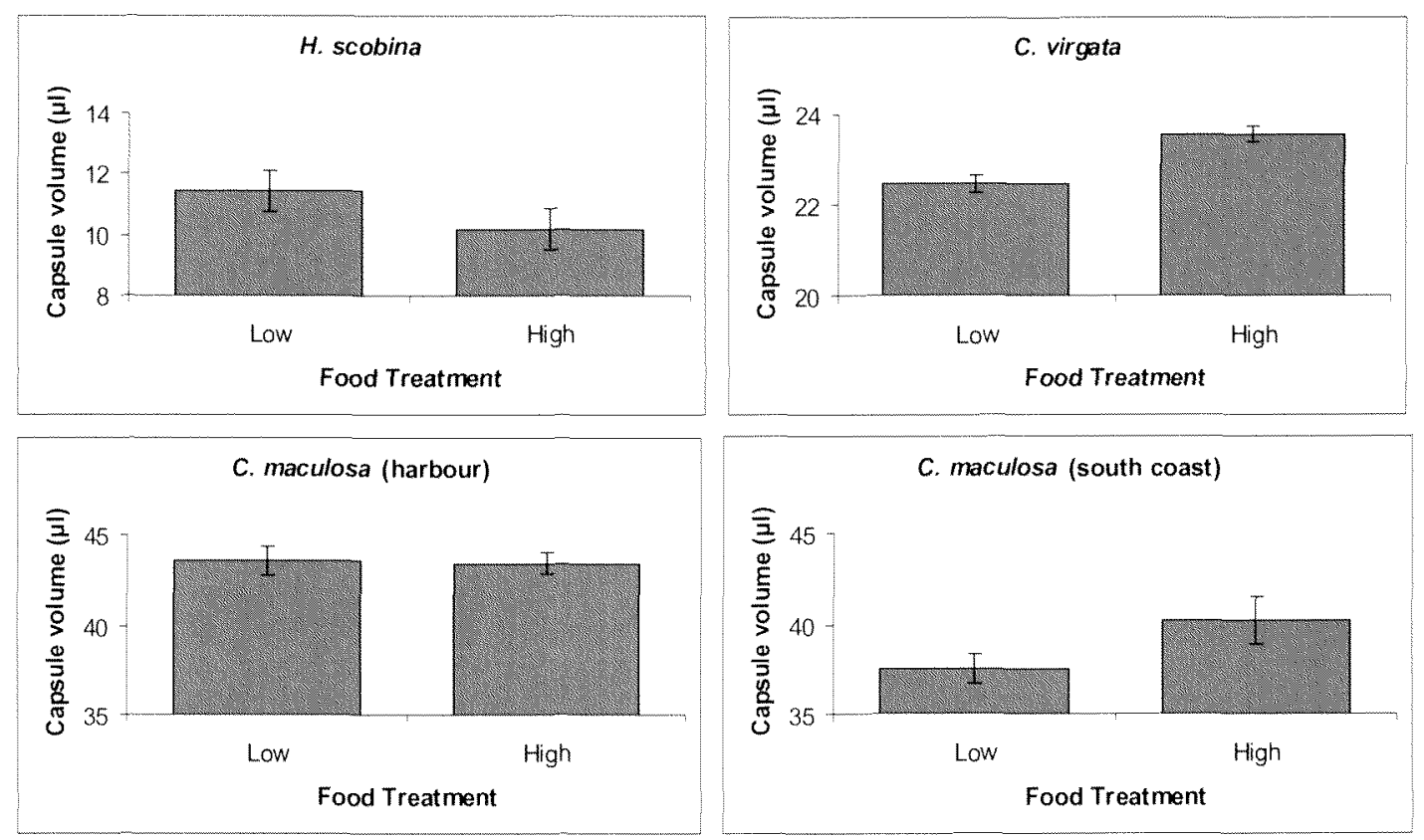

Fig. 12. Mean capsule volume between treatments for four groups of intertidal whelks. Error bars indicate $95 \%$ confidence intervals.

\subsubsection{Variation in hatchlings per capsule}

a) H. scobina

The number of hatchlings per capsule ranged from 1 to 19. Analysis of covariance detected a significant difference in the relationship of capsule volume and the number of hatchlings per capsule between food treatments $(F=4.20, p=0.04$, fig. 13). The relationship is steeper for the high food treatments indicating that as capsule volume increased, whelks from high food treatments increased the number of hatchlings per 
capsule. A large proportion of the variation in the number of hatchlings per capsule could be explained by capsule volume (low food: $R^{2}=0.15, F=9.86, p<0.01$; high food: $\left.\mathrm{R}^{2}=0.23, \mathrm{~F}=14.81, \mathrm{p}<0.01\right)$. Using the regression equations, the mean number of hatchlings that could be expected from a capsule of average volume was 6.8 and 7.7 for low and high food treatments respectively.

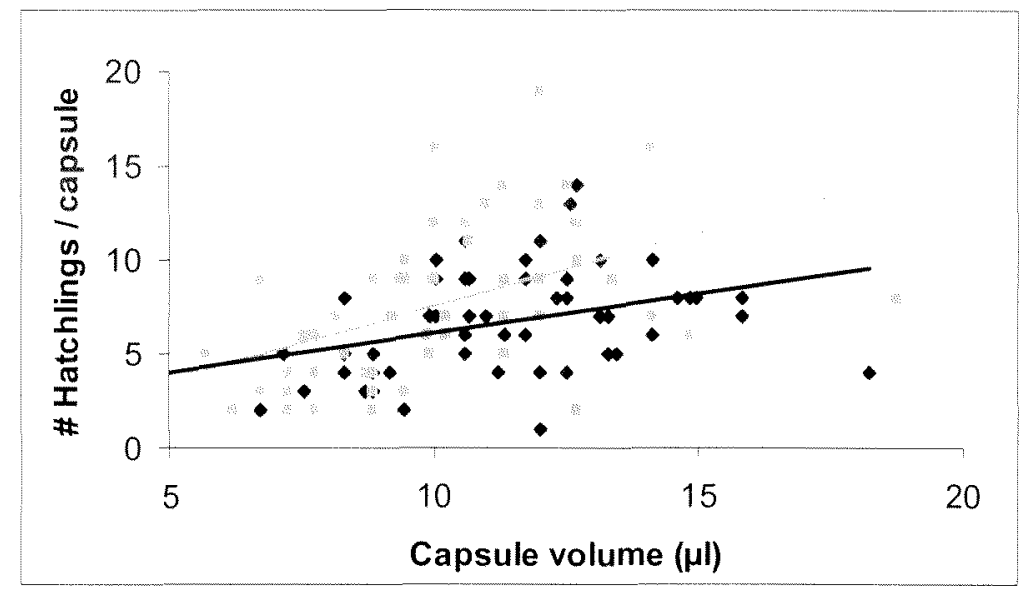

Fig. 13. Correlation between capsule volume and number of hatchlings per capsule in H. scobina. Dark coloured diamonds and line represent low food treatment data and regression line; light coloured squares and line represent high food treatment data and regression line.

b) C. virgata

Of the total capsules examined containing viable hatchlings, almost all were found to encapsulate a single individual. Ten capsules (approximately 1\%) were found to contain multiple hatchlings (eight with two hatchlings, one with three hatchlings and one capsule with twelve hatchlings). These multiple hatchlings occurred in both low (6) and high (4) food treatments.

The number of capsules in a clutch showed considerable variation ranging from 1 to 82 (average 28.0). The pattern of distribution was similar in both high and low food treatments (fig. 14A). Analysis of covariance failed to detect a significant difference in the relationship of clutch size and mean within clutch hatchling size between food treatments $(F=0.11, p=0.74$, fig. $14 \mathrm{~B})$. Variation in mean hatchling size could not be explained by clutch size in either low or high food treatments (low food: $R^{2}=0.03$, $F=1.09, p=0.30$; high food: $R^{2}=0.02, F=0.99, p=.32$ ). 
Much of the variation in the number of clutches produced could be explained by the number of females in each treatment (low food: $R^{2}=0.59, F=7.72, p=0.02$; high food: $\mathrm{R}^{2}=0.59, \mathrm{~F}=14.39, \mathrm{p}<0.01$, fig. 14C). ANCOVA detected no difference between the regression lines for high and low food treatments $(F=0.62, p=0.44)$.
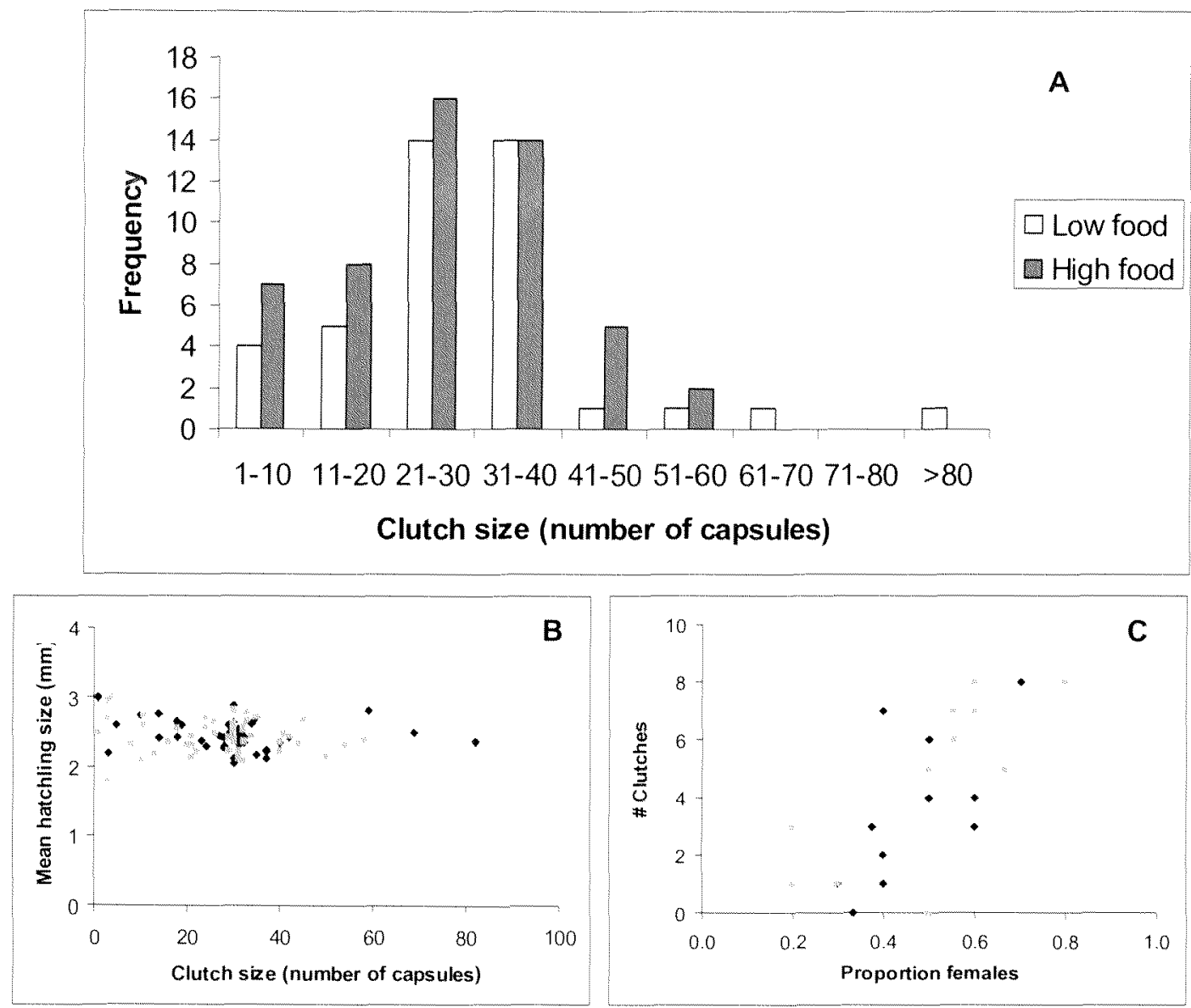

Fig. 14. A: Frequency distribution of $C$. virgata clutch sizes in low and high food treatments. B: Relationship between mean size at hatching and clutch size between low and high food treatments. C: Relationship between the proportion of females in a replicate basket and the number of clutches produced. Dark coloured diamonds represent low food treatments data; light coloured squares represent high food treatments data. 


\section{c) C. maculosa}

The number of hatchlings per capsule followed a normally distributed pattern that was similar in whelks sourced from both the Harbour and South Coast (fig. 15A). The number of hatchlings per capsule ranged from two to 28 in whelks collected from the Harbour and from two to 24 per capsule in whelks from the South Coast (median 8 and 9 hatchlings per capsule respectively). Capsules with 19 or more hatchlings had a strong influence on the regression analysis and were treated as outliers.

Analysis of covariance failed to detect a significant difference in the relationship of capsule volume and the number of hatchlings per capsule between food treatments (Harbour sourced whelks: $F=0.05 . p=0.83$, fig. 15B; South Coast sourced whelks: $\mathrm{F}=0.87, \mathrm{p}=0.35$, fig. $15 \mathrm{C}$ ). A small proportion of the variation in the number of hatchlings per capsule could be explained by capsule volume with the strongest relationship occurring in low food whelks sourced from the South Coast (Harbour sourced low food: $\mathrm{R}^{2}=0.13, \mathrm{~F}=11.32, \mathrm{p}<0.01$; Harbour sourced high food: $\mathrm{R}^{2}=0.09$, $F=9.50, p<0.01$; South Coast sourced low food: $R^{2}=0.32, F=47.72, p<0.01$; South Coast sourced high food: $\mathrm{R}^{2}=0.08, \mathrm{~F}=5.04, \mathrm{p}=0.03$ ). Using the regression equations, the mean number of hatchlings that could be expected from the capsule of a Harbour sourced whelk of average volume was 8.3 in both low and high food treatments. The mean number of hatchlings that could be expected from the capsule of a whelk sourced from the South Coast was 8.0 and 8.7 in low and high food treatments respectively. 

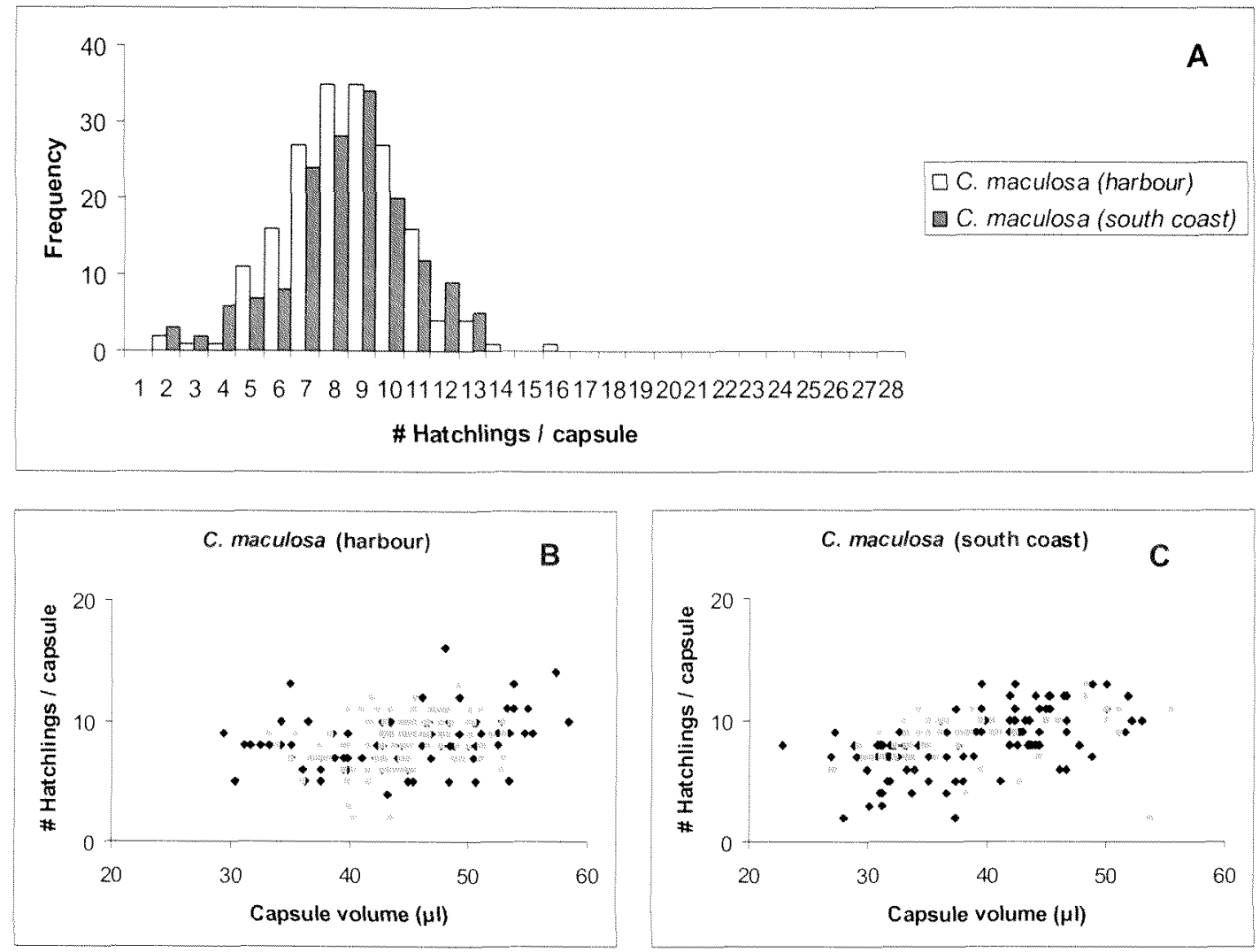

Fig. 15. Variation in number of hatchlings per capsule in whelks from the Harbour and South Coasts. A: frequency distribution, B and C: Correlation between capsule volume and number of hatchlings per capsule in Harbour and South Coast sourced whelks. Dark coloured diamonds represent data from low food treatments; light coloured squares represent data from high food treatments.

\subsubsection{Hatchling size}

Nested ANOVAs revealed that a large proportion of the variability in hatchling size occurred among and within individual capsules (or clutches) within a replicate basket, compared with the proportion of variability between baskets. The variability in hatchling size attributable to differences between replicate baskets was $1.6 \%$ in $H$. scobina, $14.7 \%$ in C. virgata and $15.8 \%$ in C. maculosa.

ANOVA revealed that the influence of food treatment on hatchling size was not significant in any of the three species (table 5, fig. 16). There was almost a significant effect of food treatment on $H$. scobina hatchling size, with larger hatchling sizes occurring in low food treatments. No trend attributable to food treatment was evident in the hatchling sizes of $C$. virgata or C. maculosa. 
Location was a significant influence on $C$. maculosa hatchling size, with larger hatchlings from whelks sourced from Harbour locations.

Table 5. Results of nested ANOVAs comparison of hatchling sizes between food treatments. Significant differences $(\mathrm{p}<0.05)$ are in bold.

\begin{tabular}{|c|c|c|c|c|}
\hline Source & df & SS & $\mathrm{F}$ & $p$ \\
\hline \multicolumn{5}{|l|}{ H. scobina } \\
\hline Adult food & 1 & 0.201 & 4.841 & 0.053 \\
\hline Basket (adult food) & 9 & 1.061 & 0.802 & 0.615 \\
\hline Capsule (basket, adult food) & 98 & 13.227 & 7.066 & $<0.001$ \\
\hline Error & 673 & 12.855 & & \\
\hline \multicolumn{5}{|l|}{ C. virgata } \\
\hline Adult food & 1 & 0.324 & 0.903 & 0.359 \\
\hline Basket (adult food) & 20 & 16.516 & 1.941 & 0.024 \\
\hline Clutch (basket, adult food) & 68 & 21.913 & 7.590 & $<0.001$ \\
\hline Error & 959 & 40.714 & & \\
\hline \multicolumn{5}{|l|}{ C. maculosa } \\
\hline Location & 1 & 2.579 & 4.818 & 0.046 \\
\hline Adult food & 1 & 0.052 & 0.097 & 0.760 \\
\hline Location $\mathrm{x}$ adult food & 1 & 0.014 & 0.028 & 0.871 \\
\hline Basket (adult food, location) & 18 & 15.304 & 3.597 & $<0.001$ \\
\hline Capsule (basket, adult food, location) & 317 & 46.555 & 12.905 & $<0.001$ \\
\hline Error & 2504 & 28.497 & & \\
\hline
\end{tabular}

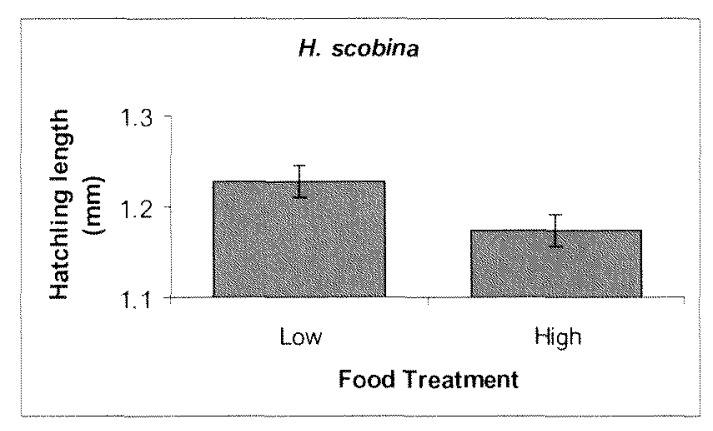

C. maculosa (Harbour)

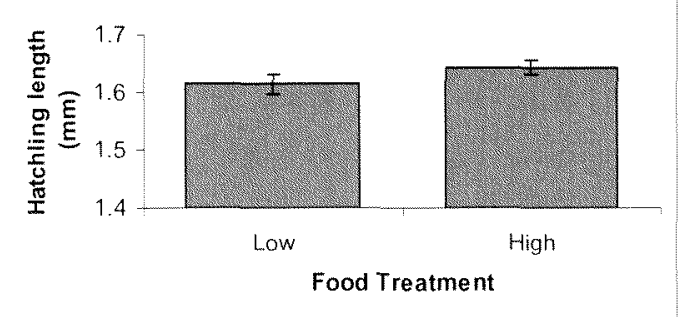

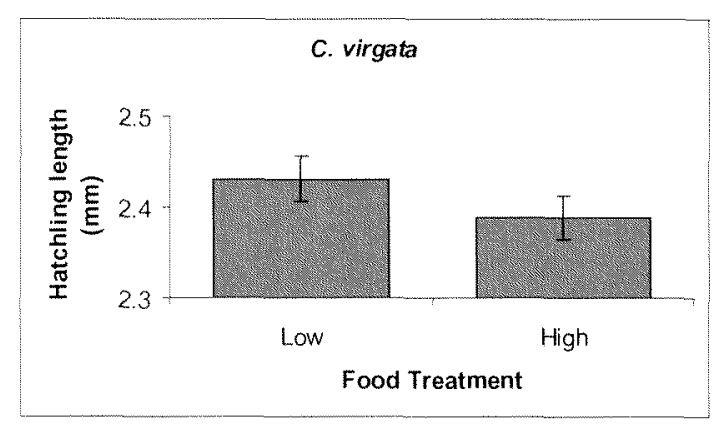

C. maculosa (South Coast)

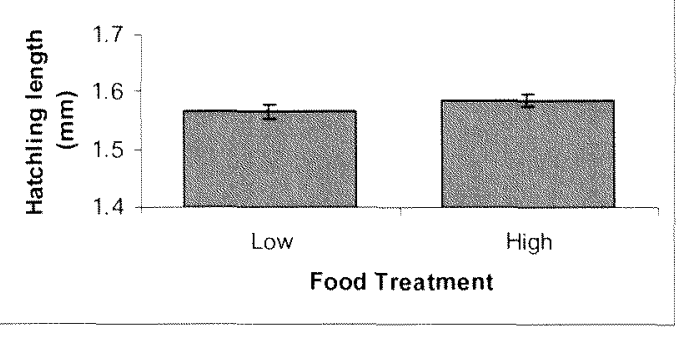

Fig. 16. Mean hatchling size at emergence from capsule in four groups of intertidal whelks. Error bars indicate $95 \%$ confidence intervals. 
Table 6. Summary of egg capsule and hatchling responses to low and high food treatments.

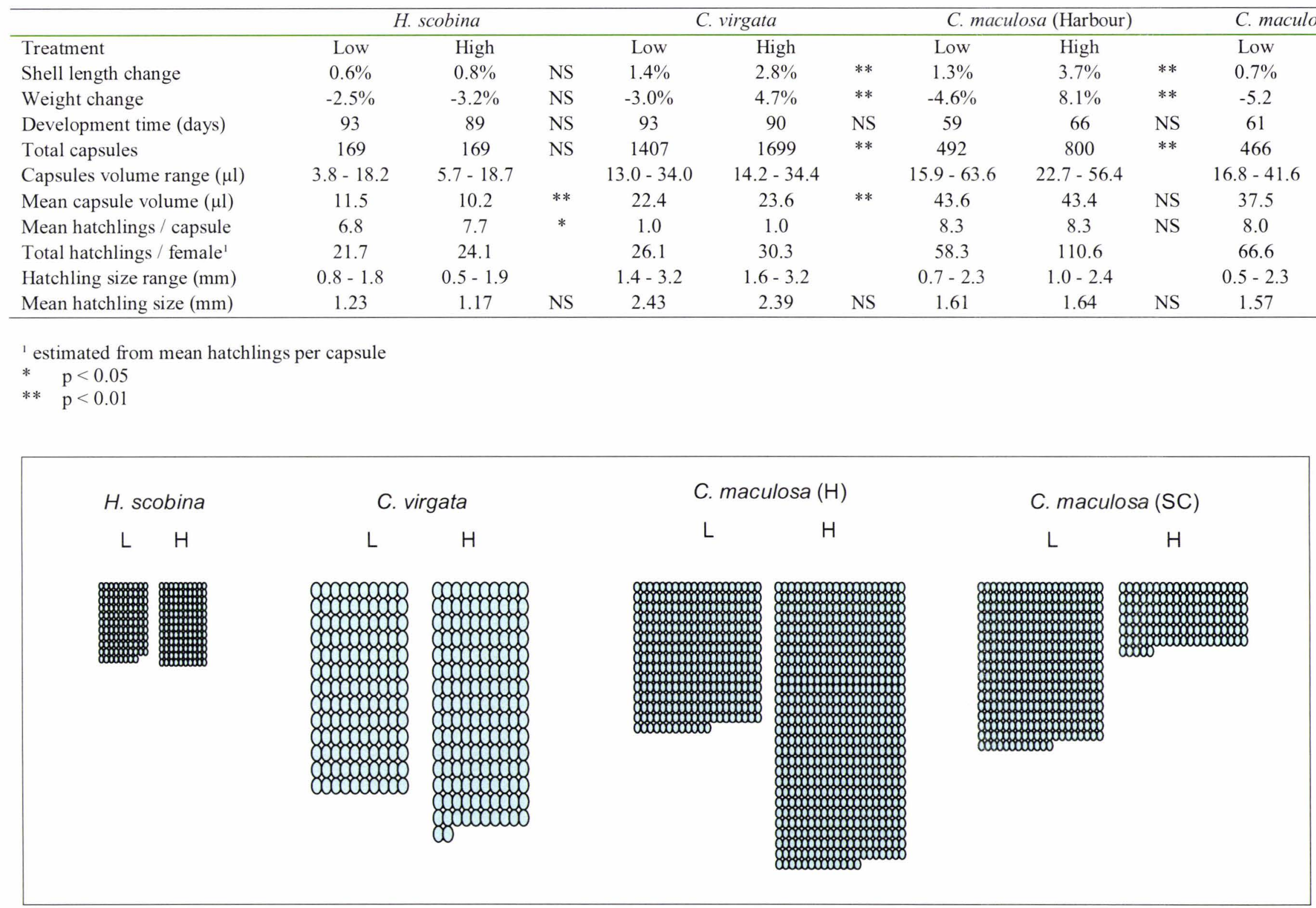

Fig. 17. Estimated numbers of hatchlings from ten adult whelks subjected to low $(\mathrm{L})$ and high $(\mathrm{H})$ food treatments (corrected to values for five adult females per basket). Oval shapes represent relative hatchling sizes. 


\subsection{DISCUSSION}

The balance of surplus energy left over after expenditure on metabolism, excretion and secretion is available either for growth or reproduction (Hughes 1986). When surplus energy is reduced and food is scarce, changes in reproductive allocation can be expected. Many life history models predict that organisms are more likely to trade off offspring number rather than offspring size when resources are limited and that an optimum offspring size exists for each species (Smith \& Fretwell 1974; Brockelman 1975; Peck \& Waxman 1997). In general the findings of this study support this contention, with numbers of capsules varying in response to food treatment while offspring size differences remained unchanged.

Results suggest that the food levels maintained in this experiment were successful in achieving relatively low and high levels in all Cominella whelk groups. With the exception of $H$. scobina, whelks responded to the food treatments by growing longer and heavier in the high food treatments, and losing weight in the low food treatments (table 6). It could be argued that the low food treatments in these groups was not low enough because shell growth continued to occur, suggesting that at least some surplus energy was diverted towards growth rather than towards reproduction. However, gastropod shell length growth can occur whenever the mantle is extended from the shell even in the absence of food (Palmer 1981; Hughes 1986). Change in tissue weight is a better measure of growth in gastropods as size increases because there is a progressively smaller change in length for a given change in body weight (Palmer 1982). The change in weight in response to low and high food treatments reported here was strong in all three Cominella groups.

While $H$. scobina did not respond to low and high food treatments differently, low mortality together with the occurrence of egg capsule deposition across all treatments suggest that either sufficient food was consumed to sustain life or that large reserves of energy were present initially, that were able sustain life for the duration of the experiment. The lack of response to the food treatments may indicate that the ability of $H$. scobina to switch diet from live food may be limited (Rovero et al. 1999). Survival for long periods without food is known to occur in $H$. scobina and other whelks (Luckens 1974; Britton \& Morton 1994; Cheung \& Lam 1999). Alternatively, 
H. scobina may be able to take up dissolved organic matter (DOM) from the water as is known to occur in significant quantities in other whelks (Colclough \& Brown 1983; Lau \& Leung 2004).

The greatest relative response to the food treatments occurred in C. maculosa. This species may divert more energy towards the growth of somatic tissue in order to increase future reproduction. Although not measured here, larger adult size is associated with higher reproductive output in whelks (Spight \& Emlen 1976). Whelk weight decreased by an average of $5 \%$ in the low food treatments and increased by an average of $8 \%$ in the high food treatments of whelks sourced from both regions.

The growth of $H$. scobina and C. maculosa adults was the same in replicate baskets containing egg capsules as in those replicate baskets without capsules. This suggests that energy allocation for reproduction is relatively small compared with energy allocation for growth in these species. Apportioning of energy for reproduction has been shown to vary according to growth and survival schedules in other gastropods, with high reproductive effort associated with low adult survivorship (Hughes 1986; Chester 1996). In a feeding experiment using the short lived scavenging gastropod Nassarius festivus for example, Cheung and Lam (1999) found that food energy was diverted towards reproduction rather than towards growth. This occurred regardless of the adult feeding regime with both low and high food adults losing weight during capsule production. In contrast, the low reproductive allocation in $H$. scobina and $C$. maculosa suggests that these species are long lived.

All groups had female: male sex ratios that were close to the 1:1 ratio often found in whelks (Kideys et al. 1993). H. scobina and C. virgata egg capsules took on average 91 days to develop while $C$. maculosa capsules developed more quickly taking on average 61 days. These times are relatively short in comparison with most other intertidal gastropods where development time of up to one year have been reported (Strathmann 1987). Most knowledge of capsule development periods comes from Northern Hemisphere species occurring in colder water temperatures than those of this study, and shorter development times may be more common in other regions. 
Food treatment had no effect on capsule development time in any of the whelk groups. However development time was shorter later in the spring when water temperatures were higher. This result conforms with accepted theory on invertebrate development (Thorson 1950), and with the findings of several other studies of intertidal whelks which show reduced developmental times in warmer temperatures (Strathmann 1987).

\subsubsection{Capsule variation}

Organisms trade off trait combinations such as size and number of offspring in order to maximise fitness (Stearns 1992; Roff 2001). When food is limited, intertidal whelks have several options available to utilise energy allocated for reproduction. In addition to control over the size and total number of embryos, whelks are able to vary the size of capsules and the number of embryos encapsulated within these capsules. Capsule size was found to be a highly plastic trait that varied in response to food treatment in all three species.

H. scobina whelks laid the same number of capsules in low and high food treatments, but laid capsules that were larger in low food treatments. It appears that this species trades off capsule size for capsule number when food is limited and does this by allocating more resources to capsule production. This may be a mechanism that mothers have to increase the likelihood of survival of offspring emerging into an environment where food is limited. Packaging of extra resources in response to adverse conditions has been reported in whelks (McKillup \& Barker 1979) and in other organisms with limited dispersal such as plants (Roach \& Wulff 1987) and insects (Fox \& Mousseau 1998).

In contrast, surplus energy was allocated towards increasing both the number and the size of $C$. virgata capsules. High food treatments contained a greater number of capsules that were significantly larger than low food treatments. Greater energy allocation in response to higher food levels has also been reported in other whelk species. In a study of egg capsule production by the intertidal scavenging gastropod Nassarius festivus, Cheung and Lam (1999) found that the proportion of energy 
allocated to reproduction after 12 weeks of feeding, was five times higher when whelks were subjected to high food treatments.

Unlike the communal clutches of $H$. scobina and $C$. maculosa, the number of $C$. virgata clutches in each replicate basket was readily identifiable. The strong relationship between the number of clutches and the number of females in each replicate basket together with the almost universal occurrence of egg laying suggests that most females laid egg capsules and that capsule laying is likely to occur at least once a year during spring in this species.

C. maculosa whelks sourced from different regions allocated energy towards capsule production differently. Harbour sourced whelks laid more capsules in high food treatments, but these capsules were no different in size than those in low food treatments. There was evidence that Harbour sourced whelks trade off capsule number instead of capsule size in response to food availability. This may occur because these whelks are unlikely to experience fluctuating food conditions under normal circumstances and adults have lost the ability to vary capsule size.

In contrast, the capsules of South Coast sourced $C$. maculosa were $7 \%$ larger in high food treatments, with some of the surplus energy diverted into making bigger capsules. The number of capsules in high food treatments was however less than half that in low food treatments and is more difficult to interpret. Surplus energy may have been diverted into storage for future reproduction or towards growth of adult somatic tissue. South coast sourced whelks gained more weight than Harbour sourced whelks in high food treatments, however the magnitude of this amount was small (table 6).

An alternative explanation for the variation in capsules between regions is that $C$. maculosa may not be physiologically capable of producing egg capsules annually, or may lay capsules at times other than those of this study. Times of capsule laying vary considerably in intertidal whelks. Most species deposit capsules in winter or early spring (Strathmann 1987), however year round capsule production depending on food supply has also been reported (Spight 1982). The outcomes reported here may have been due to the chance occurrence, within replicate baskets, of whelks that were already pre-programmed to lay capsules. The seemingly random occurrence of 
capsules across low and high food treatments (fig. 11) together with the absence of capsules in a large number of replicate baskets provides support for this view.

There are large differences in food availability in the two regions from which $C$. maculosa whelks were collected, with the Wellington South Coast considered to be a region of lower food than Wellington Harbour (Morton \& Miller 1968; Gardner 2000; Helson \& Gardner 2004; Helson et al. 2007). Results suggest that Harbour and South Coast populations are isolated from one another and may be genetically distinct. Population differences over short distances may be a consequence of limited dispersal ability that results from direct development (Wray 1995). Large regional differences in C. maculosa capsule volumes have been found in a concurrent study (Phillips unpublished data). Study of the physiological and genetic differences between Harbour and South Coast whelk populations could prove fruitful. The limited dispersal resulting from direct development is likely to have resulted in isolated populations that have some degree of separation over small geographic distances.

\subsubsection{Hatchling variation}

The proportion of size variation attributable to the food treatments was small in each species. This lack of response suggests that there is strong selection on an optimum hatchling size range for the hatchlings of each species. H. scobina is a possible exception with an almost significant effect of food treatment on hatchling size. The capsules of $H$. scobina contained hatchlings in high food treatments that were more numerous and smaller than those in low food treatments. Within capsules, it appears that $H$. scobina trades off offspring size for offspring number when food levels are high. This is consistent with widely accepted views of life history. While large offspring size is generally an advantage under adverse conditions when mortality rates are high (Einum \& Fleming 1999; Moran \& Emlet 2001; Marshall et al. 2003), larger numbers off smaller offspring increase overall fitness when conditions are more favourable (McGinley 1989; Roff 2001).

With the exception of a few rare cases, a single hatchling emerged from all $C$. virgata capsules. The rare cases with multiple embryos per capsule, demonstrate that the evolutionary step between a capsule with a single large hatchling and a capsule with 
several smaller hatchlings is not a large one. A concurrent study which measured the hatchlings of $318 \mathrm{C}$. virgata capsules collected from the field in four regions, found no evidence of multiple hatchlings in a single capsule (Phillips unpublished results), suggesting that this phenomenon is confined to benign laboratory conditions.

Hatchlings emerging from $C$. virgata capsules were no different in size in low and high food treatments despite the larger capsule volume in high food treatments. Hatchlings in high food treatments may nevertheless have been provided with extra provisioning from the larger capsule that was not detectable from shell length measurement. Extra provisioning may have been provided in the form of extra nutrients, hormones or fat reserves. Variation in lipid content strongly influences the development of other invertebrates (Sewell 2005) and is also likely to influence whelk development. While larger propagule size is generally associated with increased quality, trade-offs between offspring size and offspring quality other than size may also occur (Williams 1966; McEdward \& Chia 1991).

The number and size of hatchlings occurring within C. maculosa capsules was no different in low and high food treatments. This was true of both regions despite the larger volumes of South Coast capsules. As with $C$. virgata, the larger capsule volumes of $C$. maculosa whelks from South Coast locations may have improved hatchling quality with the provisioning of extra resources.

Adult food treatment did not affect hatchling size in any of the three species. While differences in $H$. scobina hatchlings in low and high food treatments were almost significant, there was no evidence of a similar trend in $C$. maculosa capsules or $C$. virgata despite significant differences in capsule volumes. Offspring size, measured with length as in this study, has been used in other studies as an index of offspring quality (Moran \& Emlet 2001; Marshall et al. 2003; Marshall 2005). However, the large variability that occurred within individual capsules $(H$. scobina and $C$. maculosa) and within individual clutches ( $C$. virgata), in both high and low food treatments, suggests that hatchling size may not be the optimum measure of reproductive allocation in these species. Hatchling size was sometimes different by almost double within $H$. scobina and C. maculosa capsules suggesting that size variation may be the target of selection in these species. Large differences in capsule 
volumes between treatments may be a more important factor in the longer term, influencing the growth and survival of emergent hatchlings by variable provisioning.

\subsubsection{Overall outcome of Capsule and Hatchling Variation}

The overall outcome of capsule variation and within-capsule hatchling variation in $H$. scobina was the production of slightly fewer hatchlings of marginally larger size in low food treatments (fig. 17). The reproductive strategy of this species appeared to be to produce a moderate number of small sized hatchlings regardless of food availability. This may have occurred because the energy used for reproduction was stored energy rather than energy acquired during the reproductive period. Alternatively, because there was not much change in adult size or weight, it could be argued that both food treatments were essentially "low". As different results may have been obtained by using food that this species prefers, these results are difficult to evaluate.

The outcome of $C$. virgata reproduction in response to food availability was to reduce the number of hatchlings in the low food treatments. The reproductive strategy of this species was to produce moderate numbers of relatively large hatchlings and to use energy acquired during the reproductive period for increasing reproductive output.

The reproductive strategy of $C$. maculosa was to produce large numbers of small hatchlings, and to vary hatchling number in response to food availability. Outcomes of C. maculosa capsule-laying in response to food treatments were different for whelks sourced from Harbour and South Coast regions. Harbour sourced whelks produced half as many hatchlings when in low food treatments. Extra energy acquired during the reproductive period appeared to be used to increase reproductive output. In contrast South Coast sourced whelks produced twice as many hatchlings in low food treatments. Increased output in the low food treatments may have been a maternal strategy to compensate for the likelihood of high offspring mortality.

These results are interesting in the context of the growth data because the low food whelks had the greatest decrease in weight. However while C. maculosa from the Harbour decreased reproduction and lost weight in the low food treatments, $C$. 
maculosa from the South Coast increased reproduction relative to those in high food treatments. Further, while South Coast whelks in high food treatments decreased reproduction and increased in weight, whelks from the Harbour in high food treatments increased reproduction as well as increasing in weight. Whelks from the South Coast may have a low food metabolism that favours diverting all energy towards reproduction unless food levels are high, in which case more energy is diverted to growth at the expense of reproduction. Differences in metabolic rates between whelks from the two regions may account for discrepancies in reproductive allocation. The proportion of energy consumed by metabolism may be up to four times greater than that consumed by growth or reproduction in gastropods but varies considerably between species (Hughes 1986).

It should be noted that the predicted outcomes above take no account of numbers of non-viable capsules which may be considerable (pers obs). Variation in offspring quality, independent of size is also not considered by these predictions. An interesting result was that within a capsule, offspring size and number did not change in response to the food treatments despite changes in capsule volume. Larger capsules however are likely to provide offspring with resources to enhance growth and survival. Offspring performance has been put forward as a better measure of maternal investment than propagule size (Rossiter 1996) and is the subject of the next chapter.

Whelks producing capsules containing multiple eggs may be able to control the number of encapsulated eggs in a way that is independent of capsule size (Lloyd \& Gosselin 2006). While it was intended to quantify the variation in the number and size of eggs encapsulated by $H$. scobina and C. maculosa, no data were collected due to the disintegration of eggs during storage. Freezing of newly laid capsules was not a viable method of preserving eggs. There is evidence that whelks with multiple eggs per capsule vary egg number rather than egg size in response to low food (Cheung \& Lam 1999). Low egg size variation within the capsules of field collected $H$. scobina and $C$. maculosa capsules (Chapter 4) indicates that these species also vary egg number rather than egg size in response to food availability.

The inability to identify which of the females in each replicate basket had been responsible for egg laying meant that variation in the amount of energy diverted to 
reproduction and growth could not be compared among individuals within a treatment. $C$. virgata provided an exception to some extent as individual clutches could be identified. However, in this case too, it was unknown how many females did not lay eggs, or how much difference in growth occurred between those females that reproduced and those that did not. Some means of identifying and isolating egg laying females would be useful for future studies.

Inferences based on the results reported here to events occurring in the field should be made cautiously. H. scobina in particular, responded poorly to the food treatments and may have responded differently with a different diet. While it can be argued that laboratory studies over single seasons are unrealistic (Bernardo 1996b), it can also be argued that they provide focus and direction for field studies so that effort can be minimised. Manipulative experiments that measure maternal investment most often use egg size as a response variable (Bernardo 1996a). This study takes a novel approach by using offspring size and number to measure maternal investment after a period of critical development has occurred.

In general, food treatment had greater influence on the number and the size of capsules rather than on offspring size and number within capsules (H. scobina and $C$. maculosa) or within clutches ( $C$. virgata). The large differences found in whelk populations separated by small distances, have important implications both for conservation management and for the maintenance of regional diversity. 


\section{CHAPTER 3}

\section{Carry Over Effects of Adult Nutrition on Hatchling Growth and Survival}

\subsection{ABSTRACT}

A growing body of evidence highlights the role that maternal effects play in determining the fitness of subsequent generations and in shaping community structure. In this chapter the relative influence of maternal and juvenile nutrition on growth and survival are compared. The hatchlings of three species of intertidal whelks (Haustrum scobina, Cominella virgata and Cominella maculosa) from adults of known nutritional history, were subjected to high and low food treatments over an eight week period.

Maternal nutrition influenced the growth of all three species. Maternal influence was species specific both in the strength of the effect and in the direction of the effect. The growth of $H$. scobina and $C$. virgata hatchlings was most influenced by maternal nutrition in the first four-week period of growth after hatching, suggesting maternal nutrition may be more important than juvenile nutrition in the early life of juveniles of these species. Maternal influence on the growth of $C$. virgata hatchlings faded during the experiment and was no longer a significant factor in the second four-week period of growth. In contrast, maternal influence was strongest in the second four-week period of growth in C. maculosa hatchlings and had a negative effect on hatchling growth.

Some additional support for the growth data was provided by a trial using the fluorescent dye calcein. This method was successful in leaving a visible band on the shell that could be used to monitor the growth of individual hatchlings. The fastest growth occurred in H. scobina and $C$. virgata hatchlings that were born from high food adults while C. maculosa hatchlings born from high food adults had the least growth. The negative maternal effect on the growth of $C$. maculosa hatchlings was 
unexpected, and may be a mechanism to suppress potential adverse consequences of rapid growth.

Maternal nutrition did not influence hatchling mortality. There was a trend towards lower mortality in C. virgata and C. maculosa hatchlings that were fed low food but this was not evident in H. scobina hatchlings. Mortality rates of $C$. virgata and $C$. maculosa hatchlings decreased after four weeks of growth while mortality rates for $H$. scobina remained high. The lack of response by $H$. scobina hatchlings to the food treatments suggests that this species may prefer food other than that which was provided in the experiment.

These results add weight to the body of evidence highlighting the importance of adult nutrition on the early life of juveniles. The degree of influence and the duration that maternal effects persisted differed among the three species. Predicted outcomes based on numbers of capsules laid indicate however, that these have the strongest influence on the numbers of hatchlings surviving to eight weeks. Differences in the numbers of capsules laid by populations of C. maculosa adults resulted in large differences in the predicted number of hatchlings surviving after eight weeks. Contrasting degrees of maternal influence among species and populations are likely to be alternative strategies, used to balance the advantage of high fecundity with the benefits of producing higher quality, larger offspring.

\subsection{INTRODUCTION}

There is a growing realisation that organisms pass on their experience of the environment to the next generation by altering reproductive investment. Variation in food intake during adult life is likely to influence energy reserves that mothers supply to eggs or embryos during reproduction and result in effects that are carried over to the next generation. Two potential responses of juveniles to variation in maternal nutrition are growth and survival.

Early growth influences a variety of characteristics later in life across a range of taxa including insects (Fox 1997), fish (Einum \& Fleming 2000), amphibians (Downie \& 
Weir 1997), reptiles (Sinervo \& Doughty 1996), birds (Nilsson 1990) and mammals (Lindstrom 1999; Robinson et al. 1999). Long term studies of birds and mammals have revealed that early growth may go on to influence key life-history traits such as fecundity and survival (Lindstrom 1999; Lummaa \& Clutton-Brock 2002).

In organisms lacking parental care, all energy for early growth is derived from maternal resources that are packaged along with the embryo at the time eggs are deposited. Variation in resources supplied to the embryo at the time of egg laying may continue to influence growth for some time after hatching (Roach \& Wulff 1987; Sinervo \& McEdward 1988; Sinervo 1993).

Most studies of maternal investment measure variation in propagule size and number without considering the longer term consequences (Bernardo 1996a). Juvenile quality has the ability to shape not only adult population structure (Moran 1999a; Marshall et al. 2003) but also to have ecological consequences for communities (e.g. Fox \& Mousseau 1998). Further, maternal effects may be mediated by the juvenile environment. Poor environmental conditions early in life can result in smaller adult size, lower energy reserves or inferior competitive ability and ultimately in the reduced lifetime fitness of individuals (Taborsky 2006). Maternal influences are likely to play an important role in determining an individual's ability to deal with adverse conditions early in life.

Early growth and development are important processes that can influence the size of an organism throughout life (Arendt 2000). While the relationship between large offspring size and higher fitness is not universal for marine organisms (Marshall 2005), large sized juveniles often have higher survival and growth than smaller juveniles due to reduced susceptibility to predation, starvation and physical stress (Moran \& Emlet 2001; Gosselin \& Rehak 2007). Larger sized organisms have lower surface area to volume ratios which may, for example, reduce the risk of desiccation in intertidal species. The ability to grow quickly increases competitive ability and allows the advantages of size to be gained more quickly (Morton 1986; Arendt 1997).

There are costs associated with rapid growth however. Rapidly growing individuals frequently produce less skeleton per unit body weight (Palmer 1981). Other factors 
that have been associated with rapid growth include shorter life spans, decreased reproductive output, increased likelihood of developmental errors, and poorly developed immune systems that are susceptible to parasitism (Arendt 1997; Metcalfe \& Monaghan 2001).

Studies of offspring size suggest that maternal effects become less important as an offspring ages and the offspring's genotype begins to have more influence (Einum \& Fleming 1999). In some insects, maternal environmental stresses can have a large influence on progeny body size and growth immediately after birth, but the magnitude of this maternal effect gradually diminishes throughout development and often becomes undetectable by the time the progeny mature (Fox et al. 1999). Fading maternal influence has also been reported in vertebrates (Semlitsch \& Gibbons 1990; Reznick 1991) but has not been the focus of attention and has been quantified only rarely.

While rapid growth following birth is generally advantageous, growth may be limited both by food availability externally and by energy reserves supplied by the mother. Higher maternal input is advantageous initially before juvenile feeding commences and may continue to provide advantages for some time, especially in situations where juvenile food is scarce (Marshall 2005).

In addition to juvenile growth, juvenile mortality is also a strong influence on life history traits and community structure (Thorson 1966; Stearns 1992; Gosselin \& Qian 1997). While there is good evidence in marine organisms that highest mortality occurs immediately after birth (Rumrill 1990), the degree to which maternal provisioning affects mortality is poorly understood (Gosselin \& Rehak 2007).

Intertidal whelks are ideal organisms for the study of carry-over effects of adult nutrition. Adult whelks respond to feeding regimes under laboratory conditions and readily lay egg capsules from which hatchlings can be reared successfully (Chapter 2). Development time within capsules is relatively short and initial hatchling growth is rapid, enabling comparison of growth rates in response to juvenile food availability to be measured. 
In this study, hatchlings of three species, born from adults with known nutritional histories, were subjected to low and high juvenile food treatments in order to measure potential carry-over effects of maternal nutrition and the interaction with juvenile nutrition. It was predicted that (1) hatchlings sourced from high food adults would have higher rates of growth and greater survival than hatchlings born from low food adults and (2) that maternal influences on hatchling growth and survival would be short lived, whereas hatchling feeding would become increasingly important over time.

\subsection{METHODS}

Offspring for this experiment were generated from the egg capsules laid in the experiment described in Chapter 2. In order to be able to identify which capsules hatchlings emerged from, capsules were placed in individual $30 \mathrm{~mm}^{2}$ nylex mesh bags $($ mesh size $=500 \mu \mathrm{m})$, which were sealed using hot melt glue. Egg capsules did not appear to be damaged by this procedure and remained intact. Mesh bags were kept in a large shallow tank supplied with constantly flowing fresh seawater at ambient temperature until hatching.

A sample of randomly selected capsules (maximum 20) was chosen from each replicate basket containing H. scobina and C. maculosa capsules and bagged individually. Whole clutches of $C$. virgata capsules (range 1 to 82 capsules per clutch), were placed in the mesh bags. C. virgata clutches could usually be easily identified by the regular pattern of deposition and physical separation from other clutches within a basket. All $C$. virgata capsules were bagged in this manner. Egg capsules were collected from 59 baskets originating from adult treatments as outlined in Chapter 2 (table 1). 
Table 1. Summary of numbers of egg capsules laid per basket and treatment from Chapter 2.

\begin{tabular}{lcccc}
\hline Species & Adult Treatment & $\begin{array}{c}\text { Baskets with egg } \\
\text { capsules (of 12 total) }\end{array}$ & $\begin{array}{c}\text { Range } \\
\text { (capsules per } \\
\text { basket) }\end{array}$ & Total capsules \\
\hline H. scobina & Low food & 5 & $20-49$ & 169 \\
C. virgata & High food & 9 & $4-41$ & 169 \\
& Low food & 11 & $5-250$ & 1407 \\
C. maculosa & High food & 11 & $43-288$ & 1699 \\
(Harbour) & Low food & 5 & $11-204$ & 492 \\
C. maculosa & High food & 7 & $3-219$ & 800 \\
(South Coast) & Low food & 7 & $5-204$ & 466 \\
\hline
\end{tabular}

Bagged capsules were checked daily for the emergence of the first hatchling. The remaining hatchlings usually emerged within a few days of the first. At this time forty hatchlings were randomly selected and evenly divided into two $500 \mathrm{ml}$ square plastic jars (twenty in each jar) fitted with nylex mesh sides (mesh size $=500 \mu \mathrm{m})$. Hatchlings from within the same capsule (H. scobina and C. maculosa) or within the same clutch (C. virgata) were divided between each of the jars equally. In cases where forty hatchlings had not emerged within a few days of the first arrival, the remaining hatchlings were carefully removed from their capsules using a scalpel and forceps. Initial hatchling shell length was measured using a dissecting microscope (Zeiss $9901)$ equipped with a graticulated eyepiece. Length was measured from shell apex to extremity of apical notch.

Jars were half submerged in a large shallow tank that was supplied with constantly flowing fresh seawater at ambient temperature (range $13.7-18.8^{\circ} \mathrm{C}$ over the experimental period from 1/1/2007-24/4/2007). Each jar within each pair of jars was randomly assigned to one of two feeding treatments: low hatchling food (supplied with food in alternate weeks only); or high hatchling food (supplied with food continuously). Feeding took place twice weekly and consisted of $3 \mathrm{~mm}^{3}$ portions of the adductor muscle of the bivalve Perna canaliculus. Jars were cleaned of uneaten food and debris prior to feeding.

Hatchling shell lengths were measured weekly using a microscope as above and dead individuals were removed at this time. Due to the logistics of handling so many individuals, their small size and difficulty of tagging, it was not feasible to follow the 
fates of individuals in this experiment. Therefore growth for a particular week was calculated for each jar by averaging the lengths of remaining hatchlings and subtracting the average length from the previous week. In addition to weekly measurements, all hatchlings were measured after a period of exactly four weeks and again after ten weeks when the experiment was ended. Few hatchlings survived this entire period however, and a growth period of eight weeks after hatching was used instead to increase statistical power. Hatchling mortality was particularly high for $C$. maculosa, and data from Harbour and South Coast hatchlings were combined in the analysis for the same reason.

Additional hatchlings not used in the above experiment were used to carry out a trial to follow the growth of individuals using the florescent dye calcein which is incorporated into the growing margin of the shell (Moran 2000). After emergence from egg capsules, C. virgata and C. maculosa hatchlings were subjected to high and low food treatments in conditions identical to those described above. Hatchlings sourced from low adult food replicates were pooled and divided evenly into low and high hatchling food treatment jars of the same type as above. Hatchlings sourced from high adult food replicates were similarly divided into low and high hatchling food treatment jars. On 14 February 2007, hatchling jars were immersed in aerated beakers containing a solution of $150 \mathrm{mg} / \mathrm{l}$ calcein dissolved in seawater for a period of 6 days. At the end of this period hatchling jars were returned to their normal positions in the large flat tank. Feeding continued in the manner described above throughout this time. Hatchlings were given a second calcein treatment on 13 March 2007 for a period of three days using the same procedure and the experiment ended on 4 April 2007.

Only the second of the above treatments was successful in creating a distinct mark that could be used to measure growth. It is likely that the initial mark was obliterated by the second treatment. Growth was measured as the distance between the calcein mark and the shell margin 19 days later (fig. 1). 


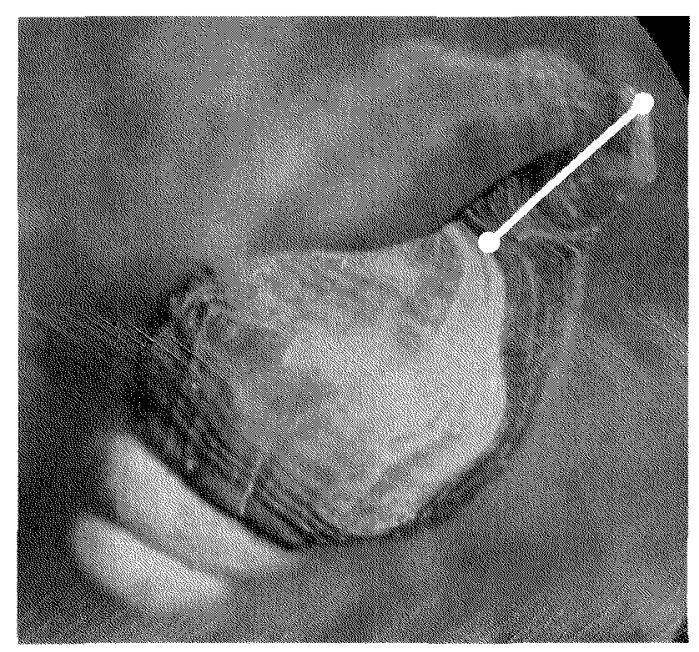

Fig. 1. Growth measurement of a calcein stained hatchling. Line illustrates 19 days of growth by a $C$. maculosa hatchling in a high food treatment. Line length $=0.8 \mathrm{~mm}$.

The statistical package SPSS ( $\mathrm{v} 12.0$ ) was used to carry out all of the data analysis.

Two way ANOVAs were used to test for differences in hatchling growth in response to the factors adult food and hatchling food. Levene's test was used to test assumptions that variances were equal. These tests were not upheld in two instances $(\mathrm{p}<0.05)$. In the first instance (H. scobina growth in second four-week period), log transformation of the data successfully reduced the variation to acceptable levels. In the second instance (C. virgata growth in first four-week period) data transformation did not reduce variance. However due to the relatively moderate deviation from equal variation $(\mathrm{p}=0.02)$, the conservative nature of Levene's test and the robustness of ANOVA against small deviations of underlying assumptions, this was thought to be acceptable.

Two way ANOVAs were also used to test for differences in the growth of calcein stained hatchlings in response to the factors adult food and hatchling food. Levene's test was used to test for equality of variance and was not upheld in one instance. Square root transformation successfully reduced variance to acceptable levels in this case.

T-tests were used to compare mean initial and final shell lengths. Levene's test pvalues below 0.05 occurred when comparing the growth rates of $C$. virgata and $C$. 
maculosa and in these cases the more conservative t-value (equal variances not assumed) was used.

Log regression curves were fitted to cumulative mortality data points. Repeated two sample Kolmogorov-Smirnov tests were used to compare curves.

Overall outcomes were estimated from the numbers of capsules laid in adult food treatments (from Chapter 2). Numbers of capsules were first adjusted according to the numbers of females in each replicate basket in order to standardise the female per basket ratio to $50 \%$. Mean numbers of capsules were then calculated for low and high adult food treatments for each whelk group. Initial numbers of hatchlings were calculated by multiplying numbers of capsules by mean number of hatchlings per capsule from Chapter 2 .

Numbers of juveniles surviving at the end of eight weeks were estimated using mean mortality rates over the period of this experiment. Juvenile mortality rates were applied to initial mean numbers of hatchlings to obtain a final predicted number of hatchlings for each combination of adult and hatchling food treatment for each species.

\subsection{RESULTS}

\subsubsection{Growth}

a) Growth Rates: H. scobina

Average growth rates in the second four weeks were higher than those in the first four weeks of growth but were highly variable (fig. 2). In the first four-week period of growth, H. scobina hatchlings grew more when born from adults that were in high food treatments $\left(\mathrm{F}_{1,1}=7.01, \mathrm{p}=0.02\right)$, while hatchling food treatment was not significant $\left(F_{1,1}=0.16, p=0.70\right)$ and the interaction between adult and hatchling food was not significant $\left(F_{1,1}=0.00, p=1.00\right.$, fig. 2). In the second four-week growth period, no significant effect of adult or hatchling food treatment was detected (adult food: 
$F_{1,1}=0.34, p=0.58$, hatchling food: $F_{1,1}=0.03, p=0.87$ ) nor was there a significant interaction between adult and hatchling food $\left(\mathrm{F}_{1,1}=0.67, \mathrm{p}=0.44\right)$.

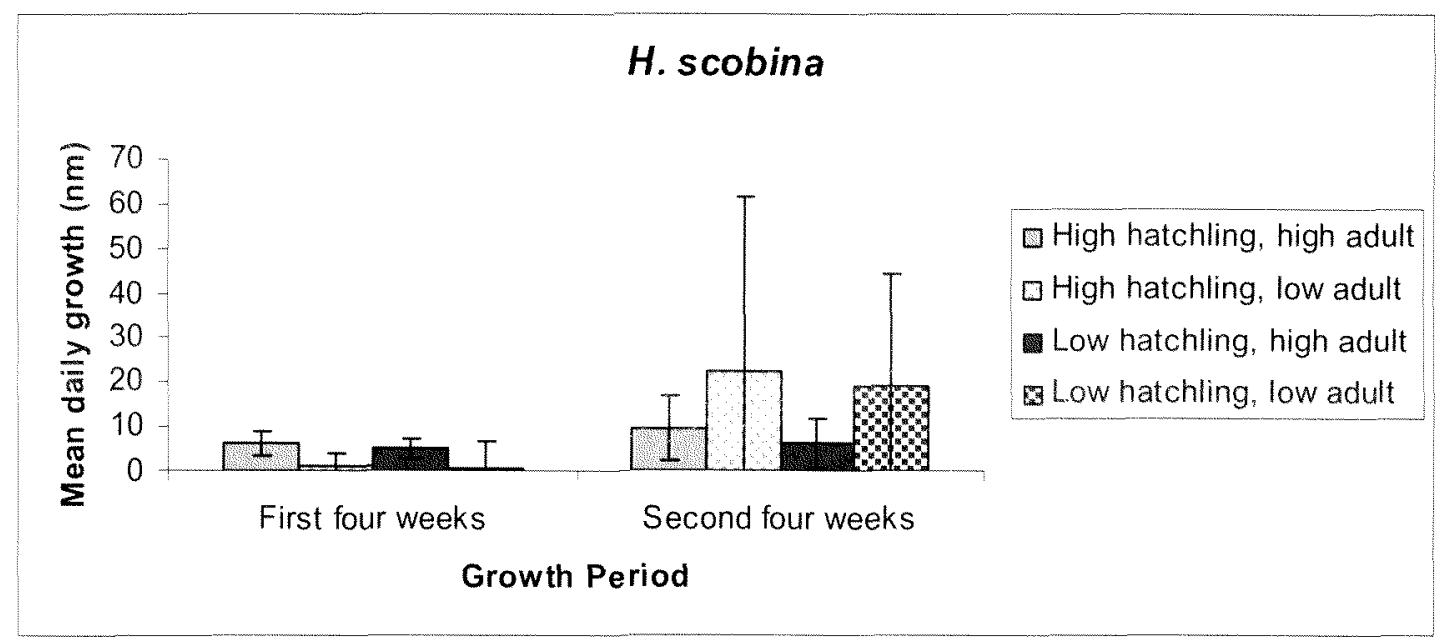

Fig. 2. Growth of H. scobina hatchlings in two four-week periods after capsule emergence. Error bars indicate $95 \%$ confidence intervals.

C. virgata

In the first four-week period of growth, $C$. virgata hatchlings grew most when they were born from adults that were in high food treatments and receiving high hatchling food (fig. 3). Hatchlings grew least when born from adults that were in low food treatments and also receiving low hatchling food. Both adult and hatchling food treatments had a significant effect on hatchling growth $\left(\mathrm{F}_{1,1}=16.04, \mathrm{p}<0.01, \mathrm{~F}_{1,1}=4.88\right.$, $\mathrm{p}=0.04$ for adult food and hatchling food treatments respectively). There was no significant interaction between the factors $\left(\mathrm{F}_{1,1}=0.00, \mathrm{p}=1.00\right)$.

Average hatchling growth was higher in the second four-week period of growth. Hatchlings grew more when they were in high hatchling food treatments $\left(F_{1,1}=59.54\right.$, $\mathrm{p}<0.01)$. Adult food treatment had no significant effect on hatchling growth $\left(\mathrm{F}_{1,1}=\right.$ $0.27, \mathrm{p}=0.61)$ and there was no significant interaction between the factors $\left(\mathrm{F}_{1,1}=0.46\right.$, $\mathrm{p}=0.50$ ). 


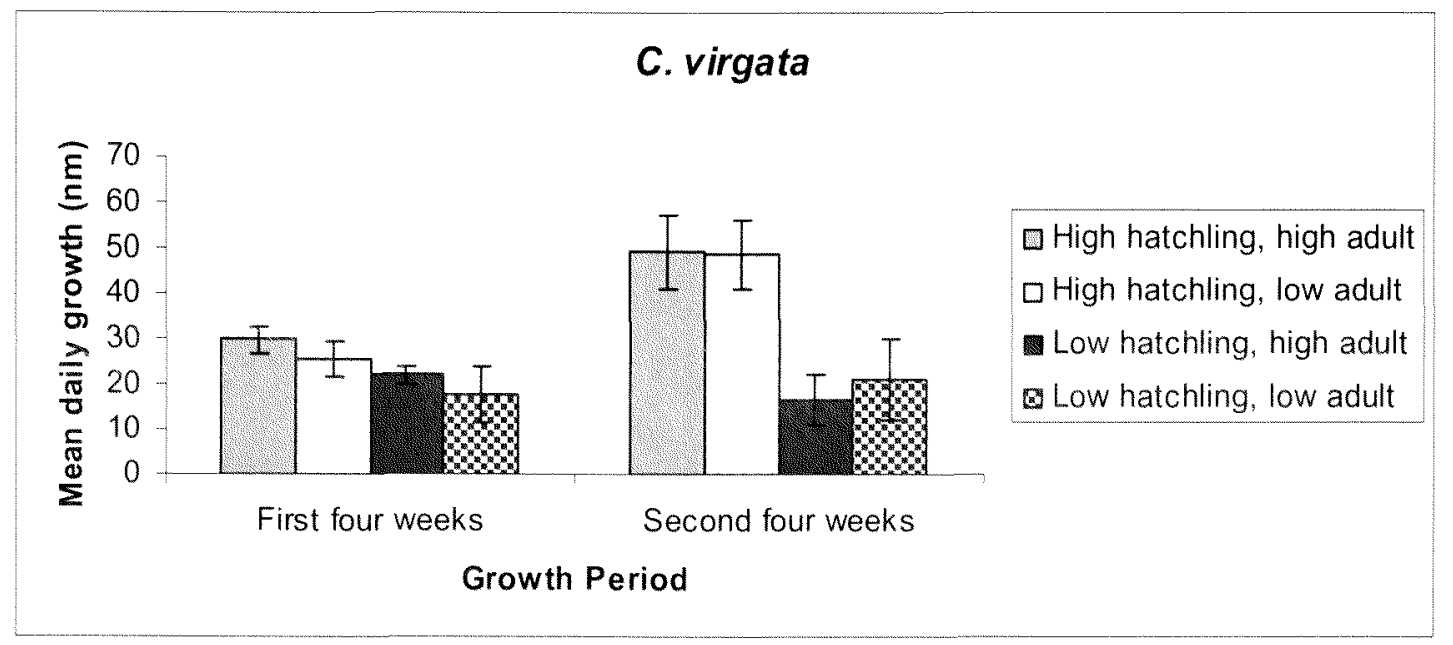

Fig. 3. Growth of C. virgata hatchlings in two four-week periods after capsule emergence. Error bars indicate $95 \%$ confidence intervals.

\section{C. maculosa}

C. maculosa hatchlings that were in high hatchling food treatments grew more than those in low hatchling food treatments in the first four-week period of growth after hatching $\left(\mathrm{F}_{1,1}=4.68, \mathrm{p}=0.04\right)$ while adult food treatment was not a significant factor $\left(F_{1,1}=0.10, p=0.76\right.$, fig. 4$)$. The interaction between the two factors was not significant $\left(\mathrm{F}_{1,1}=0.26, \mathrm{p}=0.62\right)$.

Average hatchling growth was higher but more variable in the second four-week period of growth. Both adult and hatchling food treatments had a significant effect on hatchling growth $\left(\mathrm{F}_{1.1}=5.30, \mathrm{p}=0.04, \mathrm{~F}_{1.1}=14.31, \mathrm{p}<0.01\right.$ for adult food and hatchling food treatments respectively). Hatchlings from low food adult treatments grew more than those from high food adult treatments, and hatchlings in high hatchling food treatments grew more than those in low hatchling food treatments. There was no significant interaction between the two factors $\left(F_{1,1}=0.85, p=0.38\right)$. 


\section{C. maculosa}

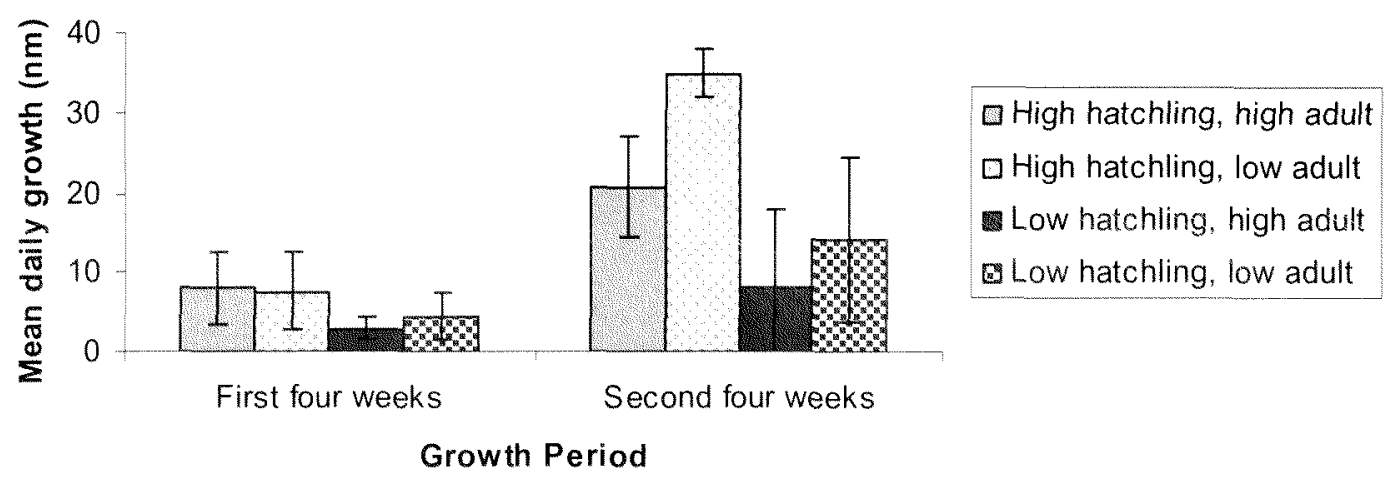

Fig. 4. Growth of C. maculosa hatchlings in two four-week periods after capsule emergence. Error bars indicate $95 \%$ confidence intervals.

\section{b) Size Increase}

The shell lengths of $H$. scobina hatchlings increased by a smaller amount than the other two species in the first eight weeks after emergence from the capsule (fig. 5). There was significant shell growth when hatchlings were born from high food adults (high hatchling, high adult: $\mathrm{t}=4.91, \mathrm{p}<0.01$; low hatchling, high adult: $\mathrm{t}=4.66, \mathrm{p}<0.01$ ) but no shell growth when hatchlings were born from low food adults (high hatchling, low adult: $t=0.89, p=0.38$; low hatchling, low adult: $t=1.46, p=0.15$ ). Hatchlings born from high food adults increased in length by an average of $28.3 \%$ when in high hatchling food treatments, and by an average of $22.1 \%$ when in low hatchling food treatments.

C. virgata and C. maculosa hatchlings had significant increases in shell length across all treatments by the end of eight weeks. C. virgata shell length increases were greatest in high hatchling food treatments, increasing in length by an average of $47 \%$ irrespective of adult food treatment. By contrast, hatchlings from low hatchling food treatments increased in length by $32 \%$ when born from adults in high food treatments and by $39 \%$ when born from adults in low food treatments.

The greatest shell growth of C. maculosa hatchlings occurred in the high hatchling, low adult food treatments (46\%). Shell length increase was about $36 \%$ for hatchlings 
from both high hatchling, high adult food treatments and for hatchlings from low hatchling, low adult food treatments. Hatchling size increases were lowest $(15 \%)$ in low hatchling, high adult food treatments.

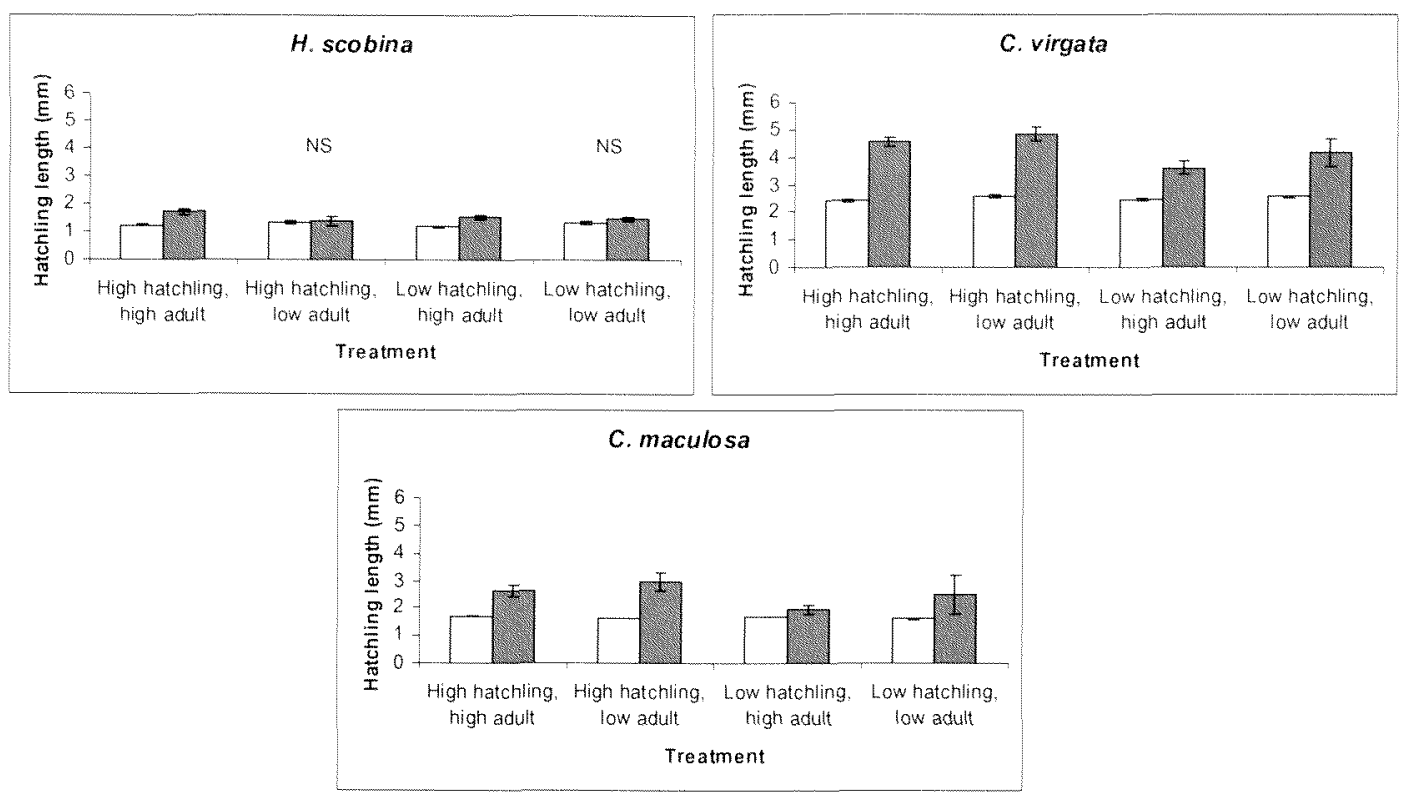

Fig. 5. Mean shell length of three intertidal whelk species at hatching and after eight weeks of growth. Open bars = initial shell length; closed bars = final shell length ; NS $=$ non significant difference. Error bars indicate $95 \%$ confidence intervals.

\section{c) Calcein Trial Results}

A single visible calcein mark was present on almost all shells after the second staining attempt. Marks could not be clearly distinguished on five C. maculosa hatchlings of a total of 80 individuals stained. All five of these hatchlings occurred in low hatchling food treatments and were not included in the analysis. Calcein marks on all $31 \mathrm{C}$. virgata hatchlings were clearly identifiable.

After 19 days, C. virgata hatchlings in high hatchling food treatments increased in length by twice as much as hatchlings from low hatchling food treatments ( $F_{1,1}=31.38$, $\mathrm{p}<0.01$, fig. 6). Adult food treatment had no significant effect on hatchling growth $(\mathrm{F} 1,1=1.96, \mathrm{p}=0.17)$ and there was no significant interaction between the factors $\left(F_{1.1}=0.94, p=0.34\right)$. 
Both adult and hatchling food treatments were significant factors in the growth of $C$. maculosa hatchlings (hatchling food: $\mathrm{F}=101.81$, $\mathrm{p}<0.01$; adult food: $\mathrm{F}=6.30, \mathrm{p}=0.01$ ), with no significant interaction between factors $(\mathrm{F}=1.48, \mathrm{p}=0.23)$. Hatchlings from high hatchling food treatments, had almost double the increase in size as those from low hatchling food treatments. Hatchlings from low adult food treatments, grew more than those from high adult food treatments, but this effect was smaller in magnitude than that for hatchling food level. Greatest growth therefore occurred in high food hatchlings that were born from low food adults.
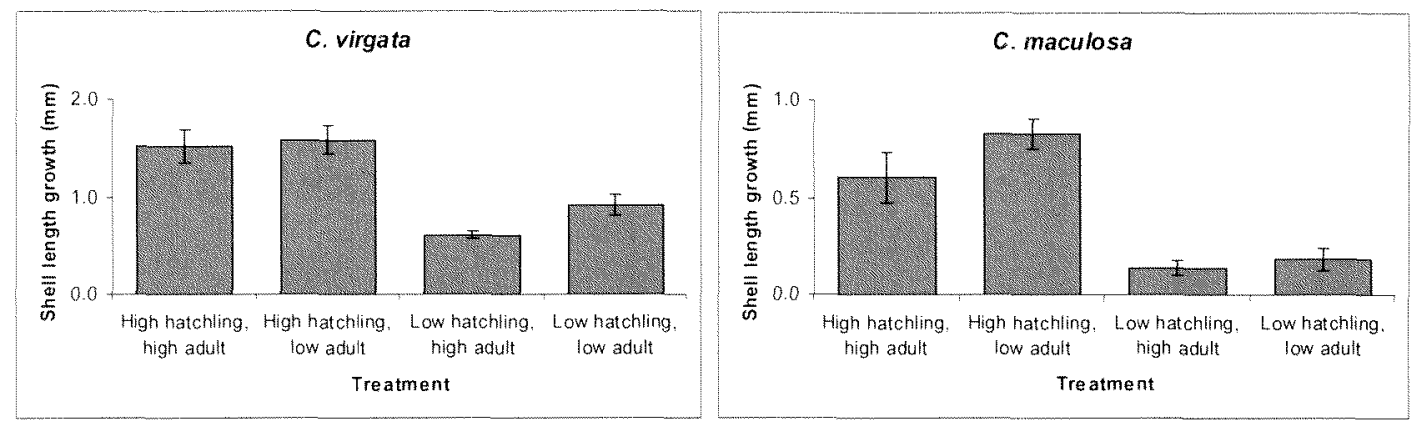

Fig. 6. Shell growth after 19 days for early juveniles of two intertidal whelk species in response to adult and hatchling food treatments. Error bars indicate $95 \%$ confidence intervals.

\subsubsection{Mortality}

Comparison of the cumulative mortality curves for the four food treatments using Kolmogorov-Smirnov tests found no significant difference in any of the species. Trends in the data were evident however, with H. scobina mortality curves for all four treatments clumped close together, indicating very similar rates of mortality for all four treatments. Mortality curves for C. virgata and C. maculosa were more discrete (fig. 7). This was reflected in the higher $\mathrm{K}-\mathrm{S}$ values and $\mathrm{p}$-values close to the $5 \%$ threshold for these species. In C. virgata differences were greatest between the curves for the high and low hatchling food treatments $(Z=1.34, p=0.06$ for high hatchling, high adult food vs. low hatchling, high adult food; $Z=1.34, p=0.06$ for high hatchling, high adult food vs. low hatchling, low adult food; $Z=1.34, p=0.06$ for high hatchling, low adult food vs. low hatchling, high adult food; $Z=1.34, p=0.06$ for high hatchling, low adult food vs. low hatchling, low adult food). The curves for the two low 
hatchling food treatments, were close together and above those for the high hatchling food treatments, indicating a trend of higher mortality in these treatments.

The greatest difference in $C$. maculosa cumulative mortality occurred between high hatchling, high adult treatments and the low hatchling, low adult food treatments $(Z=1.34, p=0.06)$.

Mortality curves for all three species had $\log$ distributions which explained almost all of the variation in mortality $\left(H\right.$. scobina: $\mathrm{R}^{2}=0.99 ; C$. virgata: $\mathrm{R}^{2}=0.97 ; C$. maculosa: $\mathrm{R}^{2}=0.96$, treatments combined). While the rate of mortality of $H$. scobina hatchlings was lower initially, the rate did not markedly decline after four weeks as did that of $C$. virgata and C. maculosa which both began to flatten out at this time (fig. 7).
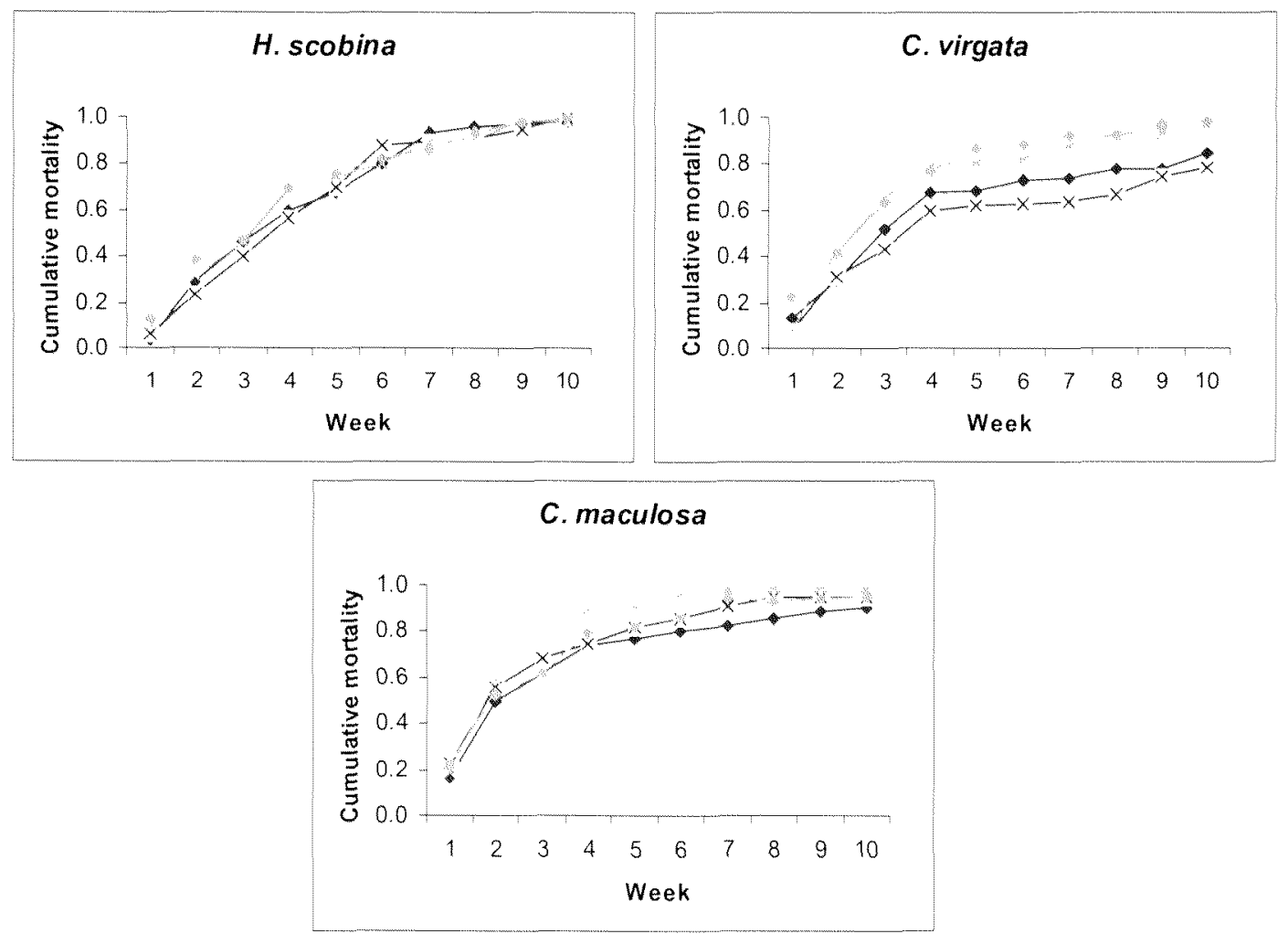

Fig. 7. Cumulative mortality of the hatchlings of three intertidal whelks showing effects of hatchling and adult food treatments. Dark colours: high hatchling food treatments; light colours: low hatchling food treatments; diamond shapes: high adult food treatments; crosses: low adult food treatments. 


\subsubsection{Predicted Juvenile Size and Number Eight Weeks after Hatching}

The combined outcome of growth and mortality varied among species and among treatments (fig. 8).

The number of $H$. scobina hatchlings predicted to survive eight weeks was very similar for the high and low adult food treatments. Therefore, adult food level had little effect on juvenile success after eight weeks. Hatchling food had little effect on juvenile size after eight weeks, but there were roughly twice as many hatchlings predicted to survive from the low hatchling food environment compared to the high hatchling food environment.

By contrast, for $C$. virgata, adult food had a strong effect on the success of surviving juveniles after eight weeks. Five times as many juveniles were predicted to survive from adults that had been fed high food than were predicted to survive from adults fed low food. Within the adult high food regime approximately 1.5 times as many hatchlings were predicted to survive when hatchlings were fed low food compared to high food. However, the juveniles from the high hatchling food environment had the benefit of being larger at eight weeks than those in low hatchling food. Hatchlings from low adult food treatments that were fed high food as hatchlings were larger, but no more numerous, than hatchlings fed low food as hatchlings.

Overall, there was a large effect of source population on the number of juvenile $C$. maculosa after eight weeks, with nearly three times as many from the Harbour as from the South Coast. Adults from both locations that were fed low food gave rise to similar low numbers of juveniles. Further, the effect of hatchling food level dramatically increased the number of juveniles from both populations by 6-7 fold. The differences between the two source locations became much more dramatic when considering the high adult food treatment, where the level of hatchling food only had a large effect on juveniles from the Harbour.

From Harbour populations, high adult food increased the overall number of hatchlings by five times. High hatchling food had a relatively greater effect on juveniles after eight weeks when hatchlings were from low food mothers than when hatchlings had high food mothers. Nevertheless, there was a combined effect of adult and hatchling 
food levels such that juveniles from high food mothers that also experienced high food, were relatively large and much more numerous than any other combination. In addition, very few juveniles were predicted to survive to eight weeks that were from low food mothers and also had low food themselves.

An interesting comparison is to examine the compensatory effect of high hatchling food on hatchlings from low food adults versus the reduced benefit of hatchlings from high food adults, but in low hatchling food treatments. Although there were 1.5 times more juveniles from high adult / low hatchling food treatments compared with low adult / high hatchling food treatments, the hatchlings from the latter were much bigger.

From South Coast populations, approximately five times more juveniles were predicted from high hatchling food treatments after eight weeks. There was little benefit of high adult food on juvenile success. In low hatchling food treatments, coming from high food adults doubled the number of juveniles after eight weeks, but the absolute number was still very low. Further, the juveniles were predicted to be slightly smaller when from high food adults. High food juveniles were overall slightly larger than low food juveniles after eight weeks, but no effect of adult food on the number of juveniles in high hatchling food treatments was predicted. 


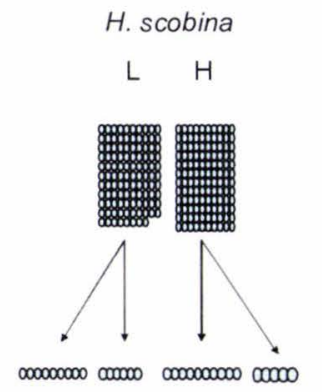

h I h

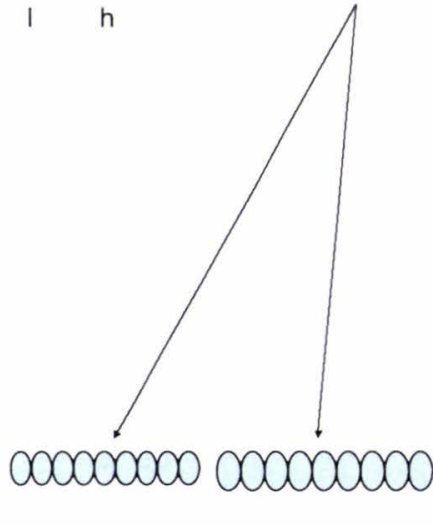

$\mathrm{h}$
C. virgata

L $\mathrm{H}$

80000000000000000000

\section{momm}

sum

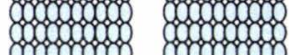

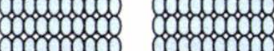

momsmom

@imum

,

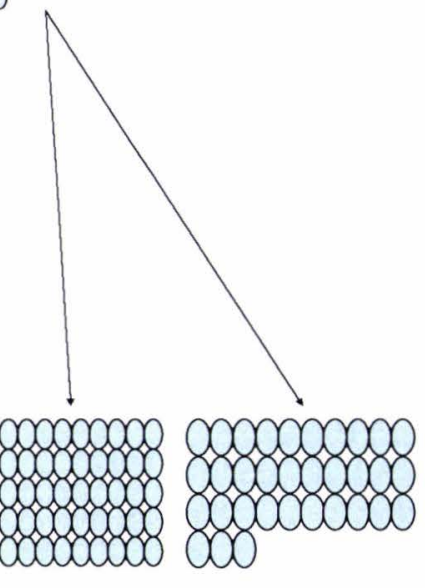

C. maculosa

(Harbour)

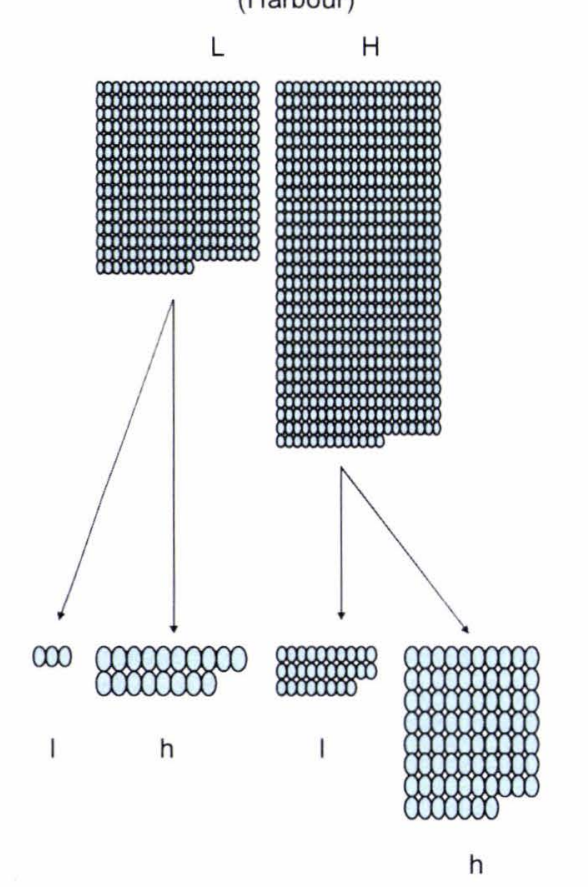

C. maculosa

(South Coast)

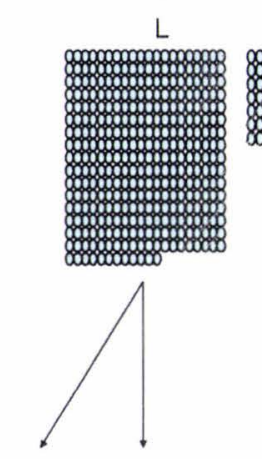

000,00000000000

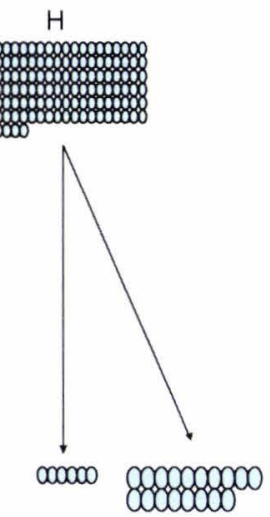

h

I

h

\section{$10 \mathrm{~mm}$}

Fig. 8. Estimated numbers of hatchlings remaining eight weeks after capsule emergence. Initial numbers of hatchlings (before arrows) are based on the mean number of capsules laid by 10 adult whelks in each of the food treatments from Chapter 2. Oval shapes represent relative hatchling sizes. L: low adult food treatment; H: high adult food treatment; 1 : low hatchling food treatment; h: high hatchling food treatment. 


\subsection{DISCUSSION}

Maternal effects have the ability to influence the growth and survival of following generations (Bernardo 1996a). The results presented here provide additional support to current understanding by highlighting the importance of adult nutrition for hatchling whelks. Maternal influence affected both the numbers of hatchlings produced as well as their growth and survival. In general, the hatchlings of well fed adults had greater growth and survival than those of poorly fed adults. Results were however highly species specific in the degree that maternal effect influenced hatchling growth and survival, in the degree of persistence of the effect and in the numbers of hatchlings that ultimately survived.

\subsubsection{H. scobina}

H. scobina growth in the first four weeks was higher in hatchlings born from adults in high food treatments. This suggests a maternal effect of nutrition that was carried over to the next generation. While this effect was not detected in the second four-week period of growth, this may have been due to the small sample size remaining after high hatchling mortality. Support for the occurrence of a maternal effect was provided by differences in shell length increases between treatments. Eight weeks after hatching, shell lengths increased by a significant amount only in treatments where hatchlings were born from high food adults.

Other outcomes for this species were less convincing. There were no differences in mortality rates between treatments and the predicted outcomes based on numbers of capsules were small. Lack of response to hatchling food treatments suggests that the diet provided may have been inappropriate. Hatchlings are unlikely to feed on dead mussels in the field and may be predisposed to a diet of live barnacles in the initial stages. Gosselin \& Chia (1994) found that the hatchlings of ecologically similar Nucella emarginata from North America, were able to bore barnacles one day after hatching and would not accept other food types. Barnacles form a major part of the diet of adult of $H$. scobina (Luckens 1974) and feeding on dead tissue is reported to occur only rarely (Stewart \& Creese 2004). Low initial H. scobina mortality rates across all treatments may have occurred because hatchlings are supplied with food 
reserves that permit survival without feeding for a short period of time. The decline in the mortality rates of $C$. virgata and C. maculosa hatchlings after four weeks did not occur in H. scobina hatchlings and mortality was almost $100 \%$ after eight weeks. It can be concluded that while an alternative diet may have resulted in a different response to hatchling feeding, the results presented here nevertheless demonstrate that the carry over effect of maternal nutrition is an important factor in early hatchling growth.

\subsubsection{C. virgata}

The growth of $C$. virgata hatchlings was influenced both by adult food treatment and by hatchling food treatment in the first four-week period after hatching. In the second four-week period, adult food treatment was no longer a significant factor. The fading influence of maternal nutrition on the growth of $C$. virgata hatchlings is consistent with observations in other taxa in which maternal effects usually decrease over the course of development and become undetectable by the time the progeny mature (Mousseau \& Dingle 1991b; Bernardo 1996a; Fox et al. 1999).

Compensatory growth of low adult food $C$. virgata hatchlings in the second fourweek period eliminated the size advantage gained by the initial larger size of hatchlings born from high adults. However, quality of growth is also an important consideration and the effects of catch-up growth may have consequences in the longer term. Nutritional conditions during key life periods of development are of profound importance in determining subsequent life history. Although compensatory growth can bring quick benefits, there may be associated costs such as reduced reproductive capacity later in adult life (Metcalfe \& Monaghan 2001).

Predicted outcomes eight weeks after hatching provide another perspective to hatchling growth in this species. In high adult food treatments, the number of surviving hatchlings was greater when hatchlings were also in low hatchling food treatments, but the size of hatchlings was larger in the high hatchling food treatments. Larger hatchling size may offset the fitness benefits of higher hatchling numbers by providing hatchlings with greater protection against the effects of desiccation and predation under natural conditions (Gosselin \& Chia 1995a). 
Shell length increases of hatchlings in high food treatments were $10 \%$ greater than those in low food treatments. Results of the calcein trial similarly found hatchling food treatment but not adult food treatment to be a significant factor. In addition, the greatest differences in hatchling mortality rates were between hatchlings in low and high food treatments while differences resulting from adult food treatments were smaller. While these results all suggest that hatchling food is a more important factor than adult nutrition for early hatchlings, another perspective is gained by considering numbers of capsules.

Predicted outcomes based on numbers of capsules laid suggest that adult food was the most important factor determining juvenile success after eight weeks, with hatchling food environment having additional supplementary effects, primarily via growth. This result demonstrates the importance of considering hatchling numbers as well as growth and mortality rates when measuring maternal investment. In conclusion, combined results highlight both the importance of hatchling nutrition and of adult nutrition on the early growth of hatchlings, with maternal influence fading as hatchlings become larger.

\subsubsection{C. maculosa}

C. maculosa hatchlings in high hatchling food treatments grew more than those in low food treatments in the first four-week period after capsule emergence, with no evidence of a maternal effect on growth. In the second four-week period however, there was an unexpected result that was contrary to the expectation of fading maternal influence. Both adult and hatchling food were significant factors but in this case there was a negative maternal effect on hatchling growth. Hatchlings born from high food adults grew less than those born from low food adults. There were other results in support of this finding. Shell lengths after eight weeks were 10-20\% smaller when hatchlings were born from high food adults. In addition, hatchlings in the calcein staining trial grew less when born from adults that were in high food treatments. Perhaps hatchlings born from high food adults possess a mechanism to suppress shell growth. Variation in hormone levels packaged within insect eggs for example is thought to influence subsequent growth in insects (Mousseau \& Dingle 1991a). 
Rapid shell growth immediately following hatching is known to occur in whelks and is thought to be a strategy to reduce predation pressure (Morton 1986, 1987). Increased body size is also often associated with greater reproductive output and it can be argued that the faster an individual grows, the more rapidly it will accrue the benefits of increased size (Munch \& Conover 2003). There is evidence however, that growth rates are seldom, if ever, at their physiological maximum (Calow 1982). This may be because there are costs associated with rapid growth such as increased risk of compromised development, reduced reproductive output and reduced lifespan (Arendt 1997; Arendt 2000). The negative maternal influence reported here may be a mechanism that high food adults used to prevent the disadvantages of rapid growth in their offspring.

While no maternal effect was detected in C. maculosa after four weeks, it is possible that an effect was nevertheless present but not manifested in shell growth. Results suggest that some means of detection other than length measurements may be better suited to quantify maternal effects in the first weeks following emergence in this species. It may be possible for example, to measure variation in factors such as egg hormone levels, fat content, yolk content, mRNA content or other chemical means to estimate levels of maternal investment at earlier life history stages (Bernardo 1996a).

Three times as many juveniles were predicted from Harbour populations of $C$. maculosa after eight weeks. This discrepancy may be a result of differences in reproductive allocation between the two regions. Harbour sourced whelks may be preadapted to higher reproductive allocation because food is likely to be more consistently available when compared with South Coast sites (Gardner 2000; Helson \& Gardner 2004; Helson et al. 2007).

Other regional differences in predicted outcomes suggest a strong effect of both hatchling food and adult food on the juveniles of Harbour sourced populations, while hatchling food was relatively more important in South Coast sourced juveniles. This suggests that there are regional differences in maternal investment within populations of C. maculosa. Regional differences in maternal investment within whelk species have been suggested by others but are poorly understood (Gosselin \& Rehak 2007). 
Taken together, the above findings suggest that while maternal effects play an important role in the growth and survival of $C$. maculosa juveniles, inherent differences in whelks sourced from different regions had a stronger influence on juvenile success. These differences may result from the limited dispersal ability that is associated with direct development (Wray 1995) and may have a genetic basis.

\subsubsection{Future Directions}

While shell length has been found to be a reliable indicator of maternal investment in the early hatchling growth of whelks (Moran \& Emlet 2001), other means of measurement may prove to be more reliable with the species of this study. If whelks keep the same shape throughout life (i.e. have isometric growth), then body weight is directly proportional to the cube of body length. This is often the case, but because shell growth can occur during starvation and changes in biomass can occur through accumulation of storage products, shell length could be a misleading index of tissue growth (Palmer 1981; Hughes 1986). Alternative methods of measurement such as dry tissue weight (eg Moran \& Emlet 2001: Palmer 1990) and lipid analysis (McEdward \& Coulter 1987; Gosselin \& Qian 1999), may prove to be more sensitive in detecting differences in the maternal effect of nutrition on the growth of hatchling whelks.

Variation in shell length growth rates within replicates may have been less than that reported, due to the method used. The inability to identify individual hatchlings meant that weekly growth rate was calculated as the sum of (live) hatchling lengths for that week, divided by the number of (live) hatchlings, rather than as the average hatchling growth. This meant that the death of a large fast-growing hatchling could indicate a growth rate that was lower than the true value. Trial results showed that calcein staining is an ideal alternative, providing a clearly visible band that can be used to track the growth of individuals. This method raises the possibility of size autocorrelation analysis which has been used to show that growth rate and size increase consistently in individuals of mobile species including whelks (Pfister \& Stevens 2002). However multiple calcein immersions may be problematic, at least for the Cominella species, as it appears that the dye is incorporated into the entire shell 
during the staining of newly hatched whelks and not just into the growing margin as reported by Moran (2000). This may occur because calcium is still being used to strengthen all parts of the shell for some time after emergence from the capsule. Calcein immersion time in future studies of early stages of hatchling growth should not exceed two days, to reduce the possibility of dye uptake over the entire shell concealing previous growth marks.

Across all three species, results suggest low maternal influence on juvenile mortality. It is conceivable that altered dynamics under natural conditions may result in different outcomes. Desiccation and predation have been found to have a strong influence on the mortality of juvenile whelks (Spight 1977; Gosselin \& Chia 1995a), and these factors may have synergistic or antagonistic effects on maternal influences. It is more plausible however, that the patterns reported here also occur in the field and that the availability of juvenile food has a greater influence on the mortality of juveniles, than any effect of nutrition carried over from the previous generation.

Predicted outcomes indicated that maternal and juvenile nutrition were interdependent to some degree. C. maculosa juveniles from Harbour populations that were in high adult/low hatchling food treatments were relatively small but numerous, while those in low adult/high hatchling treatments were relative large but fewer in number. This suggests a compensatory response by low food hatchlings which may be important. For example, hatchling size refuge from predation is known to occur in whelks (Spight 1976a; Palmer 1981; Gosselin \& Rehak 2007). Determining the influence of shell size on juvenile success under field conditions would improve understanding on the ultimate effect of the compensatory response.

\subsubsection{Conclusion}

The results presented here add weight to the body of evidence highlighting the importance of adult nutrition on the early life of hatchlings. The degree of persistence of maternal effects into the next generation is species-specific and may be more important than juvenile nutrition in the first weeks of life of some species. While maternal effects are carried over to influence hatchling growth and survival, predicted 
outcomes based on the numbers of capsules indicate that this has a greater influence on the numbers of hatchlings surviving after eight weeks.

Carry over effects of adult nutrition had a strong influence on both the numbers of hatchlings produced and on the growth of hatchlings, and are likely to play an important role in determining the makeup of community structure. Differences in maternal influence between species and between populations are likely to be alternative strategies used to balance the advantage of high fecundity with the benefits of producing higher quality larger offspring. 


\section{CHAPTER 4}

\section{The Role of Nurse Eggs in H. scobina and C. maculosa Embryo Growth and Development}

\subsection{ABSTRACT}

The intertidal whelks Haustrum scobina (Muricidae) and Cominella maculosa (Buccinidae) surround multiple eggs with a capsule in which early development takes place. When physical constraints on egg size exists, competition for limited resources is predicted to arise in the micro-environment of the capsule and lead to different outcomes, depending on the number of eggs that are encapsulated.

Samples of newly laid, field collected H. scobina and C. maculosa egg capsules were preserved at weekly stages of development until time of hatching. Capsules were later dissected and propagule size and number recorded at weekly stages of development.

H. scobina capsules initially contained an average of 89 eggs but only 6.4 went on to develop into hatchlings. Non-developing eggs are likely play a nutritive role for developing embryos in this species. In contrast $C$. maculosa did not encapsulate nondeveloping eggs. C. maculosa embryos may derive some nutrition from intracapsular fluid. However within-capsule feeding had less influence on growth than in $H$. scobina embryos.

There was little variation in initial egg size for either species. H. scobina development occurred over eleven weeks with a large proportion of within capsule growth occurring in the second week. Development occurred over eight weeks in $C$. maculosa capsules with a large proportion of growth taking place in the fourth week. H. scobina embryos were more variable in size than C. maculosa embryos. It is likely that this variation occurred as a result of variable nurse egg consumption by embryos.

Only $23 \%$ of capsules deposited by $H$. scobina were still viable at the time of the emergence of the first hatchling compared with $80 \%$ of $C$. maculosa capsules. The number of $H$. scobina capsules that remain viable is likely to be higher under natural 
conditions due to the high costs associated with capsule construction. Factors such as high water flow may be important for the development of $H$. scobina embryos.

Taken together these results highlight alternative outcomes that may arise as a result of differences in the way that embryos are provisioned with resources to complete their development. Nurse egg provisioning may be a successful strategy in an unpredictable environment where variable size among hatchlings is advantageous.

\subsection{INTRODUCTION}

Encapsulation of eggs within protective structures appears to have evolved independently in several phylogenetically diverse marine invertebrate groups in response to various risks associated with embryonic development There is evidence that the micro-environment of the capsule may provide embryos with some protection against predation, microbial attack, desiccation, and salinity fluctuation (Pechenik 1979; Rawlings 1999). Capsules are structurally and chemically complex, energetically costly to produce and require highly modified female reproductive anatomy, physiology and behaviour. Survival benefits of capsular development should therefore be considerable (Pechenik 1986).

In marine gastropods, benthic egg capsules are well documented among the whelk families Muricidae, Nassariidae, Melongenidae and Fasciolariidae (D'Asaro 1991, 1993; D'Asaro 1997; D'Asaro 2000) and are thought to occur in almost all marine neogastropod molluscs (Rawlings 1999). The number of eggs per capsule varies greatly among species $(1-50,000)$ and there is evidence that variation in egg number is correlated with adult size and environmental conditions in some species. Evidence suggests that the number of encapsulated eggs is greater when adults are larger (Miloslavich \& Dufresne 1994) and when environmental conditions are less exposed (Lloyd \& Gosselin 2006).

Some gastropods include extra provisioning with the embryos which may take the form of non-developing yolky nurse eggs. These are non-viable, although they are sometimes fertilized and may cleave (Webber 1977). In a study that examined the 
developmental characteristics of 78 species of Calyptraean mesogastropods, $15 \%$ had nurse eggs (Collin 2003). Nurse eggs are also common in the intertidal neogastropod families Muricacea and Buccinacea (Strathmann 1987), and it has been suggested that they are a favoured means of nutrition in such habitats because they accelerate developmental time and thereby reduce exposure to mortality pressure (Spight 1976b; Gallardo 1979). Nurse egg ingestion is a highly efficient means for embryos to obtain energy that provides hatchlings with sufficient reserves to exist without the need for urgent feeding at the time of hatching (Gallardo et al. 2004).

Little is known of the early development of whelk species that encapsulate multiple eggs. Competition among developing young for limited resources within the microenvironment of the capsule could be predicted to generate variation in hatchling size. While this effect may be minimal in the developing embryos of species that do not feed inside the capsule, differences in embryo size can be expected when variable consumption of nurse eggs by feeding embryos occurs (Spight 1976b; Rivest 1983; Gonzalez \& Gallardo 1999; Collin 2003). Small embryo size differences within the capsule can become amplified due to the effects of sibling cannibalism which becomes more likely when capsule-mates differ in size (Morton 1987; Miloslavich \& Penchaszadeh 2001). In contrast sibling cannibalism is minimised when all capsulemates are approximately equal in size and well synchronised in development (Polis 1983).

Generally, species with non-feeding (lecithotrophic) larvae have shortened development times, compared with those of feeding (planktotrophic) larvae (Havenhand 1993). It can therefore be predicted that for benthic developing gastropods, those species with nurse egg consumption will have extended development times compared to those that do not have nurse egg or intracapsular feeding. Evidence suggests that is the case for some species (Stockmann-Bosbach 1988), however shortened development times have also been reported among nurse feeding intertidal gastropods (Gallardo 1979).

The intertidal whelks Haustrum scobina (Muricidae) and Cominella maculosa (Buccinidae) are common and abundant on intertidal shores in New Zealand (Morton \& Miller 1968). Both surround multiple eggs with a capsule in which early 
development takes place, however there is little published information on the benthic development of either species. The purpose of this study was to examine the development of these two species in more detail than has previously been reported. It is thought that $H$. scobina provides embryos with nurse eggs while $C$. maculosa embryos contain sufficient energy reserves for complete development without intracapsular feeding. I predicted that: 1) initial C. maculosa embryo size would be larger than initial H. scobina embryo size; 2) variation in embryo size would be greater in $H$. scobina than in $C$. maculosa due to nurse egg consumption; 3) development time of $H$. scobina hatchlings would be greater than that of $C$. maculosa hatchlings due to the presence of nurse eggs; 4) capsule viability would be high in both species due to the costs associated with construction.

\subsection{METHODS}

In November 2006, egg capsules from whelks observed to be actively spawning, were collected from the intertidal zone at Point Howard in Wellington Harbour ( $H$. scobina) and Makara Bay on the Wellington west coast (C. maculosa). Whelks of both species form spawning aggregations and lay egg capsules communally. Capsules in active spawning aggregations were assumed to have been laid at the same time.

Groups of 12 randomly selected capsules were placed into $30 \mathrm{~mm}^{2}$ nylex mesh bags $($ mesh size $=500 \mu \mathrm{m})$ sealed with hot-melt glue. Bags were kept under identical conditions in a large shallow tank at the Victoria University Coastal Ecology Laboratory and supplied with constantly flowing fresh sea water at ambient temperature $\left(13.7-18.0^{\circ} \mathrm{C}\right)$. At weekly intervals until hatchling emergence, a single bag was removed and placed in a jar containing 5\% buffered formalin.

Preserved capsules were later carefully opened using a scalpel, and all embryos from each capsule were counted and measured using a dissecting microscope (Olympus SZX7) equipped with a graticulated eyepiece. Capsules volumes were estimated using the same method outlined in Chapter 2. Capsules without identifiable embryos or with degenerating embryos were regarded as unviable. These were measured but not included in analyses of propagule development. H. scobina capsules with non-viable embryos could be identified by their pink colouration, compared with healthy 
capsules which are generally white. Representative photographs of capsule contents were taken of each weekly developmental stage.

The statistical package SPSS ( $\mathrm{V}$ 12.0) was used to carry out all of the data analysis. Non-parametric Mann-Whitney tests were used to compare the mean numbers of propagules in newly laid capsules with numbers of propagules at the time of hatching. Only two out of ten $H$. scobina capsules contained hatchlings after eleven weeks (time of hatching). In order to increase sample size, mean numbers of hatchlings per capsule at the time of hatching were estimated by combining data from weeks nine, ten and eleven. Log regression was used to estimate capsule viability during development. Comparison of differences in embryo size between species were made with coefficients of variation using embryo size as a numerator, week as a denominator and species as a group variable. Weekly embryo size data for all capsules was combined for each species.

\subsection{RESULTS}

\subsubsection{Change in number of propagules during development}

The mean number of hatchlings emerging from $H$. scobina capsules was dramatically less than the mean number of eggs initially encapsulated (eggs in newly laid capsules: mean $\pm \mathrm{SE}=89.4 \pm 12.7$; hatchlings at emergence: mean $\pm \mathrm{SE}=6.4 \pm 1.6$; MannWhitney $U=0.00, p<0.01$, fig. 1). In contrast the mean number of hatchlings emerging from C. maculosa capsules was not significantly different from the mean number of eggs encapsulated (Mann-Whitney $\mathrm{U}=27.00, \mathrm{p}=0.05$ ). There was large variation in the numbers of initial embryos, ranging from 33 to 155 embryos per capsule in $H$. scobina $(\mathrm{n}=11)$ and 6 to 18 in $C$. maculosa $(\mathrm{n}=9)$. 

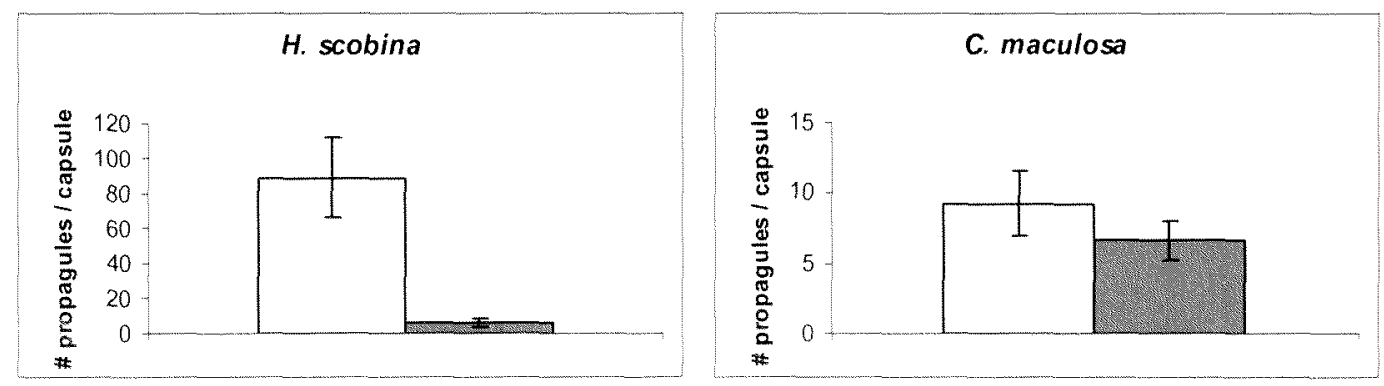

Fig. 1. Numbers of propagules encapsulated within capsules of $H$. scobina and $C$. maculosa at the time of laying (open bars) and at time of hatching (filled bars). Error bars indicate $95 \%$ confidence intervals.

Numbers of propagules encapsulated within H. scobina capsules fell sharply during the first three weeks of development and remained at a more consistent level after the fourth week. Numbers of encapsulated C. maculosa propagules remained consistent over the entire developmental period (fig. 2)
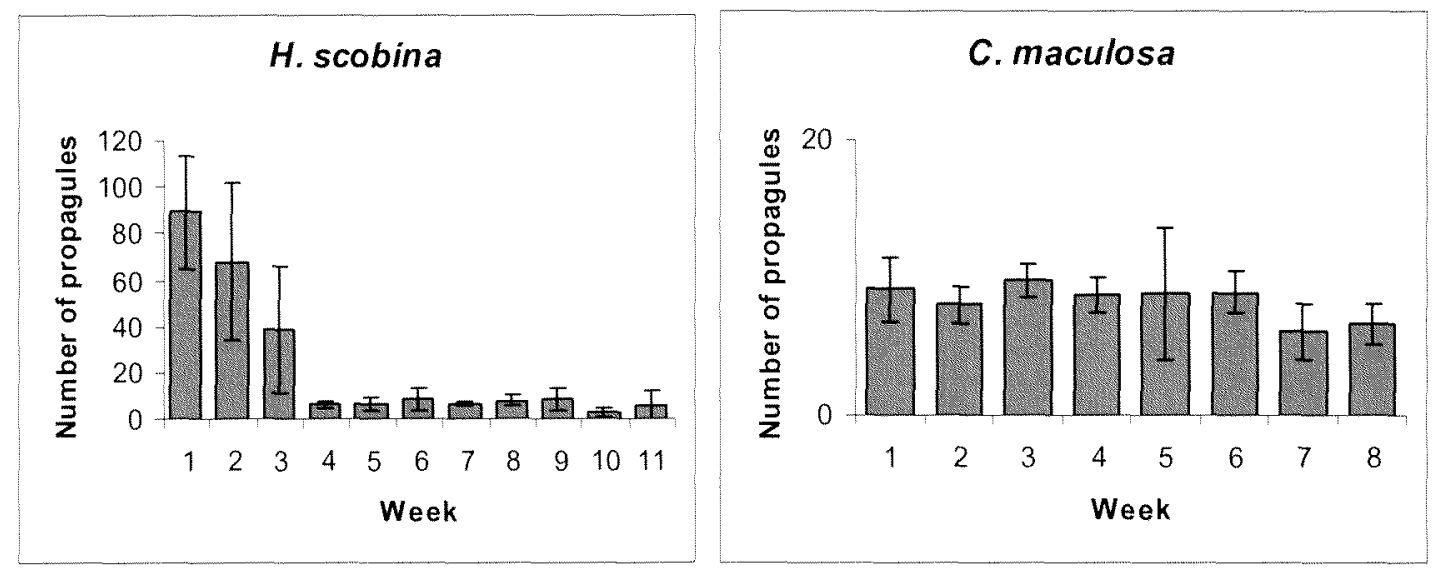

Fig. 2. Mean numbers of propagules encapsulated within $H$. scobina and $C$. maculosa capsules during development. Error bars indicate $95 \%$ confidence intervals.

Mean capsule volumes were within the range reported in Chapter 2 (H. scobina: mean $=9.9 \mu 1$, range $=5.3-16.0 \mu 1 ;$ C. maculos $:$ mean $=34.7 \mu 1$, range $=22.4-62.3 \mu 1)$.

The mean number of 6.4 hatchlings emerging from field collected $H$. scobina capsules was less but not significantly different from the mean of 7.2 hatchlings per capsule laid by laboratory raised whelks reported in Chapter 2 (Mann-Whitney $U=467.00$, $\mathrm{p}=0.23$ ). The mean number of 6.6 hatchlings emerging from field collected $C$. maculosa capsules was significantly less than the mean of 8.4 hatchlings emerging 
from laboratory laid capsules reported in Chapter 2 (Mann-Whitney U=1066.50, $\mathrm{p}=0.01)$.

\subsubsection{Embryo development}

\section{H. scobina}

Early embryos were similar in size among all capsules $(0.25-0.30 \mathrm{~mm}$ diameter $)$, with many at the four-cell stage (fig. 3A). Nurse eggs could not be distinguished from embryos in the initial measurement. In the second week of development, 2 of 10 capsules contained larger embryos (mean $\pm \mathrm{SE}=0.64 \pm 0.01 \mathrm{~mm}$ ) while the remaining capsules contained embryos within the $0.25-0.3 \mathrm{~mm}$ size range. After three weeks embryos within this small size range began to disintegrate, while size continued to increase in developing embryos and to elongate in form. After four weeks a shell was visible in some embryos (fig. 3D), and eyespots were visible after six weeks of development. Opercula could be seen after 10 weeks. Capsule plugs began to dissolve after 10 weeks and the first hatchlings emerged from the capsules after 11 weeks of development.
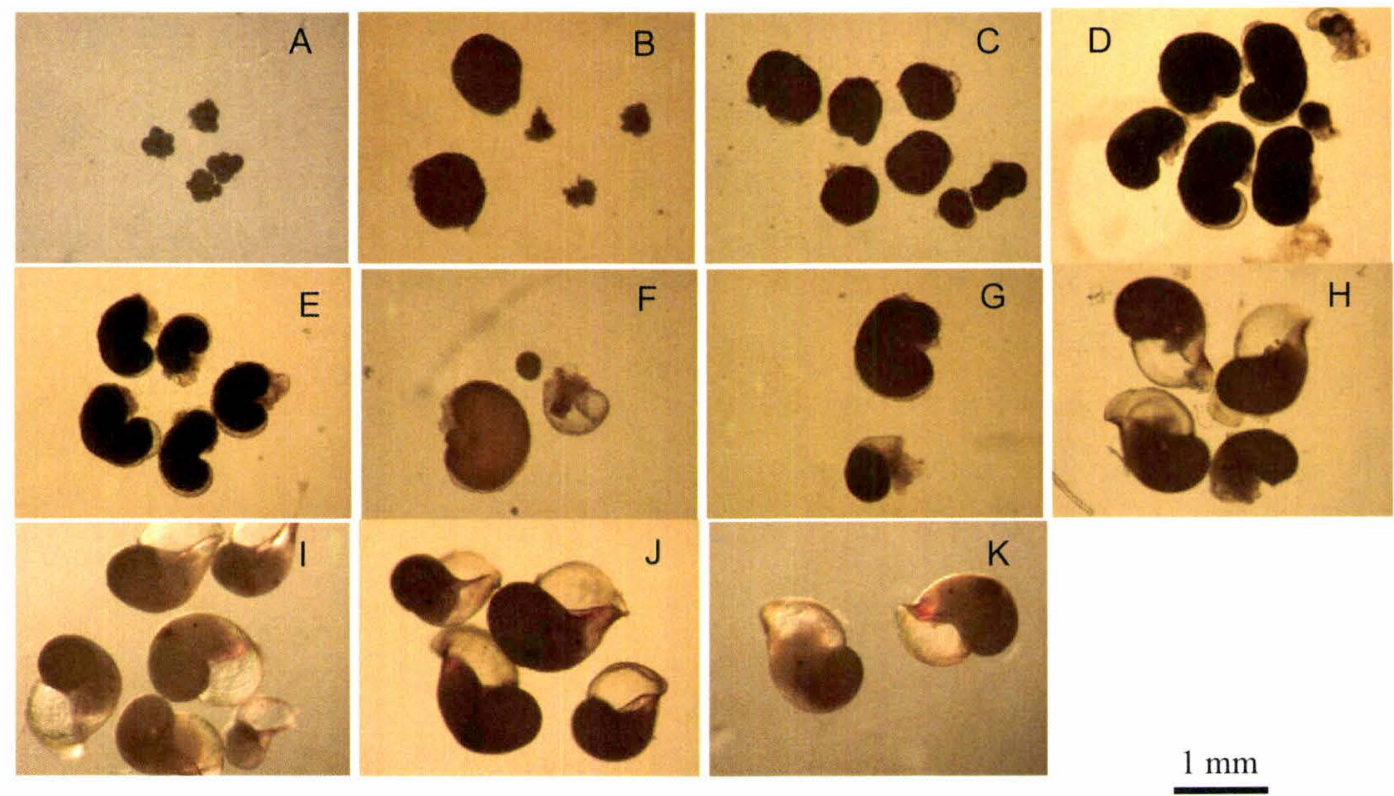

Fig. 3. H. scobina development. Photographs taken at weekly intervals (letters A-K indicate weeks one to eleven). Nurse eggs are visible in B and F. 


\section{C. maculosa}

Early embryo sizes were identical among all capsules initially $(0.3 \mathrm{~mm}$ diameter $)$, with many at the four-cell stage (fig. 4A). Embryos were surrounded by a jelly-like albumen matrix in the first three weeks of development but this was no longer present or had become more fluid after four weeks. A shell could be seen in some embryos after three weeks (fig. 4C). Capsule plugs began dissolving after five weeks and eyespots were visible after six weeks. In the week prior to hatching embryos were surrounded by mucus and the first hatchlings emerged after eight weeks of development.
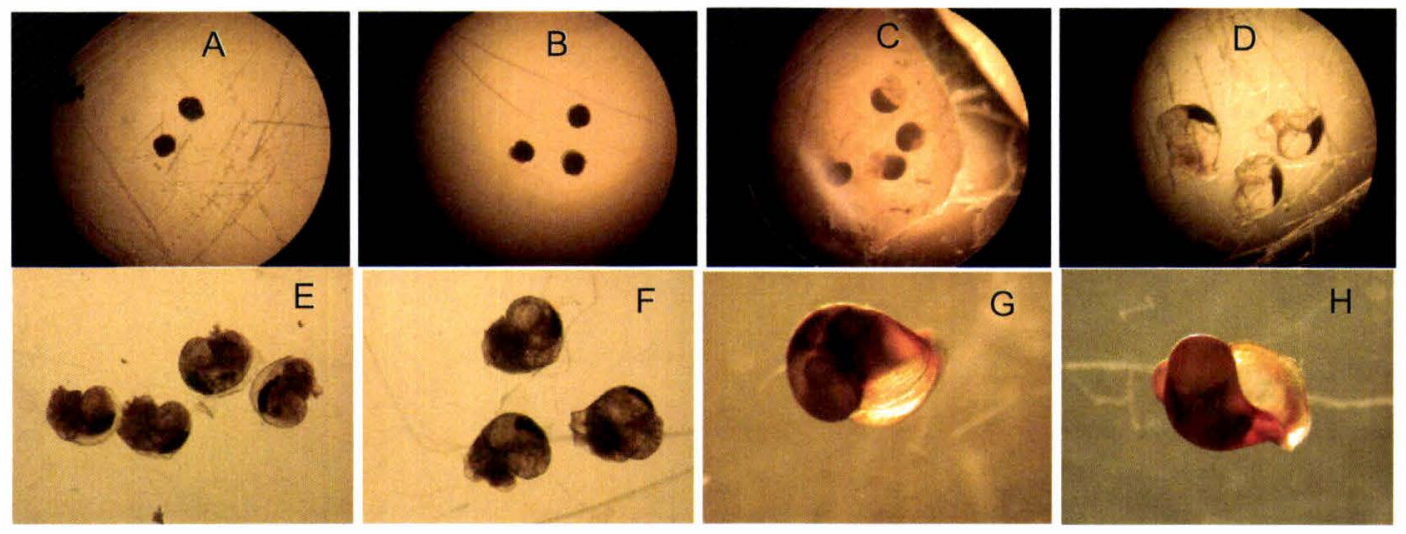

Fig. 4. C. maculosa development. Photographs taken at weekly intervals.

Letters A-H indicate weeks one to eight.

\subsubsection{Embryo growth}

H. scobina embryos grew rapidly between the first and second week of development, but between weeks three and seven there was very little growth at all. Growth increased in weeks eight and nine and then in week ten growth rate tripled (fig. 5). Growth rate appeared to be negative in week eleven but this was likely to have been a result of small sample size (just two $H$. scobina capsules contained embryos in week eleven). 

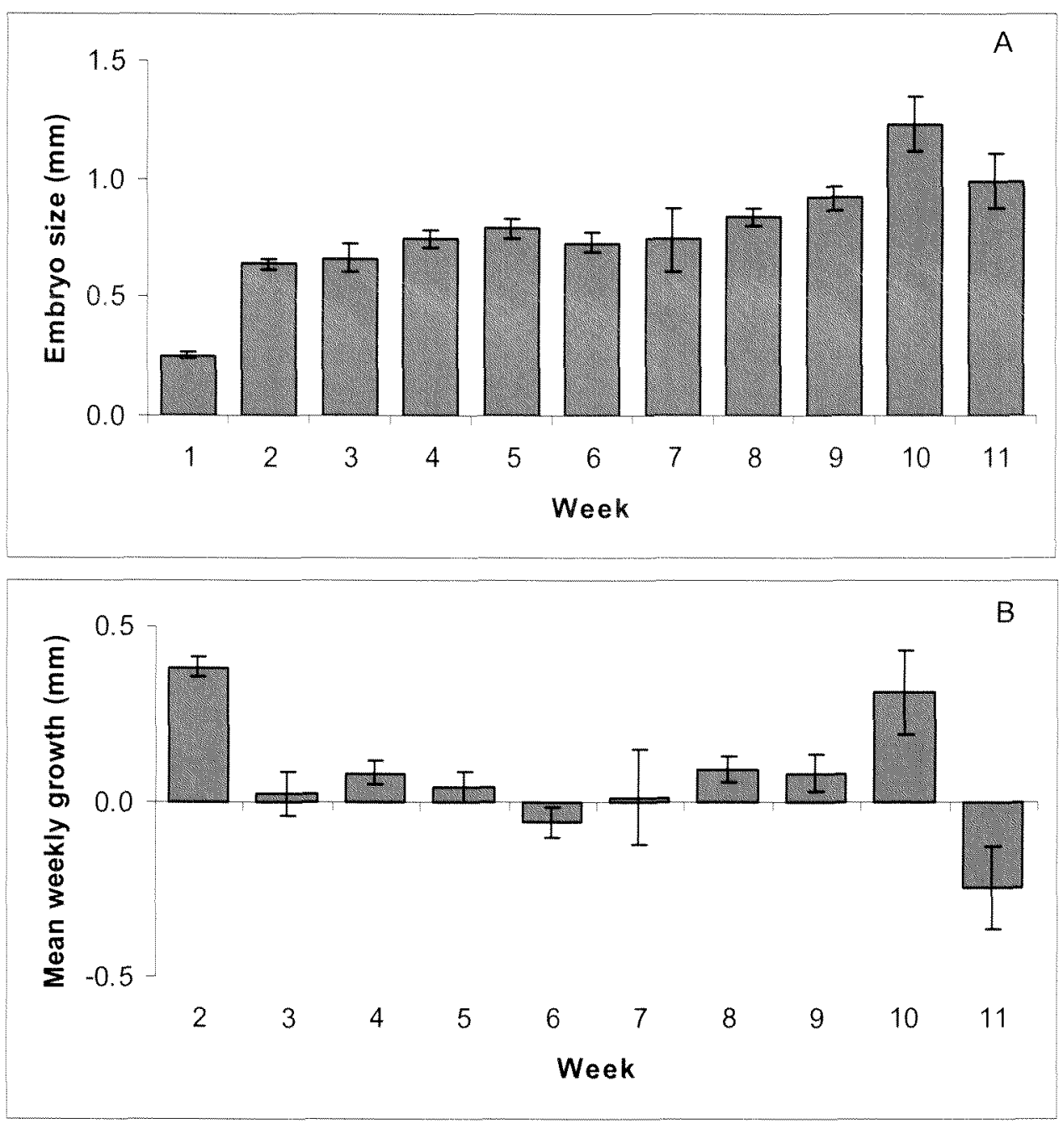

Fig. 5. H. scobina embryo growth. A: mean embryo size within capsules, B: mean weekly growth. A large increase in embryo size occurred during week two. Hatchlings emerged after eleven weeks. Error bars indicate $95 \%$ confidence intervals.

In contrast $C$. maculosa embryo size remained similar over the first three weeks of development. There was a sharp increase in size between weeks three and four with embryos doubling in size over this period. Size increased further in the following weeks until hatching but at a lower rate than that occurring in the fourth week (fig. 6).

Embryo size was more variable in $H$. scobina $(\mathrm{CV}=41.3 \%)$ than in $C$. maculosa $(\mathrm{CV}=27.5 \%)$ over the developmental period. 

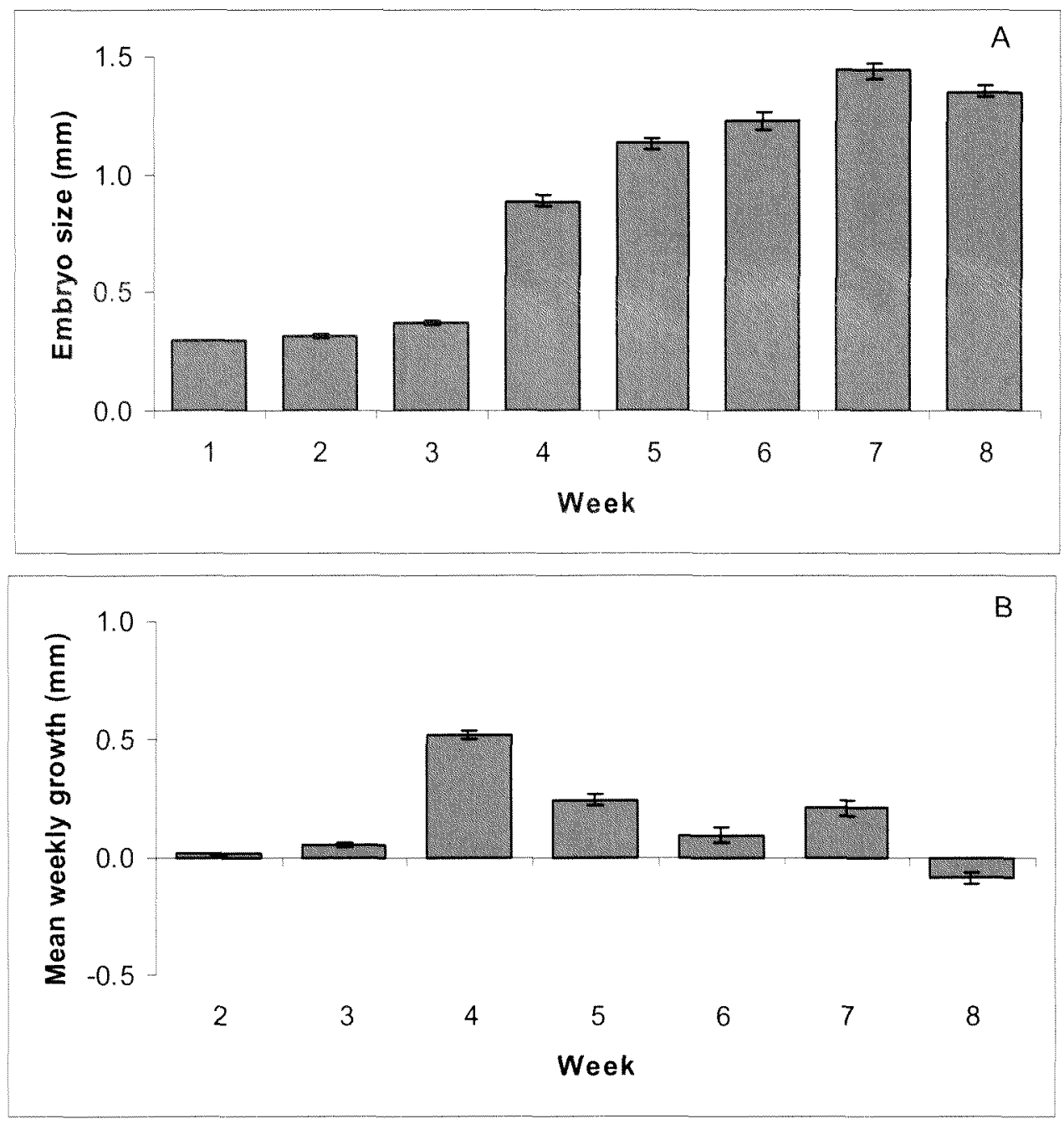

Fig. 6. C. maculosa embryo growth. A: mean embryo size within capsules, B: mean weekly growth. A large increase in embryo size occurred during week four. Hatchlings emerged after eight weeks. Error bars indicate $95 \%$ confidence intervals.

\subsubsection{Capsule viability}

The proportion of capsules containing viable embryos decreased over the period of development of both species (fig. 7). A log curve provided a good estimate of the distribution of $H$. scobina capsule viability $\left(\mathrm{R}^{2}=0.82, \mathrm{~F}=40.10, \mathrm{p}<0.01\right)$. C. maculosa viability also appeared to follow a $\log$ distribution, however the curve fit was not significant $\mathrm{R}^{2}=0.41, \mathrm{~F}=4.11, \mathrm{p}=0.08$ ). Using regression equations, the number of viable H. scobina capsules predicted after eleven weeks is $23 \%$ of that laid initially. The number of C. maculosa capsules remaining viable after eight weeks is predicted to be $80 \%$. 


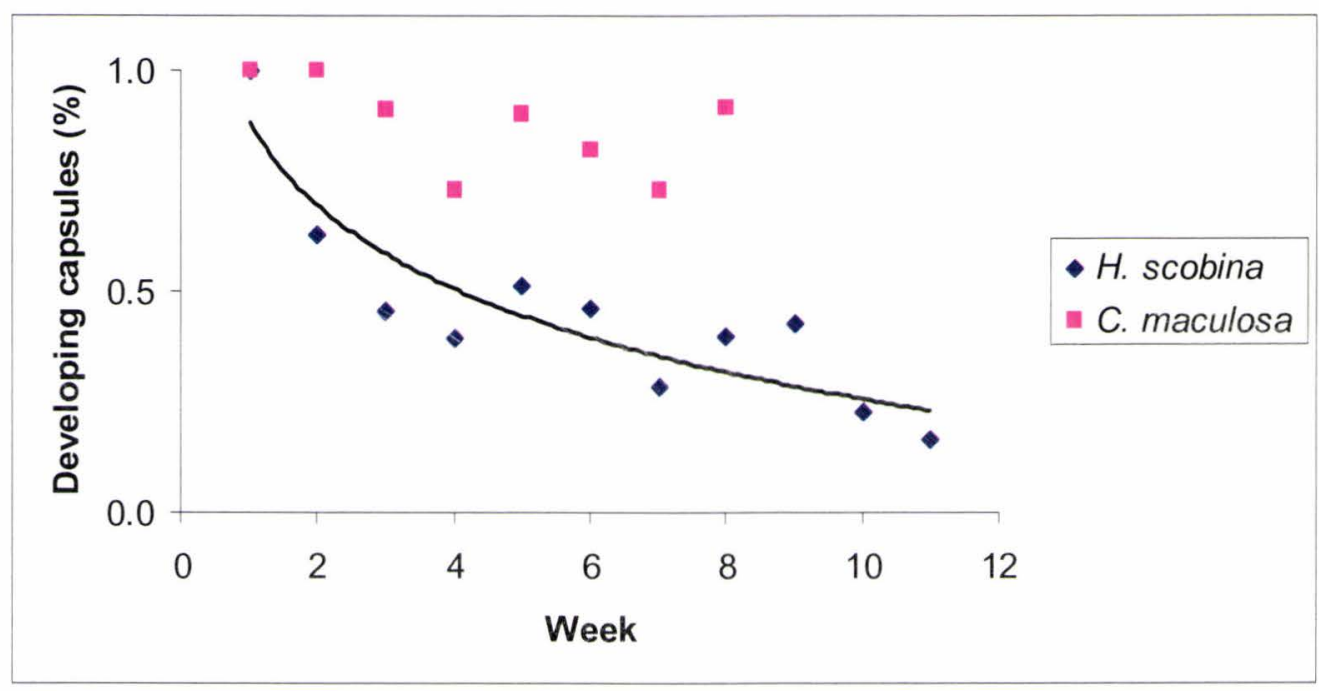

Fig. 7. Proportion of capsules containing viable embryos in the weeks before hatching. A log curve provided a good estimate of the proportion of viable H. scobina capsules in any week $\left(\mathrm{R}^{2}=0.82, \mathrm{p}<0.01\right)$ while a $\log$ curve fitted to $C$. maculosa data was non-significant $\left(\mathrm{R}^{2}=0.41, \mathrm{p}=0.08\right)$.

\subsection{DISCUSSION}

Differences in embryo development occurring within the capsules of neogastropod molluscs can have long term fitness implications. Some species provide embryos with yolky nurse eggs which are consumed during development. In other species, feeding does not occur and embryos are provided with sufficient resources to complete their development. Nurse egg feeding can result in differences in embryo size and hatchling size which may be advantageous when environmental conditions are unpredictable.

Results of this study suggest that $H$. scobina deposits nurse eggs inside its capsules while $C$. maculosa does not. Within a capsule, development occurred in only $7.1 \%$ of H. scobina eggs and it is likely that the remaining eggs provided a nutritive role for developing embryos. The proportion of fertile embryos fell within the range reported for other neogastropods with nurse eggs. This range is extreme $(0.06 \%$ to $75 \%$ embryos / nurse eggs), however ratios of between $2 \%$ and $10 \%$ are most common (Spight 1976a; Gallardo 1979; Strathmann 1987; Fretter \& Graham 1994).

In contrast with H. scobina, it appeared that all eggs within C. maculosa capsules developed into hatchlings. The absence of nurse eggs raises the possibility that $C$. maculosa embryos may have been feeding on intracapsular fluid. Intracapsular fluid is 
known to influence the growth of some opisthobranchs and pulmonate gastropods (Pechenik et al. 1984; Moran 1999b). However, while at least one case has been reported where feeding from intracapsular fluid has a significant effect on the growth of prosobranch neogastropods (Rivest 1986), most evidence suggests that its influence on growth is small (Perron 1981; Pechenik et al. 1984; Hughes 1986).

Nurse egg feeding is not universal among intertidal whelks. In many species, development inside the capsule may take place without embryo feeding. When this occurs, embryos must be provisioned with sufficient nutrients to complete development until juvenile feeding can begin. However, while the embryos of species that do not feed on nurse eggs tend to be larger than the embryos of nurse egg feeding species initially, there are several exceptions (Spight 1976a; Strathmann 1987). The results presented here provide a further example. Initial embryo sizes of non-nurse egg feeding C. maculosa were similar to that of nurse egg feeding H. scobina embryos. This result together with the relatively large embryo size at hatching, suggests that C. maculosa embryos may be provisioned initially with more lipid than H. scobina, or that some nutrition is derived from intracapsular fluid.

Nurse egg feeding can have a strong influence on hatchling size (Spight 1976a; Lloyd \& Gosselin 2006). Hatchling size is often approximately twice that of initial embryo size among non nurse egg feeding embryos (Rivest 1981), but hatchling sizes up 42 times larger than initial embryo size have been reported in nurse egg feeding species (Spight 1976a; Webber 1977). In this study however, both species had a similar initial embryo size and a similar hatchling size, suggesting that the influence of nurse egg feeding on hatchling size was minimal.

Hatchling size is also more variable in nurse egg feeding species. For example Rivest (1981) reported hatchling sizes of $0.8 \mathrm{~mm}$ to $2.5 \mathrm{~mm}$ in nurse egg-feeding Searlesia dira in sharp contrast with the $0.8 \mathrm{~mm}$ to $1.1 \mathrm{~mm}$ hatchling size of Nucella lamelosa in which nurse egg feeding does not occur. Results presented here are similar. Embryo size was more variable in nurse egg feeding $H$. scobina than in non nurse egg feeding C. maculosa. Embryo size variation in $H$. scobina is likely to have resulted from differences in nurse egg consumption between embryos (Spight 1976b; Gallardo 1979; Rivest 1983; Gonzalez \& Gallardo 1999). Size differences may have been 
reinforced by sibling cannibalism which becomes increasing likely when some individuals become larger than their capsule mates (Morton 1987; Miloslavich \& Penchaszadeh 2001).

While bigger propagules are buffered against adverse conditions such as physical stress, this advantage is lost when conditions are more benign. In these circumstances, higher fitness can be achieved by having a larger number of smaller propagules. It has been suggested that variation in the hatchling size of intertidal neogastropods can provide an advantage in unpredictable environments (Rivest 1983). While large hatchlings may always have a good chance of surviving, smaller ones also survive when the conditions are suitable.

Predatory whelks such as $H$. scobina may be more specific in terms of preferred prey compared with scavenging species such as C. maculosa (Chapter 1; Gosselin \& Chia 1996). The unpredictable availability of preferred prey for newly hatched juveniles may be another reason for greater size variation in H. scobina. Size variation may allow bigger individuals to survive for longer periods when preferred prey is scarce while smaller individuals also survive when preferred prey is plentiful.

Development times were longer for H. scobina embryos than for C. maculosa embryos as predicted. This was in agreement with the trend towards extended development time in most other nurse egg feeding intertidal gastropods (Strathmann 1987; Stockmann-Bosbach 1988). Between species comparisons are difficult however, because development times are also strongly correlated with temperature and initial embryo size (Spight 1975). Development times of both species were within the range of 55 to 150 days reported for nurse egg feeding intertidal neogastropods.

Patterns of growth were different for $H$. scobina and C. maculosa embryos. $H$. scobina growth was high in the second week of development. This is likely to have occurred due to nurse egg consumption because egg numbers fell dramatically at this time. High initial nurse egg consumption occurs in the embryos of other Muricid gastropods and whole nurse egg ingestion is possible only during early developmental stages (Gallardo 1979; Rivest 1981). Morphological changes may restrict the feeding of embryos at later stages to smaller particles (Lyons \& Spight 1973). In weeks three 
to seven when no size increase occurred, accumulated energy may have been used instead for the development of tissue such as organs and for shell construction.

In contrast, highest embryonic growth occurred during the fourth week of $C$. maculosa development. C. maculosa growth appeared to be arrested until the fourth week. Major tissue development may occur in this initial period. The suppression of growth during this period coincided with the presence of jelly like albumen surrounding the embryos. The sudden change in nature of this albumen from jelly to liquid during the fourth week was accompanied by accelerated growth suggesting that it may have been a contributing factor. There may be some chemical cue that is required to make the albumen available to the developing embryo. It has been suggested for example, that enzymes released by developing Ocenebra aciculata embryos liquefy the albumen thus making it more easily digested (Webber 1977).

Capsule viability followed a negative log distribution, with an increasing proportion of capsules remaining viable over time. While $80 \%$ of $C$. maculosa capsules were viable at hatching, only a $23 \%$ of $H$. scobina capsules contained hatchlings that completed development. It was predicted that this value would be greater because the costs of producing capsules are high. For example capsule construction represents about one third of parental investment in Nucella lamellosa (Hughes 1986). Low $H$. scobina capsule viability represents a large loss of reproductive investment that is difficult to explain. It is likely that some critical factor such as water flow or oxygen level was lacking in the laboratory conditions, and that capsule viability would be higher in the field.

Nurse eggs occur in taxa that differ widely in ecology and life history. Examples can be found among the amphibians, non-social and eusocial insects and fish as well as in marine gastropods. There are a number of ways that nurse eggs could have arisen. For example, they may be by-products of failed reproduction resulting from gamete incompatibility or sperm limitation (Perry \& Roitberg 2006). Advantages associated with the presence of non-developing eggs within a capsule such as increased offspring size would ensure their persistence. There may be physical constraints on the maximum egg size that can be produced that set limits for offspring size. The nutrition provided by nurse eggs provide a means of achieving increased offspring 
size at hatching and therefore the chances of offspring survival (Moran \& Emlet 2001; Gosselin \& Rehak 2007). Other benefits resulting from nurse egg encapsulation include increased size variation among offspring and reduction in the need for feeding immediately after hatching (Miloslavich 1996; Gonzalez \& Gallardo 1999).

Nurse egg feeding is thought to be an ancestral trait in Nucella that has been subsequently lost in some species (Collins et al. 1996). This suggests that nurse egg feeding is not an optimal strategy in all instances. While generating larger sized offspring with variable sizes may be advantageous in unpredictable conditions, creating offspring that are similar in size may be a better strategy in other circumstances. 


\section{CHAPTER 5}

\section{General Discussion}

Understanding of whelk reproduction may be skewed because most studies are confined to the Northern Hemisphere genus Nucella. This study helps to improve this understanding by contrasting trade-offs in reproductive allocation among three Southern Hemisphere species. Trade-offs in reproductive allocation were highly species specific. Each species used different strategies to maximise fitness with different offspring number and size combinations. Trade-offs were adjusted in response to food treatments in both Cominella species, by varying the number rather that the size of the hatchlings. In contrast, H. scobina did not adjust reproductive allocation in response to food treatment.

Differences in response to food treatments among these genera are likely to have occurred because of the trophic positions they occupy. While the scavengers $C$. virgata and $C$. maculosa occupy positions lower on the shore and are generalist feeders (Morton 1986), the predator H. scobina occupies positions higher on the shore and is more specific in its diet (Luckens 1974). Daily exposure to air during low tide cycles may mean that $H$. scobina is limited to a specific diet and is unable to switch to alternative sources of nutrition (Rovero et al. 1999).

Alternative reproductive strategies among the three species may have resulted in differences in reproductive allocation. While C. maculosa produced large numbers of small offspring, C. virgata produced a smaller number of larger offspring. Lower mortality rates in $C$. virgata hatchlings suggests a size advantage which may offset the negative aspect of reduced numbers of offspring (Stearns 1992). While both species are similar in morphology and ecology (Morton \& Miller 1968), C. virgata hatchling size was almost double that of $C$. maculosa hatchling size and capsules contained a single hatchling in contrast to the multiple hatchlings in C. maculosa capsules. However, while these differences are large, altering the number of hatchlings in a capsule may not be difficult to achieve evolutionarily, as the small proportion of $C$. virgata capsules containing multiple hatchlings suggests. 
In all three species, reproduction occurred in low food treatments as well as in high food treatments. This suggests that stored energy, derived from food eaten before the experiment began, was used for reproduction in addition to energy derived from food during the reproductive period. The degree to which stored energy influenced reproductive output in this study is unknown. Organisms vary widely in the way that reproduction is supported. While some birds derive all reproductive energy from food consumed during the reproductive period, some reptiles are not influenced by food availability for periods of up to nine months before the reproductive period (Fraser 1980; Meijer et al. 1989). Use of stored energy rather than energy derived over the developmental period is common among ectotherms (Bonnet et al. 1998). Use of stored energy for reproduction could be predicted to be highest in marine organisms as the costs associated with increasing body mass (from extra storage) are less due to the support that the water medium provides (Nybakken \& Bertness 2005). In a study of reproductive response to feeding by the whelk Nassarius pauperatus, whelks in low food treatments laid more capsules suggesting that stored energy was used for reproduction (McKillup \& Barker 1979). However N. pauperatus is a short lived species with planktonic larval development. The opposite effect was found in longer lived $N$. festivus that has direct development. After 12 weeks of feeding, whelks in low food treatments laid fewer, smaller capsules, suggesting that at least some of the energy used for reproduction was derived during the reproductive period in this species (Cheung \& Lam 1999).

Maternal effects of nutrition influence the growth and survival of subsequent generations in ways that differ widely among species. While no maternal effect was evident on the success of $H$. scobina juveniles after eight weeks, maternal nutrition was the most important factor affecting the success of $C$. virgata juveniles at his time. The success of $C$. maculosa juveniles was also strongly influenced by maternal nutrition but only when adults were sourced from Harbour populations.

Maternal influence on juvenile mortality was small compared with maternal influence on growth. Overall, the greatest maternal influence on the number of hatchlings surviving after eight weeks was the initial number of capsules produced by the adults. These results are likely to be modified under natural conditions however. Differences 
in juvenile size become more important when the impacts of factors such as predation and desiccation are considered (Gosselin \& Chia 1995b).

Maternal influence on juvenile growth differed in strength and in persistence among species. In addition, the direction of maternal influence was unexpectedly different among species. While the growth of $C$. virgata juveniles born from high food adults was enhanced, the growth of $C$. maculosa juveniles born from high food adults was suppressed. The suppression on C. maculosa hatchling growth may have occurred to ameliorate the negative consequences of rapid growth (Metcalfe \& Monaghan 2001).

Overall there was a large effect of source population on the numbers of C. maculosa juveniles surviving after eight weeks. In addition, while adult nutrition had a large effect on the success of juveniles when adults were sourced from Harbour populations, adult nutrition had little effect on the success of juveniles from South Coast sourced populations. Together with the large regional difference in capsule volume, these results suggest Harbour and South Coast populations of C. maculosa may be distinct and may not be able to disperse between these locations. There are conservation implications for the management of this species and possibly other whelk species with limited dispersal.

This study is important because it looks beyond the immediate effects of maternal nutrition on the size and number of propagules (Bernardo 1996a). In marine environments, few studies have examined longer term maternal carry over effects. Evidence suggests that in some fish species, key life history traits are shaped by juvenile and not adult nutrition (Taborsky 2006). However this work is not well supported. Work with ascidians and bryozoans suggest that there are long lasting maternal effects on fitness (Wendt 1998; Marshall et al. 2003; Marshall 2005). While evidence suggests that maternal effects have a strong influence on whelk life history (Moran \& Emlet 2001; Lloyd \& Gosselin 2006), no studies appear to have examined this specifically. 


\section{Future directions}

There may be better ways to measure maternal investment than offspring growth (Mousseau \& Dingle 1991a). Lipid content has been found to be critical for early larval development in invertebrates (Sewell 2005), and may prove to be a useful measure of maternal investment in juvenile whelks. In addition, analysis of the lipid content in juvenile whelks over time, may help to gain a better understanding of the changing maternal influence on juvenile growth and survival.

Capsule size was a plastic trait that varied in response to the adult food treatments in all three species. Further, capsule volumes were significantly different in populations of the same species. However, the advantage of large capsule size is unknown, but could be expected to be significant due to the cost associated with capsule construction (Hughes 1986). As larger capsules contain more intracapsular fluid, an interesting direction for future work would be to determine the role of intracapsular fluid in the development and growth of hatchling whelks.

Embryos of the intertidal whelk Nucella ostrina have nurse egg nutrition. Lloyd \& Gosselin (2006) found that N. ostrina adjusted the embryo / nurse egg ratio within its capsules in response to wave exposure. Female whelks with nurse eggs may also be able to adjust the embryo / nurse egg ratio within a capsule in response to food availability. It was intended to measure this response in $H$. scobina in this study, however eggs disintegrated during freezing and this was not possible. Another attempt to detect this potential maternal effect may be productive.

Predicted outcomes after eight weeks of hatchling growth indicated that prolonged conditions of low food had a strong influence on fitness, in all three species. Few hatchlings of low food adults that were also fed low food survived. This suggests that the abundance of whelks from areas experiencing consistently low food levels is less than that in areas where food is more plentiful and would be interesting to quantify.

Despite regional differences in closely separated whelk populations, it is unclear whether these differences have a genetic basis. While the dispersal ability of whelks appears to be limited, the widespread distribution of some species suggests otherwise. 
For example, the neogastropod Buccinum polaris seems to have 'walked' around the shelf of the Arctic since the Miocene (Scheltema 1989). Examination of DNA microsatellites could help to determine the degree to which populations should be managed separately for conservation purposes. 


\section{APPENDIX 1}

\section{Feeding trial}

During April of 2006 a feeding trial was carried out to estimate the amount of food consumed, and the food preferred by three species of intertidal whelks. Adult whelks of similar size were collected from Point Halswell in Wellington Harbour and from Moa Point on the Wellington South Coast (H. scobina: mean shell length $=18.2 \mathrm{~mm}$, mean weight $=1.22 \mathrm{~g}, \mathrm{n}=23 ; \mathrm{C}$. virgata: mean shell length $=30.5 \mathrm{~mm}$, mean weight $=$ $3.99 \mathrm{~g}, \mathrm{n}=31 ;$ C. maculosa: mean shell length $=36.2 \mathrm{~mm}$, mean weight $=7.10 \mathrm{~g}, \mathrm{n}=$ 28). Whelks of each species were divided equally into two groups (group one fed mussel and group two fed limpet). Whelks were contained in identical baskets within a tank supplied with constantly flowing fresh seawater at ambient temperature.

Whelks were fed fresh, chopped mussel (Mytilus edulus) or limpet (Cellana denticulata) meat that had been removed from the shell. Both $C$. virgata and $C$. maculosa were observed feeding during the trial. Food was wet weighed in the manner described by Morton (1986). Whelks were fed daily ad libitum over a period of one week. Before feeding, left over food from the previous day was wet weighed and the difference in weight was assumed to have been eaten. This resulted in a measure of the total food consumed by each group.

More mussel food than limpet food was consumed by all three species over the period of the trial. On day one food consumption was much higher than for the following days (fig. 1) and this data was ignored. Temporary higher ingestion rates following a period of starvation have been reported in whelks elsewhere (Hughes 1986). The average amount eaten on days two to seven was calculated and used as a guide for the amount to use in the experiment. Mean daily consumption was estimated to be $0.82 \mathrm{~g} / \mathrm{kg}$ whelk $/ \mathrm{hr}$ for H. scobina, $1.75 \mathrm{~g} / \mathrm{kg}$ whelk $/ \mathrm{hr}$ for C. virgata and $2.00 \mathrm{~g} / \mathrm{kg}$ whelk/hr for C. maculosa. 

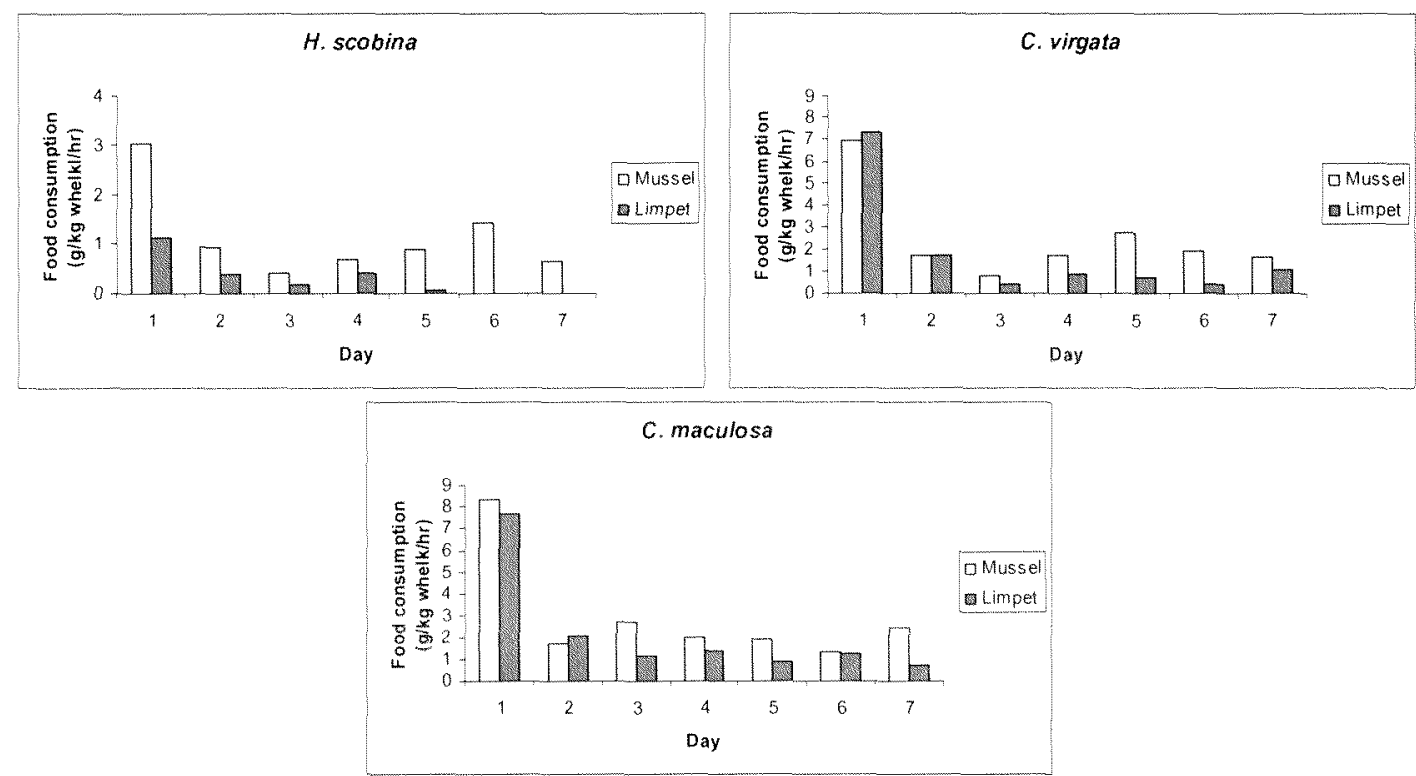

Fig. 1. Total daily consumption of three whelk species during a seven day trial using two types of food. Consumption was high on the first day of the trial then slowed. More mussel food was eaten over the period. 


\section{APPENDIX 2}

\section{Justification for combining treatments}

Adult treatments were combined for the analysis in order to simplify the analysis and to increase statistical power. This was necessary because egg capsules were not laid in all of the replicate baskets ( $H$. scobina: egg capsules in 14 of 24 baskets; $C$. virgata: 22 of 24; C. maculosa (Harbour): 12 of 24; C. maculosa (South Coast): 11 of 24). While differences between some of the combined groups were found to be significant (Table 1), nested analysis indicated that differences between replicates accounted for some of this variation.

Shell length increase in $C$. virgata and $C$. maculosa (Harbour and South Coast) from $50 \%$ and $100 \%$ food treatments was large compared with shell length increase in whelks from 10\% and $20 \%$ treatments (fig. 1). In addition, $C$. virgata and $C$. maculosa decreased in weight in $10 \%$ and $20 \%$ treatments while increasing in weight in $50 \%$ and $100 \%$ treatments. H. scobina did not respond to the food treatments. Shell length increases were similar and whelks lost weight across all treatments.

Table 1. Results of independent t-tests between treatments of adult whelk groups that were combined for the analysis. $(*$ : $p<0.05$ : $\uparrow$ : significant difference between replicates)

\begin{tabular}{|c|c|c|c|c|c|}
\hline Species & $\begin{array}{l}\text { Treatments } \\
\text { compared }\end{array}$ & Measure & $\mathrm{t}$ & $\mathrm{p}$ & n \\
\hline \multirow[t]{4}{*}{ H. scobina } & \multirow[t]{2}{*}{$10 \%$ vs. $20 \%$} & Length & -2.277 & $* 0.025$ & 118 \\
\hline & & Weight & 2.487 & $\dagger^{*} 0.014$ & 118 \\
\hline & \multirow[t]{2}{*}{$50 \%$ vs. $100 \%$} & Length & 1.441 & 0.152 & 120 \\
\hline & & Weight & -1.012 & 0.313 & 120 \\
\hline \multirow[t]{4}{*}{ C. virgata } & \multirow[t]{2}{*}{$10 \%$ vs. $20 \%$} & Length & 2.056 & $\dagger^{*} 0.042$ & 117 \\
\hline & & Weight & -2.513 & $\dagger^{*} 0.013$ & 117 \\
\hline & \multirow[t]{2}{*}{$50 \%$ vs. $100 \%$} & Length & -0.541 & 0.590 & 117 \\
\hline & & Weight & -4.492 & $* 0.000$ & 117 \\
\hline \multirow[t]{4}{*}{ C. maculosa (Harbour) } & \multirow[t]{2}{*}{$10 \%$ vs. $20 \%$} & Length & -1.915 & 0.058 & 120 \\
\hline & & Weight & -4.385 & $\uparrow^{*} 0.000$ & 120 \\
\hline & \multirow[t]{2}{*}{$50 \%$ vs. $100 \%$} & Length & -2.417 & $*_{0.017}$ & 117 \\
\hline & & Weight & -2.771 & $\dagger^{*} 0.007$ & 117 \\
\hline \multirow[t]{4}{*}{ C. maculosa (South Coast) } & \multirow[t]{2}{*}{$10 \%$ vs. $20 \%$} & Length & -2.732 & $\dagger^{*} 0.007$ & 120 \\
\hline & & Weight & -3.582 & $* 0.000$ & 120 \\
\hline & \multirow[t]{2}{*}{$50 \%$ vs. $100 \%$} & Length & 0.379 & 0.705 & 116 \\
\hline & & Weight & -1.122 & 0.264 & 116 \\
\hline
\end{tabular}



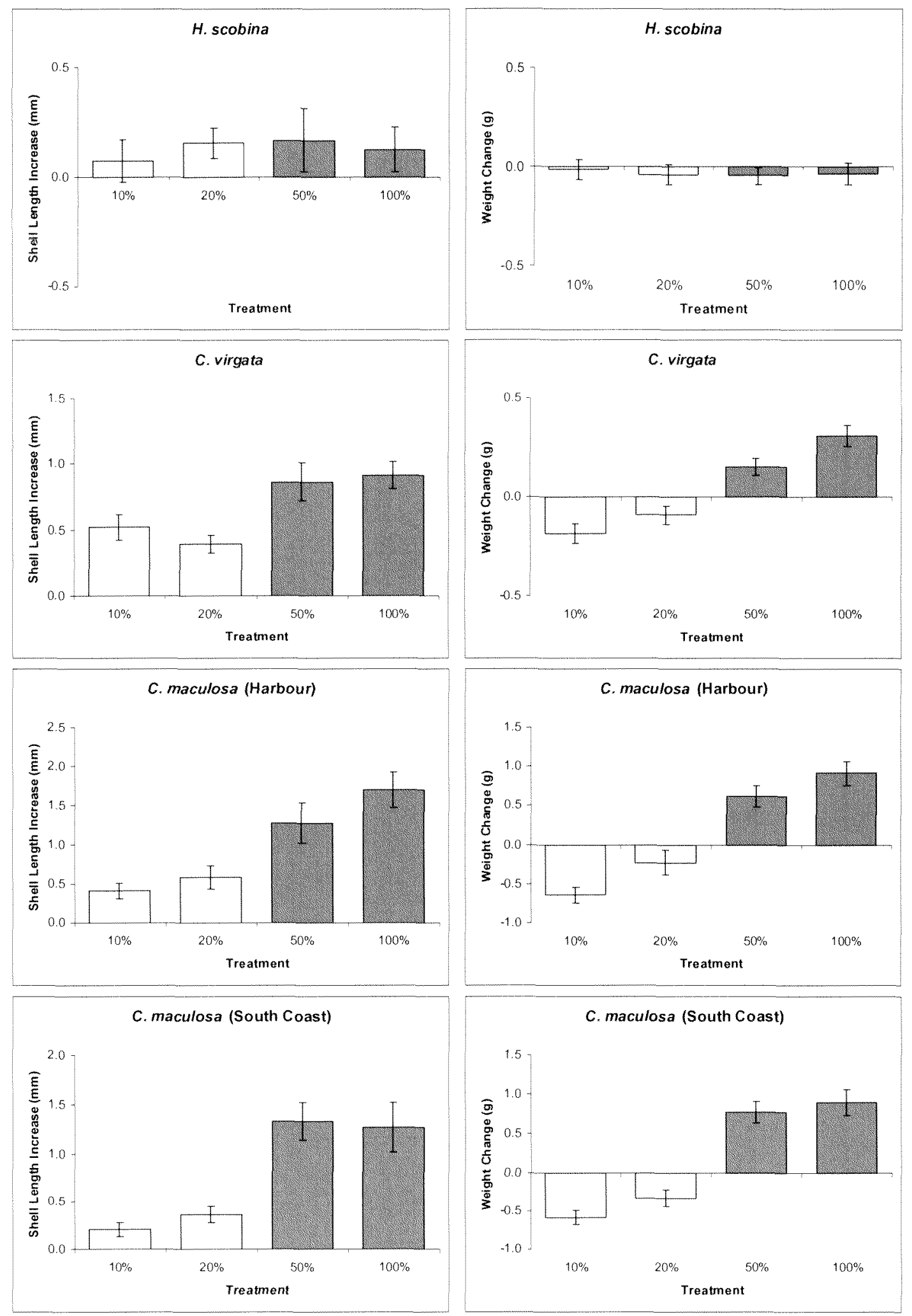

Fig. 1. Changes in shell length (left) and wet weight (right) in four food treatments for four groups of intertidal whelks. The $10 \%$ and $20 \%$ treatments (open bars), and the $50 \%$ and $100 \%$ (filled bars) treatments, were combined for the analysis. Differences within groups that were combined $(10 \%$ and $20 \% ; 50 \%$ and $100 \%)$ were small when compared with differences between combined groups. Error bars indicate 95\% confidence intervals. 


\section{REFERENCES}

Arendt J. (1997). Adaptive intrinsic growth rates: an integration across taxa. Quarterly Review of Biology, 72, 149-177.

Arendt J. (2000). Allocation of cells to proliferation vs. differentiation and its consequences for growth and development. Journal of Experimental Zoology, 288, 219-234.

Bernardo J. (1996a). Maternal effects in animal ecology. American Zoologist, 36, 83105.

Bernardo J. (1996b). The particular maternal effect of propagule size, especially egg size: patterns, models, quality of evidence and interpretations. American Zoologist, 36, 216-236.

Bonnet X., Bradshaw D. \& Shine R. (1998). Capital versus income breeding: an ectothermic perspective. Oikos, 83(2), 333-342.

Boycott A., Diver C., Garstang S. \& Turner F. (1930). The influence of sinistrality in Limnaea peregra (Mollusca, Pulmonata). Proceedings of the Royal Society of London. Series B, 219, 51-131.

Britton J. \& Morton B. (1994). Marine carrion and scavengers. Oceanography and Marine Biology Annual Review, 32, 269-434.

Brockelman W. (1975). Competition and fitness in offspring and optimal clutch size. American Naturalist, 109, 677-699.

Calow P. (1982). Homeostasis and fitness. American Naturalist, 120, 416-419.

Capinera J. (1979). Qualitaive variation in plants and insects: effect of propagule size on ecological plasticity. American Naturalist, 114, 350-361.

Chaffee C. \& Strathmann R. (1984). Constraints on egg masses. I. Retarded development within thick egg masses. Journal of Experimental Marine Biology and Ecology, 84, 73-83.

Chester C. (1996). The effect of adult nutrition on the reproduction and development of the estuarine nudibranch, Tenellia adspersa (Nordman, 1845). Journal of Experimental Biology and Ecology, 198, 113-130.

Cheung S. \& Lam S. (1999). Effect of food availability on egg production and packaging in the intertidal gastropod Nassarius festivus. Marine Biology, 135, $281-287$.

Colclough J. \& Brown A. (1983). Uptake of dissolved organic matter by a marine whelk. Transactions of the Royal Society of Africa, 45, 169-176.

Collin R. (2003). Worldwide patterns in mode of development in calyptraeid gastropods. Marine Ecology-Progress Series, 247, 103-122.

Collins T.M., Frazer K., Palmer A.R., Vermeij G.J. \& Brown W.M. (1996). Evolut ionary history of northern hemisphere Nucella (Gastropoda, Muricidae): Molecular, morphological, ecological, and paleontological evidence. Evolution, 50, 2287-2304.

Cowley D. (1991). Parental effects on mammalian growth: embryo transfer results. In: The unity of evolutionary biology (ed. Dudley E). Dioscorides Portland, Oregon, pp. 762-779.

D'Asaro C. (1991). Gunnar Thorson's world-wide collection of prosobranch egg capsules: Muricidae. Ophelia, 35 (1), 1-101.

D'Asaro C. (1993). Gunnar Thorson's world-wide collection of prosobranch egg capsules: Nassadiidae. Ophelia, 38 (3), 149-215. 
D'Asaro C. (1997). Gunnar Thorson's world-wide collection of prosobranch egg capsules: Melonngenidae. Ophelia, 46, 83-125.

D'Asaro C. (2000). Gunnar Thorson's world-wide collection of prosobranch egg capsules: fasciolaridae. Ophelia, 52(2), 77-112.

Davis A. \& Kibblewhite A. (1986). The predatory effect on barnacles of the oyster borer (Lepsilla scobina). University of Auckland, Auckland.

Downie J. \& Weir A. (1997). Developmental arrest in Leptodactylus fuscus tadpoles (Anura: Leptodactylidae) III: Effect of length of arrest period on potential growth. Herpetological Journal, 7, 85-92.

Einum S. \& Fleming I. (1999). Maternal effects of egg size in brown trout (Salmo trutta): norms of reaction to envirnmental quality. Proceedings of the Royal Society of London. Series B, 266, 2095-2100.

Einum S. \& Fleming I. (2000). Selection against late emergence and small offspring in Atlantic salmon (Salmo salar). Evolution, 54, 628-639.

Etter R. (1989). Life history variation in the intertidal snail Nucella lapillus across a wave exposed gradient. Ecology, 70, 1857-1876.

Fox C. (1997). The ecology of body size in a seed beetle, Stator limbatus. Persistence of environmental variation across generations? Evolution, 51, 1005-1010.

Fox C., Czesak M. \& Savalli U. (1999). Environmentally based maternal effects on development time in the seed beetle Stator pruininus (Coleoptera: Bruchidae): consequences of larval density. Environmental Entomology, 28, 217-223.

Fox C. \& Mousseau T. (1998). Maternal effects as adaptations for transgenerational phenotypic plasticity in insects. In: Maternal effects as adaptations (eds. Mousseau T \& Fox C). Oxford University Press Oxford.

Fraser D. (1980). On the environmental control of oocyte maturation in a plethodontid salamander. Oecologia, 46, 302-307.

Fretter V. \& Graham A. (1994). British prosobranch molluscs, revised edition. Ray Society, No. 161, Andover, England.

Gallardo C. (1979). Developmental pattern and adaptations for reproduction in Nucella crassilabrum and other muricacean gastropods. Biological Bulletin, 157(3), 453-463.

Gallardo C.S., Manque C. \& Filun M. (2004). Comparative resistance to starvation among early juveniles of some marine muricoidean snails. Nautilus, 118, 121126.

Gardner J. (2000). Where are the mussels on Cook Strait (New Zealand) shores? Low seston quality as a possible factor limiting multi-species distributions. Marine Ecology Progress Series, 194, 123-132.

Gonzalez K. \& Gallardo C. (1999). Embryonic and larval development of the muricid snail Chorus giganteus (Lesson, 1892) with assessment of the developmental nutrition source. Veliger, 51(2), 77-92.

Gosselin L. \& Chia F. (1994). Feeding habits of newly hatched juveniles of an intertidal predatory gastropod, Nucella emarginata. Journal of Experimental Marine Biology and Ecology, 176, 1-13.

Gosselin L. \& Chia F. (1995a). Characterising temperate rocky shores from the perspective of an early juvenile snail: the main threat to survival of newly hatched Nucella emarginata. Marine Biology, 122, 625-635.

Gosselin L. \& Chia F. (1995b). Distribution and dispersal of early juvenile snails: effectiveness of intertidal microhabitats as refuges and food sources. Marine Ecology Progress Series, 128, 213-223. 
Gosselin L. \& Qian P. (1999). Analysing energy content: a new micro-assay and an assessment of the applicability of acid dicromate assays. Hydrobiologia, 390, $141-151$.

Gosselin L. \& Rehak R. (2007). Initial juvenile size and environmental severity: influence of predation and wave exposure on hatchling size in Nucella ostrina. Marine Ecology Progress Series, 339, 143-155.

Gosselin L.A. \& Chia F.S. (1996). Prey selection by inexperienced predators: Do early juvenile snails maximize net energy gains on their first attack? Journal of Experimental Marine Biology and Ecology, 199, 45-58.

Gosselin L.A. \& Qian P.Y. (1997). Juvenile mortality in benthic marine invertebrates. Marine Ecology-Progress Series, 146, 265-282.

Havenhand J. (1993). Egg to juvenile period, generation time, and the evolution of larval type in marine invertebrates. Marine Ecology Progress Series, 97, 247260.

Helson J.G. \& Gardner J.P.A. (2004). Contrasting patterns of mussel abundance at neighbouring sites: does recruitment limitation explain the absence of mussels on Cook Strait (New Zealand) shores? Journal of Experimental Marine Biology and Ecology, 312, 285-298.

Helson J.G., Pledger S. \& Gardner J.P.A. (2007). Does differential particulate food supply explain the presence of mussels in Wellington Harbour (New Zealand) and their absence on neighbouring Cook Strait shores? Estuarine Coastal and Shelf Science, 72, 223-234.

Hughes R. (1986). A functional biology of marine gastropods. Croom Helm, London.

Kaplan R. (1998). Maternal effects, developmental plasticity, and life history evolution. In: Maternal effects as adaptations (eds. Mousseau T \& Fox C). Oxford University Press Oxford.

Kideys A., Nash R. \& Hartnoll R. (1993). Reproductive cycle and energetic cost of reproduction of the neogastropod Buccinum undatum in the Irish Sea. Journal of the Marine Biological Association of the United Kingdom, 73 (2), 391-403.

Kirkpatrick M. \& Lande R. (1989). The evolution of maternal characters. Evolution, 43(3), 485-503.

Lau D.C.P. \& Leung K.M.Y. (2004). Feeding physiology of the carnivorous gastropod Thais clavigera (Kuster): do they eat "soup"? Journal of Experimental Marine Biology and Ecology, 312, 43-66.

Lee C. \& Strathmann R. (1998). Scaling of gelatinous clutches: effects of siblings' competition fro oxygen on clutch size and parental investment per offspring American Naturalist, 151(4), 293-310.

Lindstrom J. (1999). Early development and fitness in birds and mammals Trends in Ecology and Evolution, 14, 343-348.

Lloyd M. \& Gosselin L. (2006). Role of maternal provisioning in controlling interpopulational variation in hatchling size in the marine snail Nucella ostrina. Biological Bulletin.

Luckens P. (1974). Predation and intertidal zonation of barnacles at Leigh, New Zealand. New Zealand Journal of Marine and Freshwater Research 9 (3), 355-378.

Lummaa V. \& Clutton-Brock T. (2002). Early survival and reproduction in humans. Trends in Ecology and Evolution, 17, 141-147.

Lyons A. \& Spight T. (1973). Diversity of feeding mechanisms among embryos of Pacific Northwest Thais. Veliger, 16, 189-194. 
Marshall D. (2005). Geographical variation in offspring size effects across generations. Oikos, 108, 602-608.

Marshall D., Bolton T. \& Keough M. (2003). Offspring size affects the post metamorphic performance of a colonial marine invertebrate. Ecology, 84, 3131-3137.

McEdward L. (1996). Experimental manipulations of parental investment in echinoid echinoderms. American Zoologist, 36(2), 169-179.

McEdward L. \& Chia F. (1991). Size and energy content of eggs from echinoderms with pelagic lecithotrophic development. Journal of Experimental Marine Biology and Ecology, 147, 95-102.

McEdward L. \& Coulter L. (1987). Egg volume and energetic content are not correlated among sibling offspring of starfish: implications for life history theory, Evolution, 41, 914-917.

McGinley M. (1989). The influence of a positive correlation between clutch size and offspring fitness on the optimal offspring size. Evolutionary Ecology, 3, 150156.

McGinley M., Temme D. \& Geber M. (1987). Parental investment in offspring in variable environments: theoretical and empirical considerations. American Naturalist, 130(3), 370-398.

McKillup S. \& Barker A. (1979). Modification of egg production and packaging in response to food availability by Nassarius pauperatus. Oecologia, 43, 221231.

Meijer T., Masman D. \& Daan S. (1989). Energetics of reproduction in female kestrals. Auk, 106, 549-559.

Menge B. (1992). Community regulation: under what conditions are bottom-up factors important on rocky shores? Ecology, 73, 755-765.

Metcalfe N. \& Monaghan P. (2001). Compensation for a bad start: grow now, pay later? Trends in Ecology and Evolution, 16(5), 254-260.

Miloslavich P. (1996). Nurse egg feeding prosobranchs: a comparitive biochemical and electrophoretic analysis of eggs and hatchlings. American Malacological Bulletin, 13, 37-46.

Miloslavich P. \& Dufresne L. (1994). Development and effect of female size on egg and juvenile production in the neogastropod Buccinum cyaneum from the Saguenay Fjord. Can. J. Fish. Aquat. Sci., 51, 2866-2872.

Miloslavich P. \& Penchaszadeh P.E. (2001). Adelphophagy and cannibalism during early development of Crucibulum auricula (Gmelin,1791) (Gastropoda : Calyptraeidae) from the Venezuelan Caribbean. Nautilus, 115, 39-44.

Moran A. (1999a). Size and performance of juvenile marine invertebrates: potential contrasts between intertidal and subtidal benthic habitats. American Zoologist 39, 304-312.

Moran A. (2000). Calcein as a marker in experimental studies of newly hatched gastrpods. Marine Biology, 137, 893-898.

Moran A. \& Emlet R. (2001). Offspring size and performance in variable environments: field studies on a marine snail. Ecology, 82(6), 1597-1612.

Moran A.L. (1999b). Intracapsular feeding by embryos of the gastropod genus Littorina. Biological Bulletin, 196, 229-244.

Morton B. (1986). Reproduction, juvenile growth, consumption and the effects of starvation upon the South China Sea whelk Hemifusus tuba (Gmelin) Journal of Experimental Marine Biology and Ecology, 102, 257-280. 
Morton B. (1987). Juvenile growth of the South China Sea whelk Hemifusus tuba (Gremlin) (Prosobranchia: Melongenidae) and the importance of sibling cannibalism in estimates of consumption. Journal of Experimental Marine Biology and Ecology, 109, 1-14.

Morton J. \& Miller M. (1968). The New Zealand Sea Shore. C. Tinling and Co., Liverpool.

Mousseau T. \& Dingle H. (1991a). Maternal effects in insect life histories. Annual Review of Entomology, 36, 511-534.

Mousseau T. \& Dingle H. (1991b). Maternal effects of insects: examples, constraints and geographic variation. In: The Unity of Evolutionary Biology (ed. Dudley E). Dioscorides Press, pp. 745-761.

Munch S. \& Conover D. (2003). Rapid growth results in increased susceptibility to predation in Menidia menidia. Evolution, 57(9), $2119-2127$.

Nilsson J. (1990). Establishment success of experimentally delayed juvenile marsh tits Parus palustris. Ethology, 83, 73-79.

Nybakken J. \& Bertness M. (2005). Marine Biology: an ecological approach. 6 edn. Benjamin Cummings, San Francisco.

Palmer A. (1981). Do carbonate skeletons limit the rate of body growth. Nature, 292, 150-152.

Palmer A. (1982). Growth in marine gastropods: a non-destructive technique for independently measuring shell and body weight. Malacologia, 23(1), 63-73.

Palmer A. (1990). Predator size, prey size, and the scaling of vulnerability: hatchling gastropods vs. barnacles. Ecology, 71(2), 759-775.

Pechenik J. (1979). Role of encapsulation in invertebrate life histories. American Naturalist, 114, 859-870.

Pechenik J. (1986). The encapsulation of eggs and embryos by molluscs: an overview. American Malacological Bulletin, 4(2), 165-172.

Pechenik J., Chang S. \& Lord A. (1984). Encapsulated development of the marine prosobranch gastropod Nucella lapillus. Marine Biology, 78, 223-229.

Peck J. \& Waxman D. (1997). What determines fitness when dispersal is limited? Evolution, 51(4), 1036-1043.

Perron F. (1981). The partitioning of reproductive energy between ova and protective capsules in marine gastropods of the genus Conus. American Naturalist, 118, 110-118.

Perry J.C. \& Roitberg B.D. (2006). Trophic egg laying: hypotheses and tests. Oikos, $112,706-714$.

Pfister C.A. \& Stevens F.R. (2002). The genesis of size variability in plants and animals. Ecology, 83, 59-72.

Phillips N. (2007). Victoria University of Wellington. In.

Polis G. (1983). Intraspecific predation and "infant killing" among invertebrates. In: Infanticide an evolutionary perspective (eds. Hausfater G \& Hrdy S). Ohio Press Columbia, Ohio, pp. 87-104.

Rawlings T.A. (1999). Adaptations to physical stresses in the intertidal zone: The egg capsules of neogastropod molluscs. American Zoologist, 39, 230-243.

Reznick D. (1991). Maternal effects in fish life histories. In: The unity of evolutionary biology (ed. Dudley E). Dioscorides Press Portland, Oregon.

Reznick D. \& Yang P. (1993). The influence of fluctuating resources on life history: patterns of allocation and pasticity in female guppies. Ecology, 74(7), 2011 2019 . 
Rivest B. (1981). Nurse egg consumption and the uptake of albumen in the embryonic nutrition of marine snails. In. Ph.D. Diss, University of Washington Seattle.

Rivest B. (1986). Extra-embryonic nutrition in the prosobranch gastropod Urosalpinx cinera (Say, 1822). Bulletin of Marine Science, 39(2), 498-505.

Rivest B.R. (1983). Development and the influence of nurse egg allotment on hatching size in Searlesia dira (Reeve, 1846) (Prosobranchia, Buccinidae). Journal of Experimental Marine Biology and Ecology, 69, 217-241.

Roach D. \& Wulff R. (1987). Maternal effects in plants. Anmual Review of Ecology and Systematics, 18, 209-235.

Robinson J., Sinclair K. \& McEvoy T. (1999). Nutritional effects on foetal growth Animal Science, 68, 315-331.

Roff D. (2001). Life history evolution. Chapman and Hall, New York.

Rossiter M. (1996). Incidence and consequences of inherited environmental effect. Annual Review of Ecology and Systematics, 27, 451-476.

Rovero F., Hughes R. \& Chelazzi F. (1999). Effect of experience on predatory behaviour of dogwhelks. Animal Behaviour, 57, 1241-1249.

Rumrill S. (1990). Natural mortality of marine invertebrate larvae. Ophelia, 32, 163 198.

Scheltema R. (1989). On the children of benthic invertebrates: their rambling and migrations in time and space. In: Environmental Quality and Ecosystem Stability (ed. Quality ISoEaE), pp. 93-112.

Schwarzkopf L. (1994). Measuring trade-offs: a review of studies of casts of reproduction in lizards. In: Lizard Ecology (eds. Vitt L \& Pianka E). Princetown University Press New Jersey, pp. 7-29.

Semlitsch R. \& Gibbons J. (1990). Effects of egg size on success of larval salamanders in complex aquatic environments Ecology, 71(5), 1789-1795.

Sewell M.A. (2005). Utilization of lipids during early development of the sea urchin Evechinus chloroticus. Marine Ecology-Progress Series, 304, 133-142.

Sinervo B. (1990). The evolution of maternal investment in lizards: and experimental and comparitive analysis of egg size and its effects on offspring performance. Evolution, 44(2), 279-294.

Sinervo B. (1991). Experimental and comparitive analysis of egg size in lizards: constraints on the adaptive evolution of maternal investment per offspring. In: The unity of evolutionary biology (ed. Dudley E). Dioscorides Portland, OR, pp. $725-734$.

Sinervo B. (1993). The effect of offspring size on physiology and life history. Bioscience, 43(4), 210-219.

Sinervo B. \& Doughty P. (1996). Interactive effects of offspring size and timing of reproduction: experimental maternal and quantitative genetic aspects. Evolution, 50(3), 1314-1327.

Sinervo B. \& McEdward L. (1988). Developmental consequences of and evolutionary change in egg size: an experimental test. Evolution, 42, 885-899.

Smith C. \& Fretwell S. (1974). The optimal balance between the size and number of offspring. American Naturalist, 108, 499-506.

Spight T. (1975). Factors extending gastropod embryonic development and their selective cost. Oecologia, 21, 1 16.

Spight T. (1976a). Ecology of hatchling sizes for marine snails. Oecologia, 24(4), 283-294.

Spight T. (1976b). Hatchling size and the distribution of nurse eggs among prosobranch embryos. Biological Bulletin, 150(3), 491-499. 
Spight T. (1977). Do intertidal snails spawn in the right places? Evolution, 31, 682691.

Spight T. (1982). Population sizes of two marine snails with a changing food supply. Journal of Experimental Marine Biology and Ecology, 37, 195-217.

Spight T. \& Emlen J. (1976). Clutch sizes of two marine snails with a changing food supply. Ecology, 57, 1162-1178.

Stearns S. (1992). The evolution of life histories. Oxford University Press, Oxford.

Stewart M.J. \& Creese R.G. (2004). Feeding ecology of whelks on an intertidal sand flat in north-eastern New Zealand. New Zealand Journal of Marine and Freshwater Research, 38, 819-831.

Stockmann-Bosbach R. (1988). Early stages of the encapsulated development of Nucella lapillus (Lineaus)(Gastropoda, muricidae).

Strathmann M. (1987). Reproduction and development of marine invertebrates of the Northern Pacific Coast. University of Washington Press, Seattle.

Strathmann R. (1985). Feeding and non-feeding larval development and life-history evolution in marine invertebrates. Annual Review of Ecology and Systematics, $16,339-361$.

Strathmann R. \& Strathmann M. (1989). Evolutionary opportunities and constraints demonstrated by artificial gelatinous egg masses. In: Reproduction, Genetics and Distributions of Marine Organisms (eds. Ryland J \& Tyler P). Olsen and Olsen Fredensborg, pp. 201-209.

Strathmann R.R. (1995). Peculiar constraints on life-histories imposed by protective or nutritive devices for embryos. American Zoologist, 35, 426-433.

Taborsky B. (2006). The influence of juvenile and adult environments on life-history trajectories. Proceedings of the Royal Society of London. Series B, 273, 741 750 .

Thorson G. (1950). Reproductive and larval ecology of marine bottom invertebrates. Biological Revue, 25, 1-45.

Thorson G. (1966). Some factors influencing the recruitment and establishment of marine benthic communities. Netherlands Journal of Sea Research, 3, 267293.

Webber H. (1977). Gastropoda: Prosobranchia. In: Reproduction of Marine Invertebrates $(\mathrm{Vol} \mathrm{IV})$ (eds. Giese A \& Pearse J). Academic Press New York, pp. $1-97$.

Wendt D.E. (1998). Effect of larval swimming duration on growth and reproduction of Bugula neritina (Bryozoa) under field conditions. Biological Bulletin, 195, 126-135.

Williams G. (1966). Adaptation and natural selection. Princetown University Press, Princetown.

Wray G. (1995). Evolution of Larvae and Developmental Modes. In: Ecology of Marine Invertebrate Larvae. CRC Press Boca Raton. 